\title{
STREAMFLOWS AND CHANNELS OF THE GREEN RIVER BASIN, WYOMING
}

\author{
U.S. GEOLOGICAL SURVEY
}

Water-Resources Investigations $81-71$

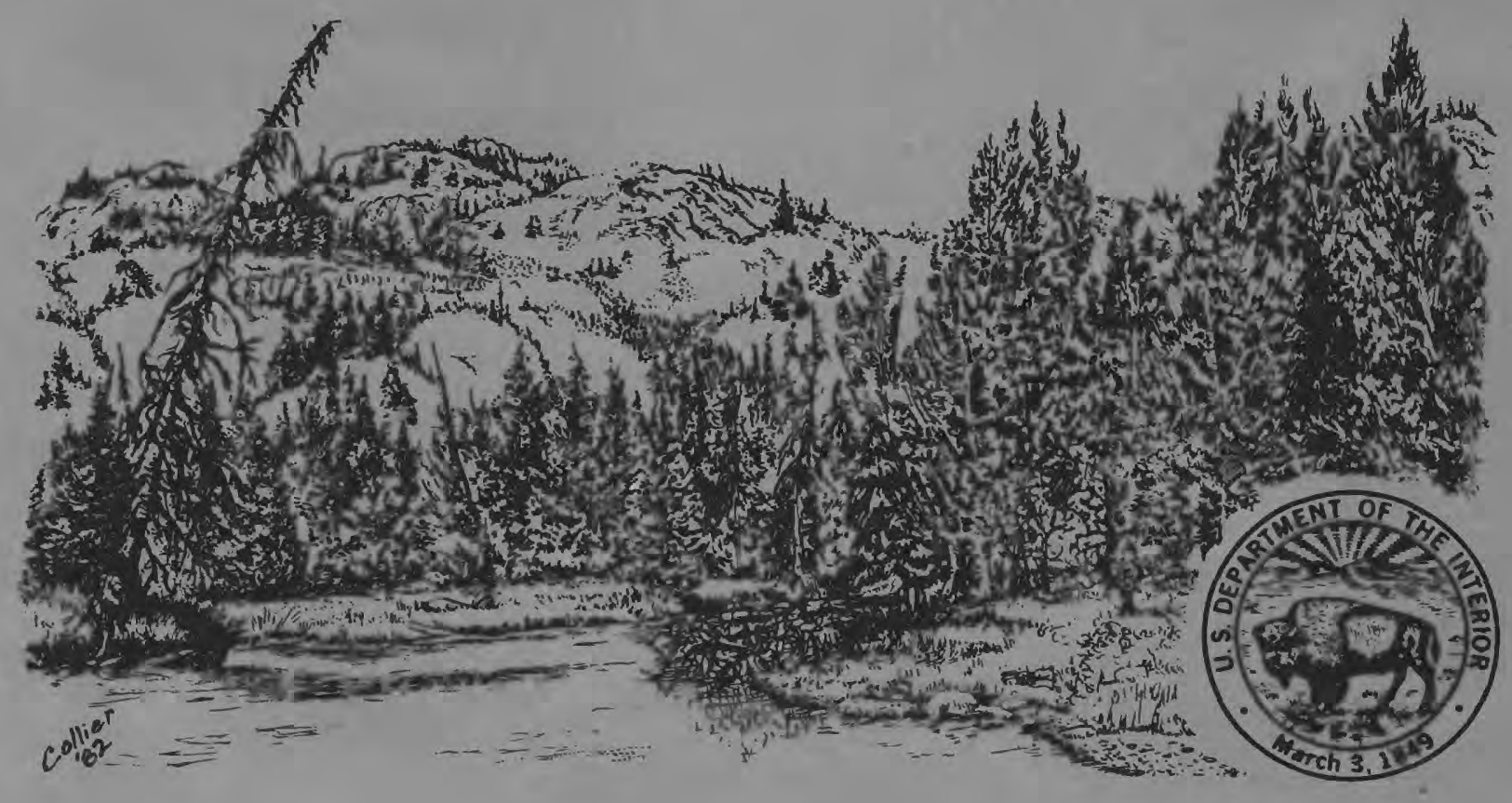




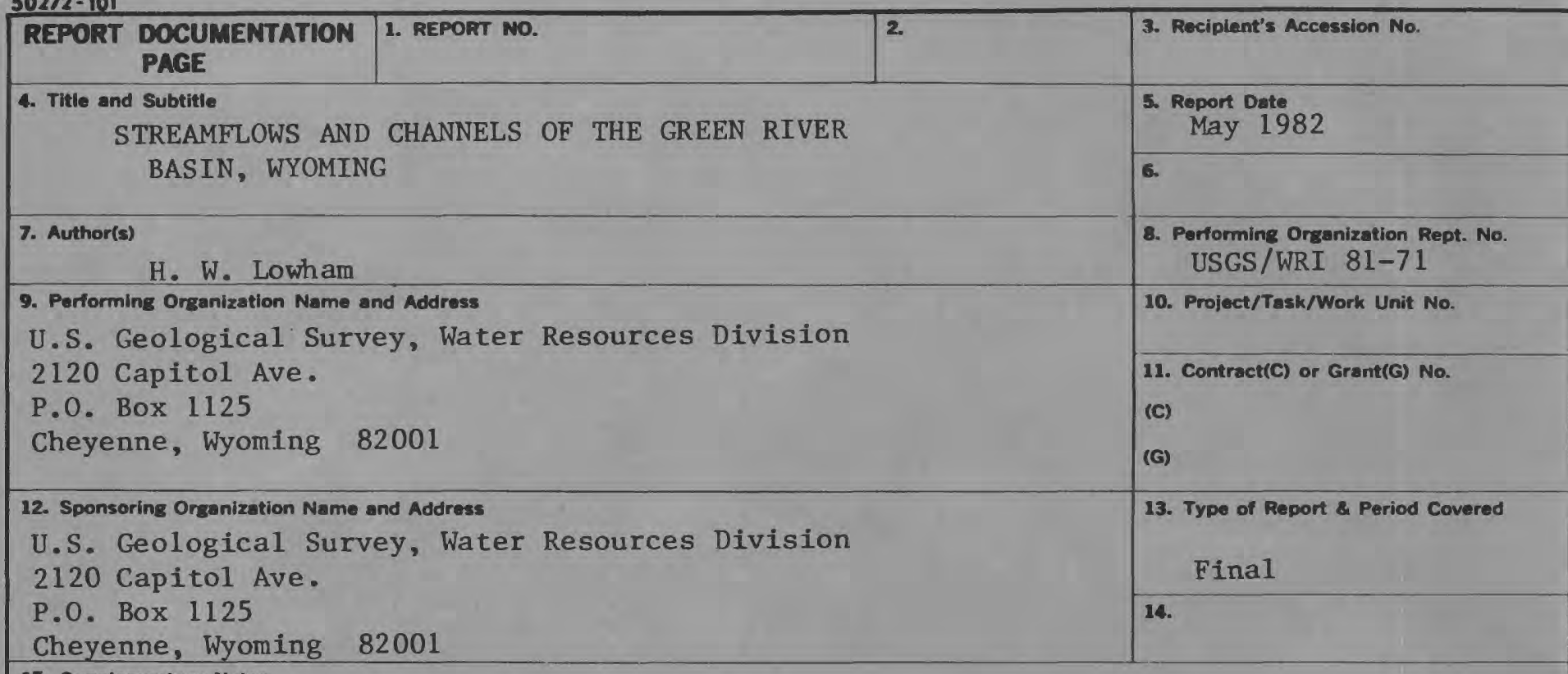

15. Supplementary Notes

16. Abstract (Limit: 200 words)

Width, depth, cross-sectional area, and velocity of streamflow were depicted for 51 gaged sites by summarizing data obtained from current-meter discharge measurements. Using these at-a-station relations as a base, regional relations were then developed that characterize hydraulic features of streams throughout the study area.

Channel size is an indication of flow magnitude. High flows influence channel formation, and the annual peak-flow array is a representation of these flows. The geometric mean of this array is a viable statistical index of channel-forming flows because it represents the relative magnitude of high flows at a site. Bankfull discharge is a physical index of flows dominating channel formation. The magnitude of the geometric mean equates closely to bankfull discharge, on the average. Relations depicting hydraulic characteristics of a discharge equal to the geometric mean of annual peak flows may therefore be considered to be generally representative of channel conditions existing during bankfull discharge. The relations have application for predicting channel response to developments that would alter streamflow.

17. Document Analysis ascriptor:

*Channel morphology, channel erosion, alluvial channels, channels, banks, *shape, *width, *depth, slopes, Wyoming

b. Identifiers/Open-Ended Terms

U.S. Geological Survey, formative discharge, Green River basin, Green River basin Project

c. COSATI FIeld/Group

18. Availability Stetemen:

No restriction on distribution.

19. Socurity Class (This Report)

Unclassified

20. Socurity Class (This Paga)
21. No. of Pages

81

22. Price 
STREAMFLOWS AND CHANNELS OF THE

GREEN RIVER BASIN, WYOMING

By H. W. Lowham

U.S. GEOLOGICAL SURVEY

Water-Resources Investigations 81-71

May 1982

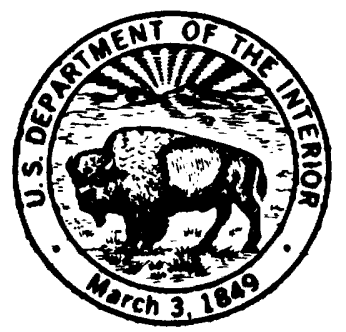


UNITED STATES DEPARTMENT OF THE INTERIOR

JAMES G. WATT, Secretary

GEOLOGICAL SURVEY

Dallas L. Peck, Director

For additional information write to:

District Chief

U.S. Geological Survey

2120 Capitol Avenue

P.0. Box 1125

Cheyenne, Wyoming 82001 
Abstract-1- 1

Int roduction-1-

Location-numbering system- 3

Streamflow- 3

Cause and occurrence-1... 3

Measurement-_- 6

Data analysis-- 10

Hydraulic characteristics-a 16

At-a-station hydraulic characteristics-a. 16

Channel formation-_. 20

Formative discharge-1 20

Regional hydraulic relations-_. 26

Channel shape-10 30

Channel slope and pattern-1 30

Channel geometry for estimating streamflow- 37

Application of relations-_. 38

Case histories- 40

Dye studies-... 48

Velocity relations-_. 62

Traveltime prediction- 67

Summary-10

References- 72

\section{ILLUSTRATIONS}

Figure 1. Map showing location of major streams-a 4

2. Hydrograph showing daily discharge for a typical perennial stream- 5

3. Hydrograph showing daily discharge for a typical intermittent stream-7

4. Diagram showing procedure for streamflow-data collection-_a 9

5. Map showing location of streamflow-gaging stations--- 11

6. Hydrograph showing yearly and long-term average discharge-14

7. Graphs showing occurrence and distribution of annual peak flows- 15

8-10. Sketches showing:

8. Cross section and vertical profile of a stream, showing relative velocities-a-n 17

9. Cross sections occupied by various flows of a perennial stream-18

10. Average direction of flow of stream at various discharges-a 18

11. Graph showing changes of mean width, depth, and velocity with discharge at a channel cross section-_. 19

12. Diagram showing magnitude and frequency of flows dominating channel formation- 24 
Figures 13-18. Graphs showing:

13. Regional hydraulic relations for

14. Relation of $Q_{\text {a }}$ versus $P_{\text {gm }}$ for 28 perennial streams-_. gm 29

15. Width/depth ratio of channel cross section in relation to $P$

16. Altitude of streambed and gmze of bed material in relation to downstream distance for the Big Sandy River-.... 32

17. Slope of streambed in relation to $\mathrm{P}_{\mathrm{gm}}$, type of bed material, and sinuosity--

18. Sinuosity versus valley slope, Big Sandy River- 36

19. Map showing downstream reach of Pole Creek----- 42

20. Map showing Bitter Creek and tributaries near Rock Springs: 43

21-24. Photographs showing:

21. Gully of Bitter Creek- 44

22. Dewatering well for coal mine at Superior- 45

23. Progressive headcutting of small tributary of Bitter Creek- 47

24. Diversion structure for Pierotto Ditch on Bitter Creek, about 3 river miles downstream from Horsethief Canyon-.....-

25. Map showing location of dye injection and sampling sites for the Green, East Fork, and Big Sandy Rivers, Horse Creek, and Blacks Fork- 50

26. Map showing location of dye injection and sampling sites for the Little Snake River--- 52

27. Graph and sketch showing downstream movement and dispersion of dye cloud, Little Snake River, May 18, 1977- 53

28. Graph showing mean velocity between sites, average discharge, and river profile for dye studies of the Green River-- 63

29-34. Graphs showing mean velocity versus discharge:

29. Green River-1 64

30. East Fork River-an 64

31. Big Sandy River-an 65

32. Horse Creek- 65

33. Blacks Fork-_ 66

34. Little Snake River-a 66

35. Graph showing cumulative traveltime for the Green River between sites 1 and 10-68

36. Graph showing cumulative traveltime for the Green River between sites 11 and 16-. 


\section{TABLES}

Page

Table 1. Streamflow characteristics- 12

2. Summary of at-a-station hydraulic characteristics---- 21

3. Summary of regional hydraulic relations-....- 27

4. Results of data collected during traveltime measurements-_. 54 
The following factors may be used to convert the inch-pound units used in this report to metric units:

Multiply
foot
mile
acre
square mile
cubic foot per second
foot per mile
foot per second
mile per hour
gallon

$\quad \frac{B y}{3048}$
1.609
0.4047
2.590
0.02832
0.1894
0.3048
1.609
3.785

To obtain meter kilometer hectare square kilometer cubic meter per second meter per kilometer meter per second kilometer per hour liter

National Geodetic Vertical Datum of 1929 (NGVD of 1929) is a geodetic datum derived from a general adjustment of the first-order level nets of both the United States and Canada, formerly called mean sea level. 
A Flow area of stream, in square feet $(=W \times D)$

D Mean flow depth in stream, in feet

N Number of data sets

P Peak flow, expressed as momentary maximum discharge, in cubic feet per second

Q Discharge of stream, in cubic feet per second

R Correlation coefficient

SE Average standard error of estimate, in percent

S Slope of streambed, in feet per mile

T Traveltime of solute, in hours

$\mathrm{V}$ Mean flow velocity in stream, in feet per second

W Mean flow width in stream, in feet

$W_{f}$ Width of main channel at stable, narrow section, in feet

a Coefficient of width in hydraulic equations

c Coefficient of depth in hydraulic equations

k Coefficient of velocity in hydraulic equations

\section{Superscripts}

b Exponent of width in hydraulic equations

f Exponent of depth in hydraulic equations

m Exponent of velocity in hydraulic equations

\section{Subscripts}

a With reference to average for period of record

b With reference to bankfull

gm With reference to geometric mean

1 With reference to leading edge of solute

1.5 to 100 With reference to average recurrence interval, in years

p With reference to peak concentration of solute 


\section{ABSTRACT}

Width, depth, cross-sectional area, and velocity of streamflow were depicted for 51 gaged sites in or near the Green River basin of Wyoming by summarizing data obtained from current-meter discharge measurements. Relations developed by this method vary from site to site depending on channel features unique to each location. Using these at-a-station relations as a base, regional relations were then developed that characterize hydraulic features of streams throughout the study area.

Channel size is an indication of flow magnitude. High flows affect channel formation, and the annual peak-flow array is a representation of these flows. The geometric mean of this array is considered to be a viable statistical index of channel-forming flows because it represents the relative magnitude of high flows at a site. Bankfull discharge is a physical index of flows dominating channel formation. The magnitude of the geometric mean approximately equates to bankfull discharge, on the average. Relations depicting hydraulic characteristics of a discharge equal to the geometric mean of annual peak flows may therefore be considered generally to be representative of channel conditions existing during bankfull discharge. The relations have application for predicting channel response to developments that would alter streamflow.

Dye-tracer studies were made of six streams in the study area, and velocity relations from these studies were compared to the at-a-station velocity relations. The relations generally are similar. Where the relations are not similar, the differences are attributed to: (1) The gaged reach not being representative of adjacent reaches where dye studies were made, or (2) inaccuracies in the dye-velocity computation in a determined stream distance because the path of travel for low flows is longer than for high flows. 


\section{INTRODUCTION}

Vast deposits of mineral resources, including coal, oil, gas, trona, and oil shale, occur in the Green River basin of Wyoming. As development of these resources increases, another resource--water--commonly becomes central to planning. Some developments, such as processing plants and municipalities, will require streamflows of the basin as a source of water supply. Other developments, such as strip mines and transportation facilities, will involve streams in consideration of their channels.

One purpose of this study was to describe streamflows of the Green River and its tributaries. In addition to describing the cause and occurrence of streamflows in the study area, a brief discussion of how streamflow data are collected and summarized is presented as background information to users of this report who may be unfamiliar with streamflow mea surement.

The second and primary purpose of the study was to describe hydraulic characteristics of streams in the study area. The hydraulic characteristics of streams, including their slopes, velocities, and crosssection properties, commonly need to be considered in the planning and design of water-related projects. Information concerning these characteristics is vital to the design of sound structures; the information also may be useful for environmental considerations. Streams extend upstream and downstream from actual development sites; a change may therefore affect the stream some distance away as well as locally.

Quantitative channel relations are available that may be used in the planning of some stream-related developments. This report presents such relations, along with explanations of why they are relevant. Many of these relations are universal and apply to streams in general; however, their applicability to streams within the Green River basin is emphasized in this report.

Case histories of channel response to development are described to highlight the need for planning and design of stream-related projects. The case histories are not described to discourage development or economic progress. Streams commonly are used for the benefit of man; with proper planning and design, a development may avoid adverse effects and sometimes improve the overall stream environment. For example, reservoir storage commonly is used to augment downstream low flows for recreation and fishery improvement.

The third purpose of the study was to accurately define solutetransport characteristics for main reaches of the Green River and several of its major tributaries. These characteristics were determined through the use of dye tracing. Results from the dye studies were used to develop stream-velocity and traveltime relations that are particularly useful for depicting the transport of waterborne solutes. 


\section{LOCATION-NUMBERING SYSTEM}

Streamflow-gaging stations that are referred to in this report are assigned eight-digit numbers, such as 09212500. The first two digits identify the major river basin in which the stream is located. The digits ' 09 ' refer to the Colorado River basin. The remaining six digits identify the relative location of the station, with numbers increasing in the downstream direction. On maps and other illustrations where space is limited, an abreviated station number containing only the middle four (or if necessary, the last six) digits is used.

Simplified site numbers, ranging from 1 to 16 are used to identify locations on each of the streams where dye studies were made. A streamflow-gaging station may also be located at a dye-study site, and both a streamflow station number and simplified number are shown for such a location.

\section{STREAMFLOW}

\section{Cause and Occurrence}

A variety of stream types exist in the Green River basin due to areal differences in climatic, geologic, and orographic conditions. Perennial streams, such as the Green River and its major tributaries, originate in the mountainous areas where significant annual precipitation occurs and where geologic conditions induce ground-water inflows. Streams originating in the interior semiarid and arid plains areas generally are ephemeral or intermittent, flowing mainly in direct response to rainstorms and snowmelt with little or no ground-water contribution. Locations of major streams in the study area are shown in figure 1.

A hydrograph of a typical perennial stream is shown in figure 2 . The major part of a perennial stream's annual runoff occurs during spring and early summer as a result of snowmelt. Streamflow generally peaks during June, although this varies annually and from site to site depending on local climatic conditions and on physical features of the individual basins. Late summer, fall, and winter flows are mainly the result of ground-water inflows. Minimum streamflows occur during January through March. Perennial streams are important for their water supplies (principally for agricultural purposes at present--1982); they also provide recreational opportunities.

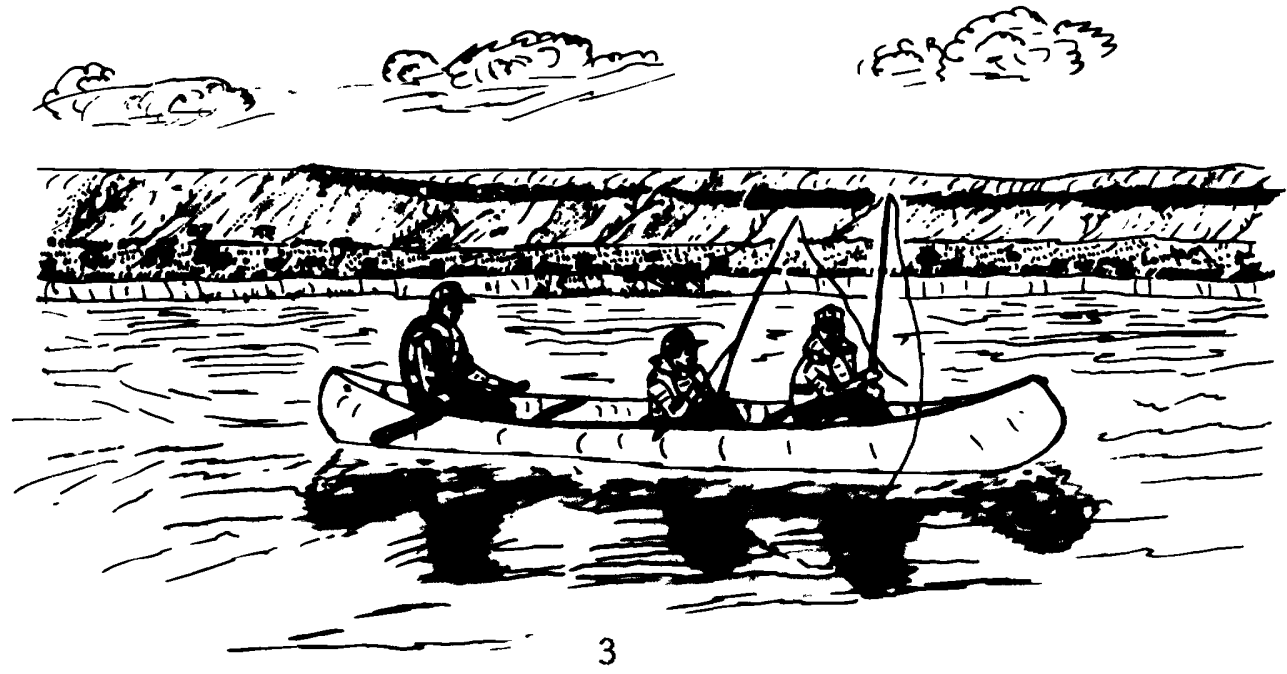




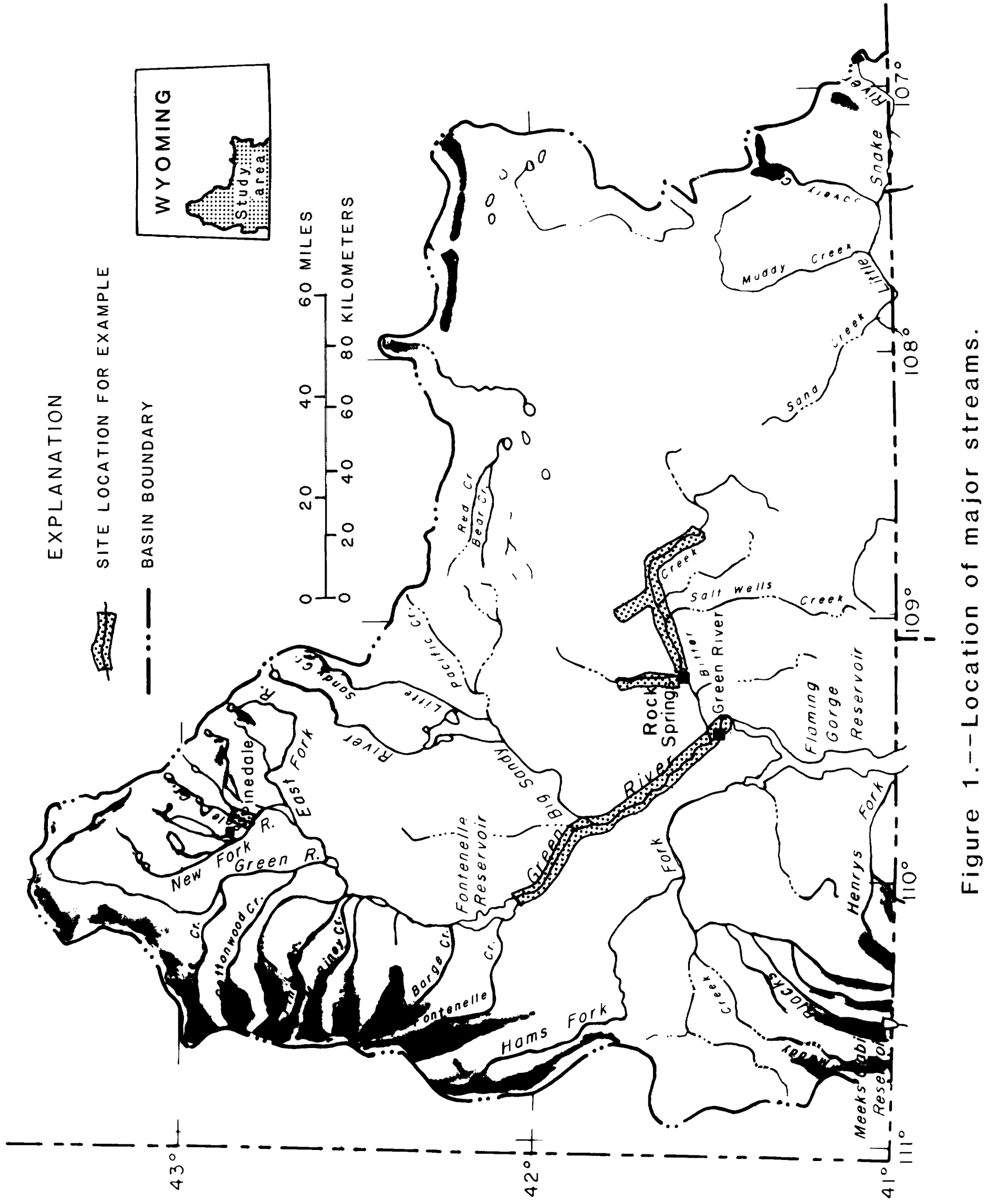




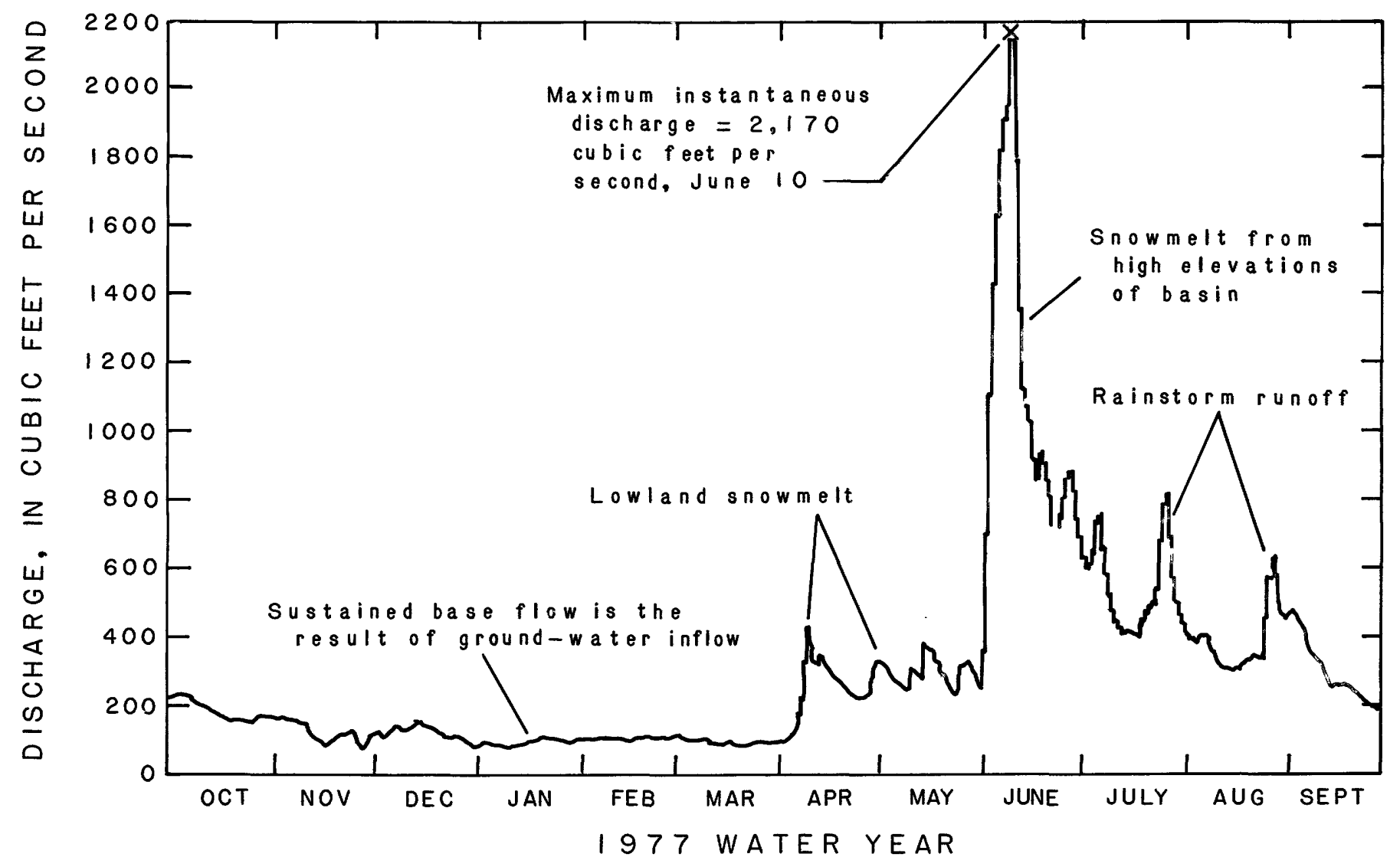

Figure 2.--Daily discharge for a typical perennial stream (streamflow-gaging station 09188500 , Green River at Warren Bridge, near Daniel). 
A hydrograph of a typical intermittent stream is shown in figure 3 . Such streams flow only periodically and they often have extended periods of no flow. Intermittent streams may receive some ground-water inflows in addition to direct surface runoff, but the ground-water inflows are insufficient to sustain flow throughout the year. There are springs in some areas of the plains, and these springs commonly contribute small perennial inflows to streams. However, losses of water to evaporation, transpiration, seepage, and freezeup generally limit the extent of these flows to only short reaches downstream from the springs.

Intermittent and ephemeral streams of the plains areas are important as local water supplies, mostly for consumption by livestock and wildlife. Although they flow only periodically, plains streams have an important effect on water quality of the large perennial streams and storage reservoirs. This is because the first flows of plains streams commonly contain large concentrations of natural materials. These materials include sediment, salts, and organic material that accumulate on the basin surfaces and in the stream channels. After a dry period, first flows of a flood flush these materials as a pulse, which may temporarily degrade the quality of receiving waters.

The classification of a stream as being perennial, intermittent, or ephemeral is somewhat arbitrary. It depends on what reach of the stream is being referred to; also, the length of time the stream has been observed. The strict classification of a large plains stream is especially difficult, as such a stream may have perennial flows from springs in its headwater tributaries, yet downstream reaches may have flows only several times per year. Salt Wells Creek, for which a hydrograph is shown in figure 3 , is such a stream. Several of its headwater tributaries have perennial flows, but these are lost within short distances due to seepage and evapotranspiration. Tributaries entering downstream reaches of the main channel are ephemeral. The downstream reach of the main channel has flow only several times per year. The major part of flow at the gaged site near the mouth occurs as a result of direct runoff from precipitation. However, runoff may continue for several days as a result of continued snowmelt or delayed inflows from upstream bank storage. The stream as a whole is, therefore, considered to be intermittent.

\section{Measurement}

The amount of water flowing in a stream generally is expressed as a flow rate, or discharge (Q). Discharge can be determined by measuring the cross-sectional area (A) and velocity (V) of flow. These quantities are related as:

$$
Q=A V \text {. }
$$

Measurement of discharge at a particular time generally is accomplished as follows: (1) A stream cross section is selected that has fairly uniform flow conditions across its width; (2) the width is subdivided into about 20 subsections having approximately equal flow increments; (3) the area of each subsection is determined by measuring width with a tape and depth with a rod or sounding apparatus; (4) velocity of each subsection is measured with a current meter; (5) area is multiplied by velocity to calculate discharge of each subsection; and (6) the incremental discharges are then summed to determine total discharge of the stream. 


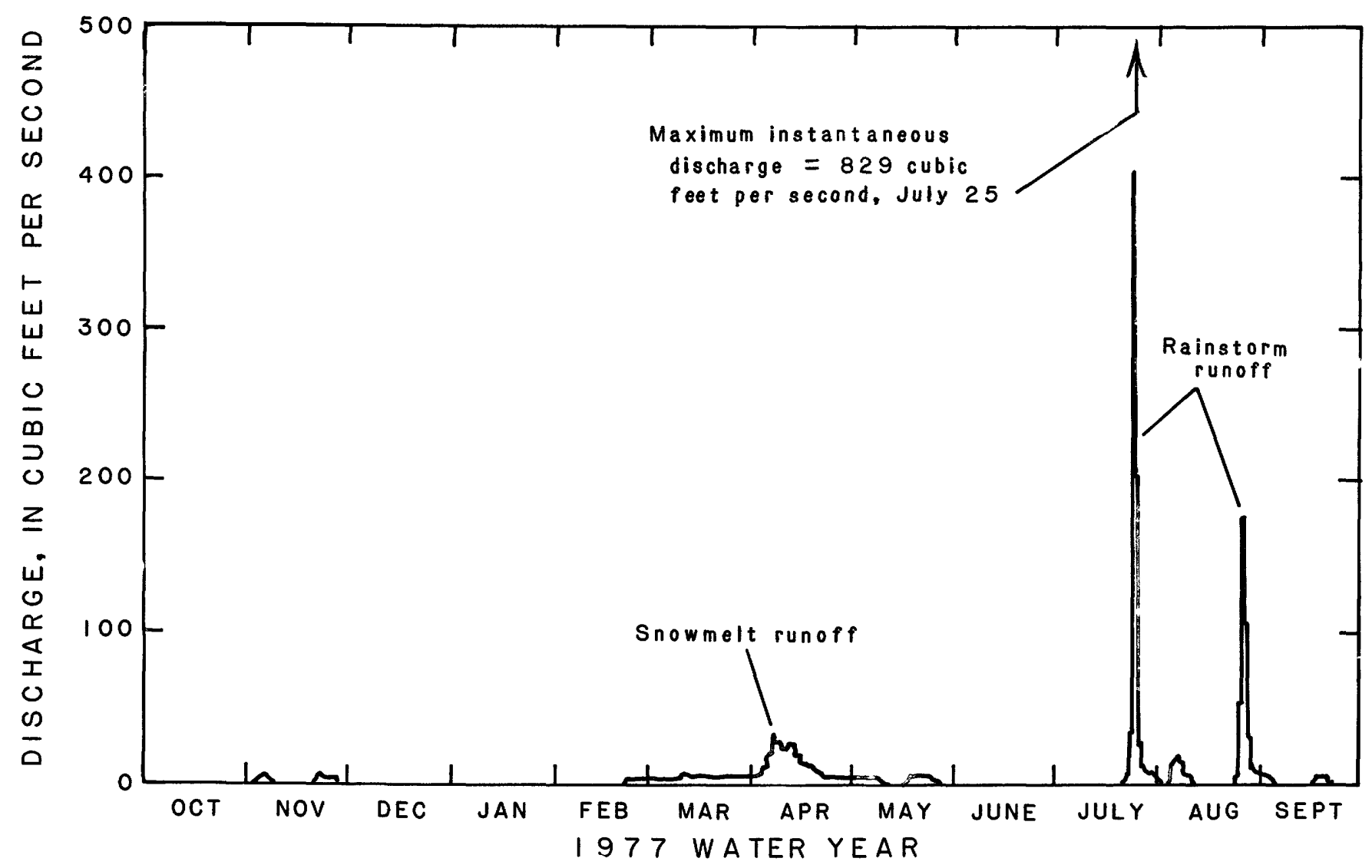

Figure 3.--Daily discharge for a typical intermittent stream (streamflow-gaging station 09216750 , Salt Wells Creek near Salt Wells). 
Streamflow data are collected at gaging stations. The hydrographs of figures 2 and 3 are examples of such data. At these installations a continuous record of stage (water level) is recorded. From discharge measurements that have been made at the site, a stage-discharge rating is constructed that enables discharge to be determined for any stage of the stream. Combining the rating with the continuous record of stage yields streamflow values, which may be expressed as average daily, monthly, and yearly rates or volumes of flow. In addition, other flow quantities such as momentary peak flows and total runoff for a period also may be determined. A diagram summarizing the procedure for streamflow-data collection is shown in figure 4 .

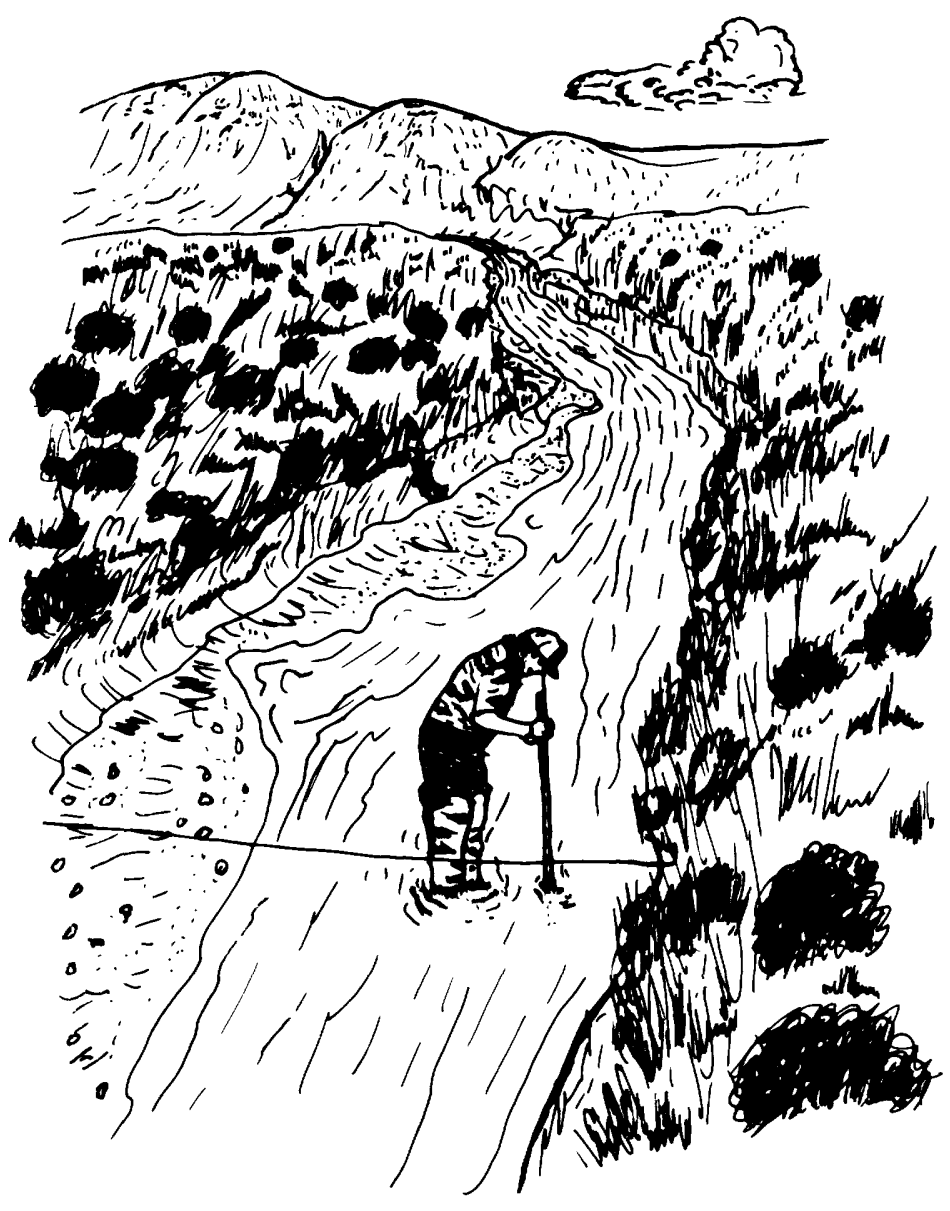



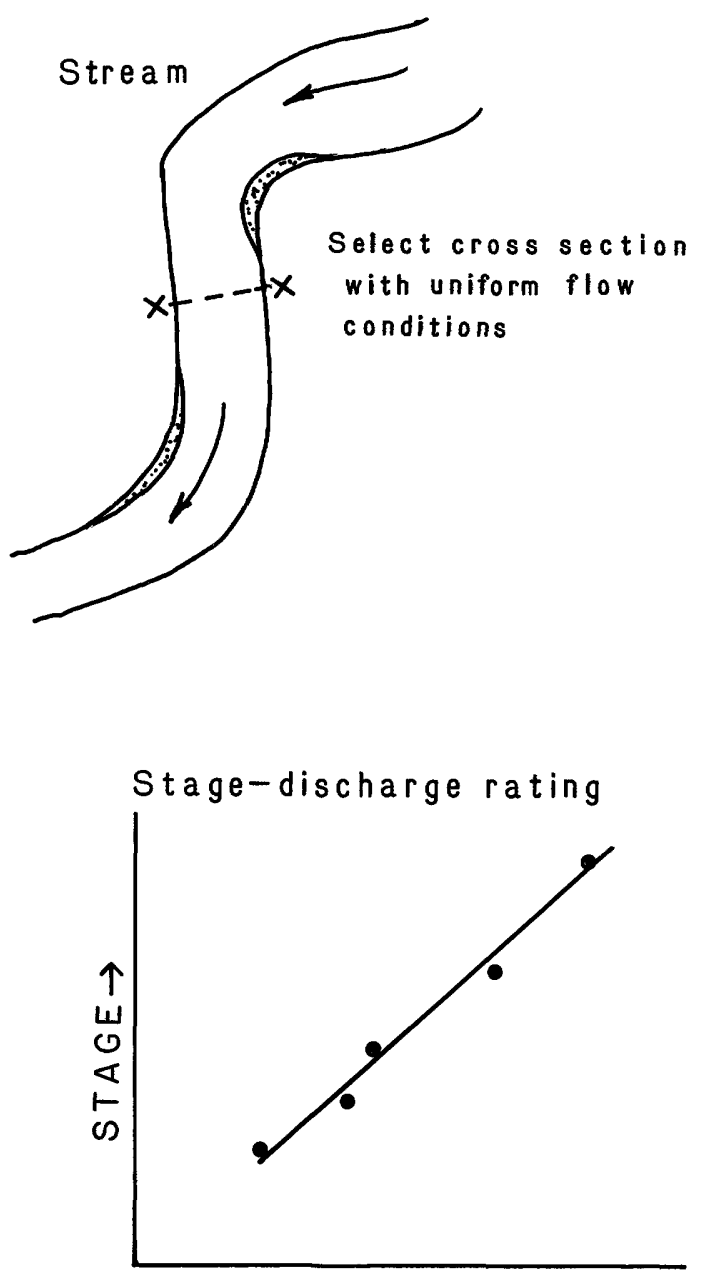

DISCHARGE $\rightarrow$
Channel cross section
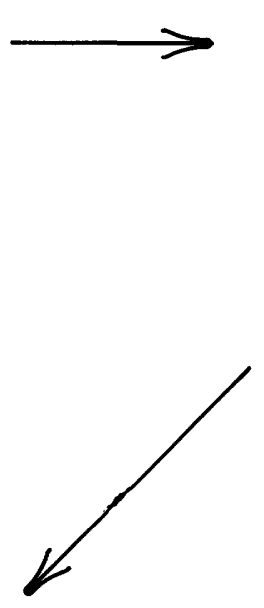

Using data from several current-meter discharge measurements, construct stage-dischargerating

Subdivide cross section and measure width, depth, and mean velocity of each subsection. Sum increments to determine total discharge of stream

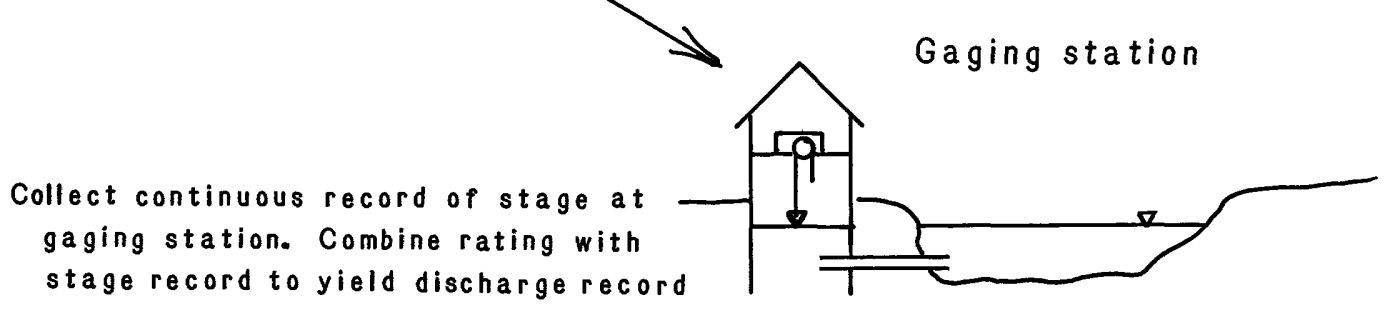

Figure 4.--Procedure for streamflow-data collection. 
For planning and design, analyses of streamflow data generally are made using averages or statistical summaries. For example, if interested in runoff of a stream for water-supply purposes, a hydrologist probably would use monthly and yearly runoff values. If a bridge or other structure is to be constructed that must withstand floods, a statistical calculation of expected high flows would be used.

Data that have been collected at 50 gaging stations in the Green River basin were used in this report. In addition, data for streamflowgaging station 06637550, Sweetwater River near South Pass City, were included as this stream is located in the Green River structural basin and has similar runoff characteristics. Location of the stations is shown in figure 5, and table 1 is a summary of streamflow characteristics at the sites.

The streams listed in table 1 are affected by works of man as noted. If diversions or storage alter streamflow, the gaged data may not represent true natural flows. For example, consumption of water due to irrigation would result in the gaged average discharge being less than the natural runoff of the stream. Peak flows also might be affected, especially by large storage reservoirs. For some purposes, the user might want to make adjustments to the gaged data so that it would represent natural flows. For purposes of this study, actual flows at the sites were desired and no adjustments were made.

The average discharge $\left(Q_{a}\right)$ expressed in table 1 is the average for the period of record. The average flow for any particular year is likely to be somewhat different from the long-term average, as shown by figure 6. At least 5 years of record generally are required before average discharge is computed for a site, and longer periods are desired for greater accuracy.

High flows generally are analyzed through the use of a frequency distribution of peak flows. An array of annual peak flows commonly is used to depict the frequency of peak flows at a site. An annual peak is the highest momentary peak discharge during a water year. More than one peak flow may occur at a site during a year, but only the largest peak for each year is used in this array. The occurrence and distribution of annual peak flows is illustrated in figure 7 . The frequency distribution of peak flows may be mathematically described by an equation known as a probability-distribution function. One of the most widely-used such functions in hydrology is the Pearson Type III. To fit this function to an array of peaks, logarithms of the peaks are first determined. Using the log-transformed array, the mean, standard deviation, and skewness are computed. The mean describes the relative magnitude of the array, the standard deviation describes variability, and skewness indicates degree of symmetry of values about the mean. These three statistics are applied to the Pearson Type III equation to obtain a curve representing the probability distribution of peak flows at the site. From this curve, peak flows having expected average recurrence intervals can be determined. In this report, peak flows are designated by the symbol $P$, and a subscript is used to identify peak magnitude. For example, $\mathrm{P}_{2}$ designates an annual peak flow that would be equaled or exceeded every 2 years, on the average. 


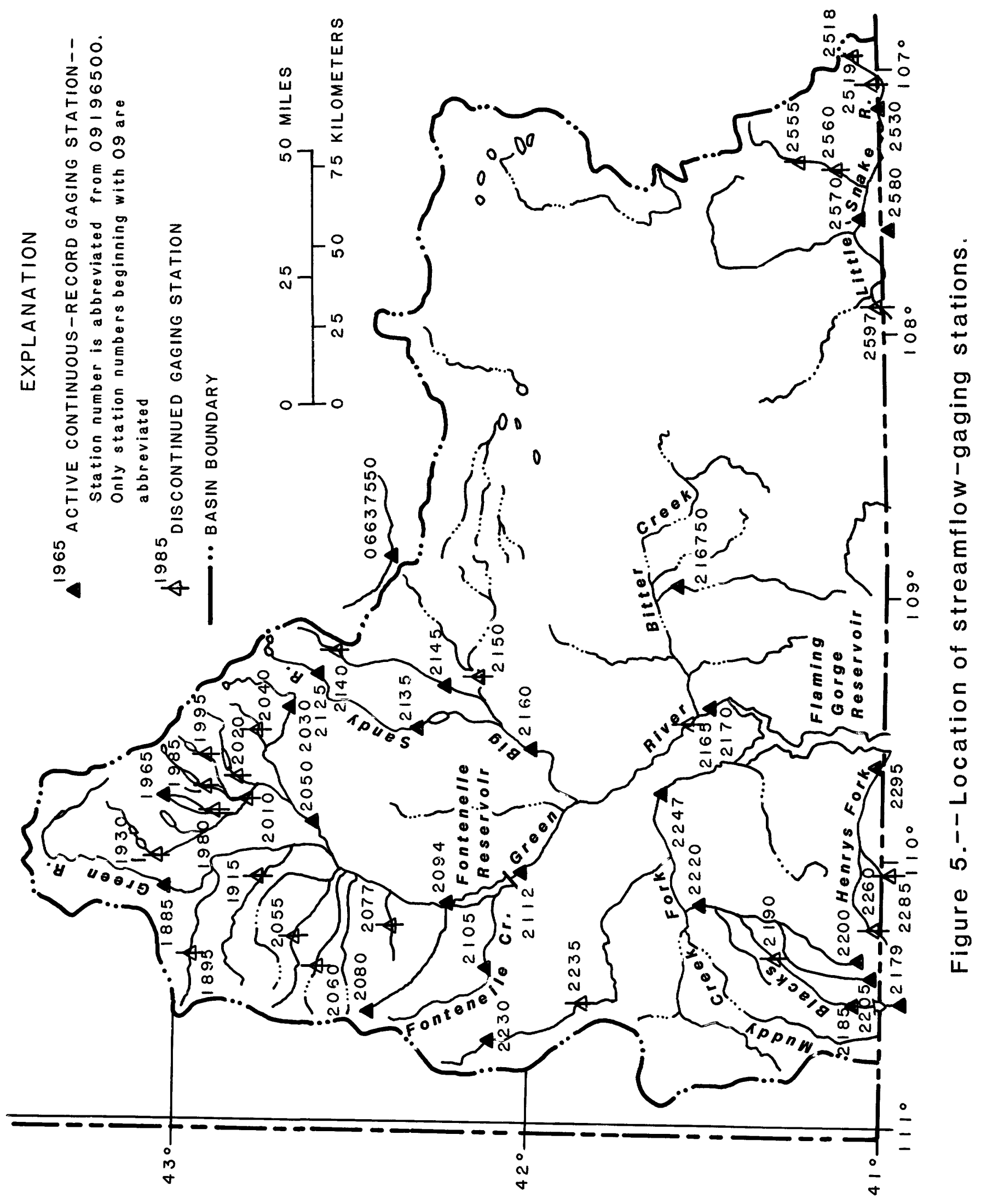




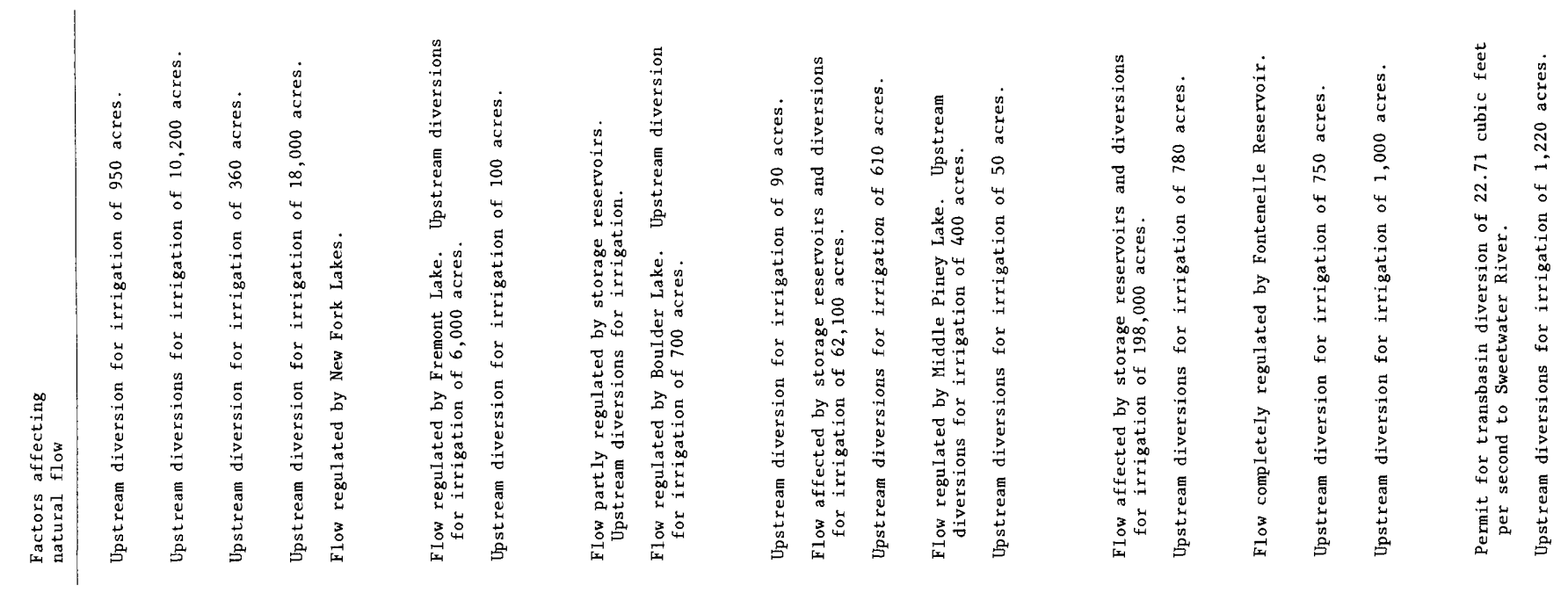

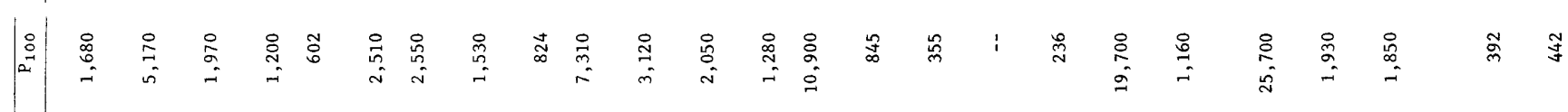

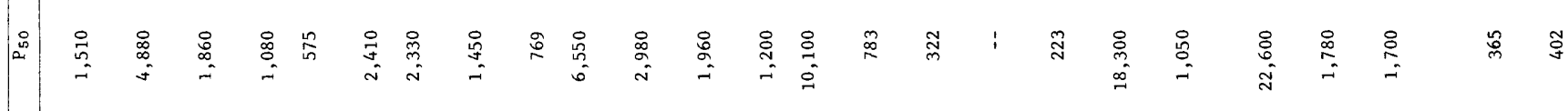

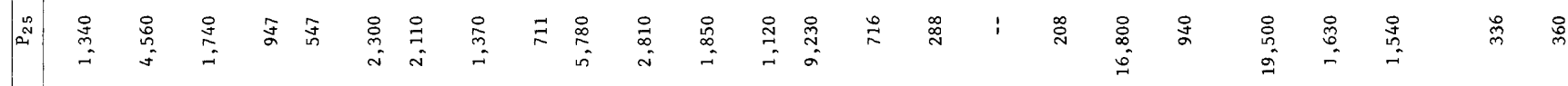

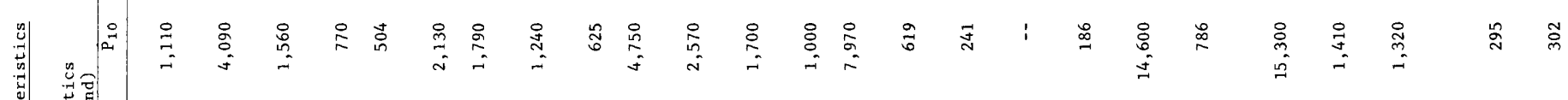

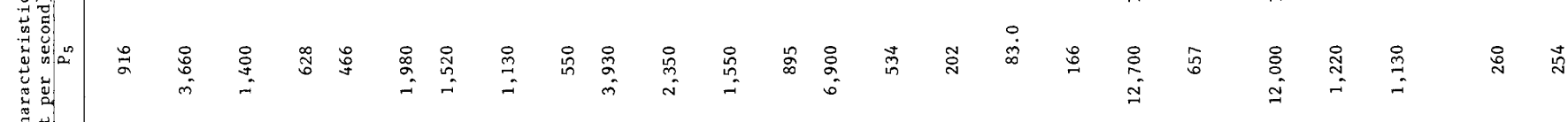

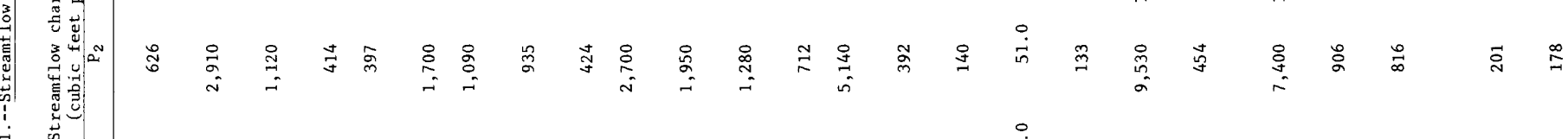

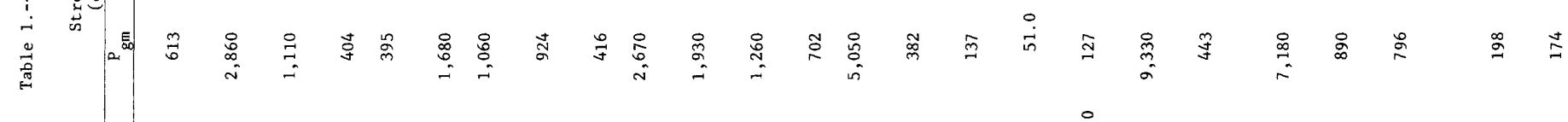

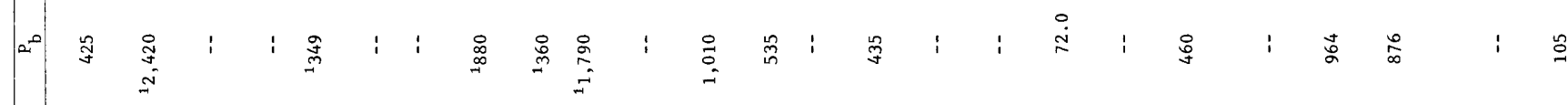
|

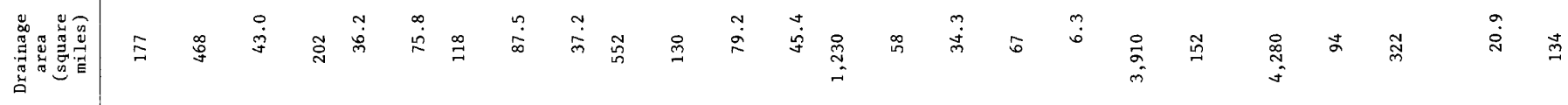

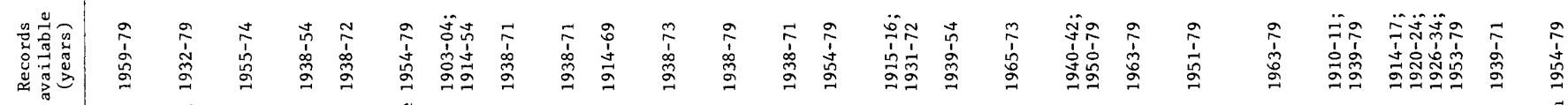

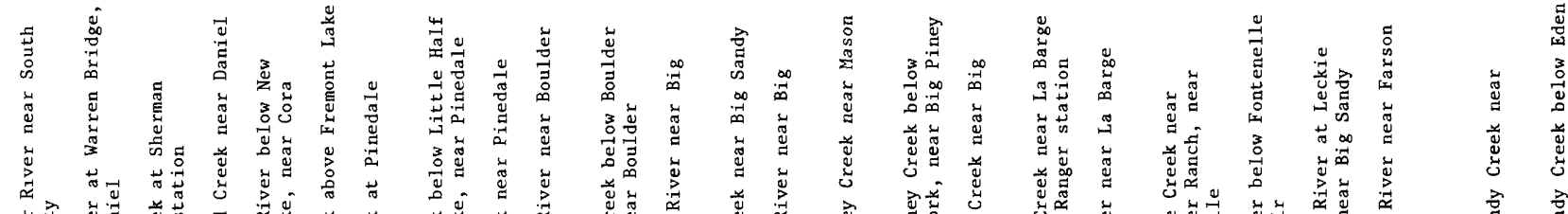

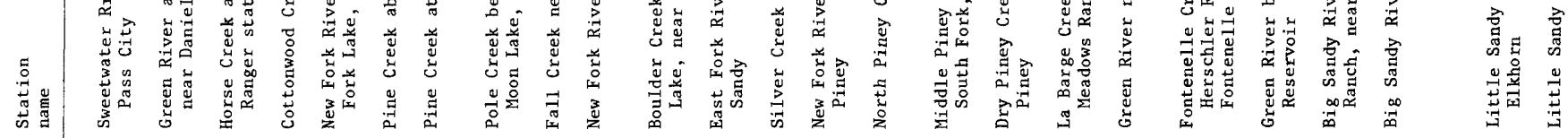

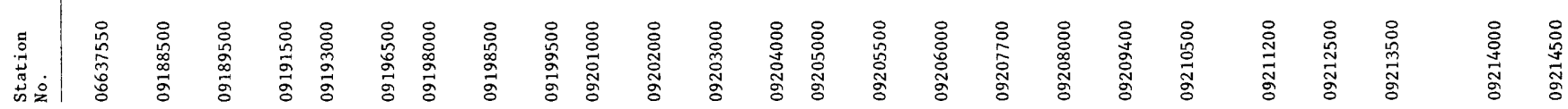




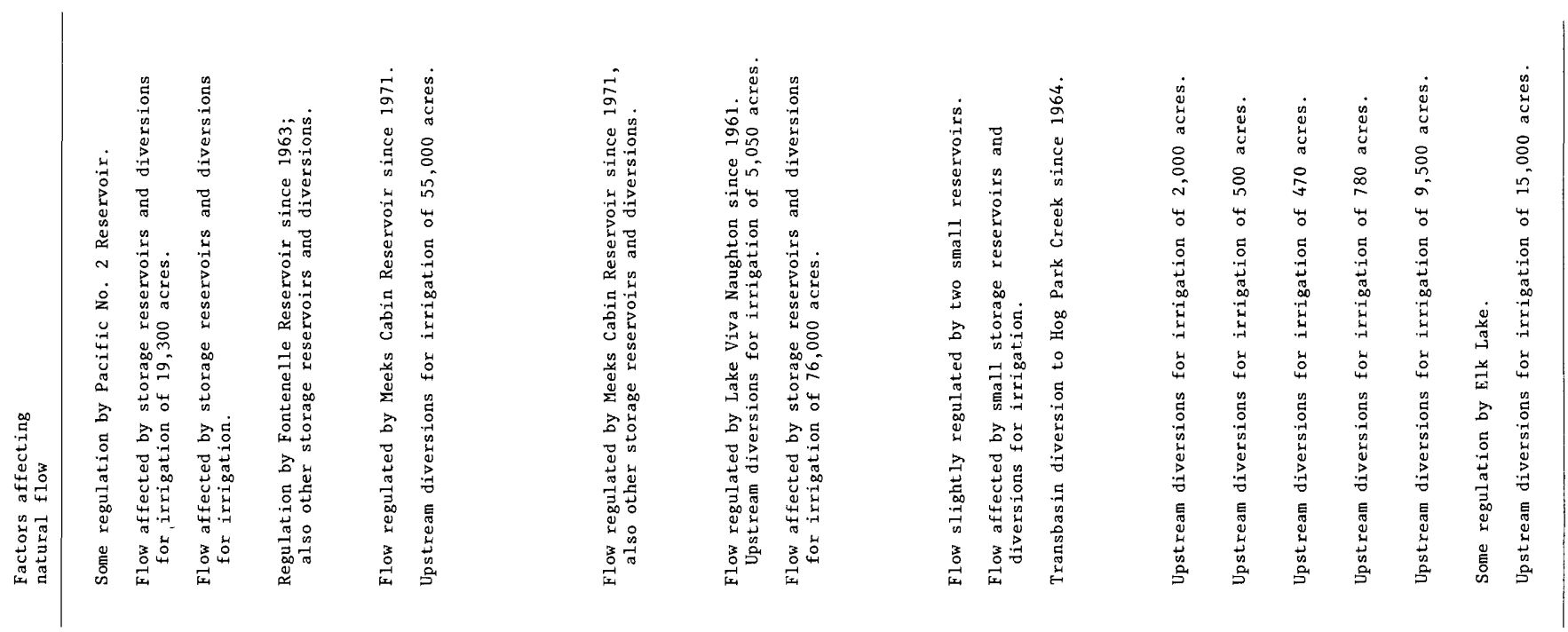

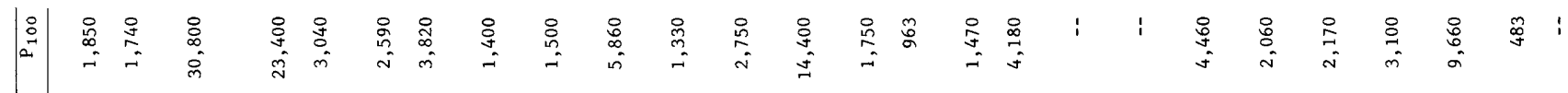

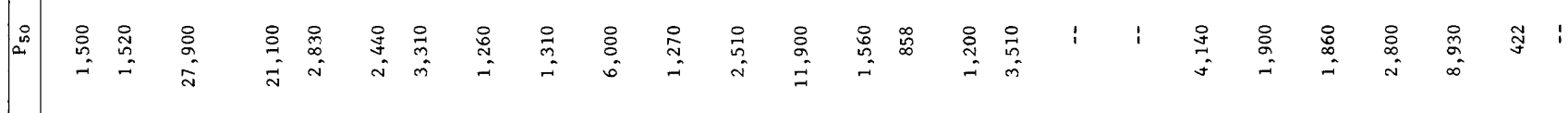

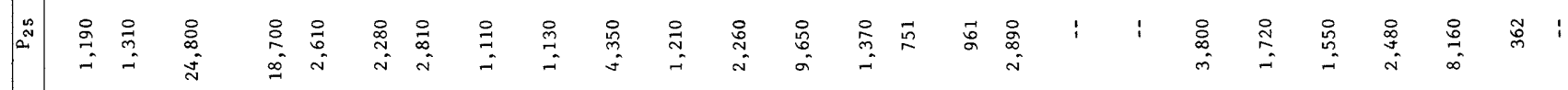

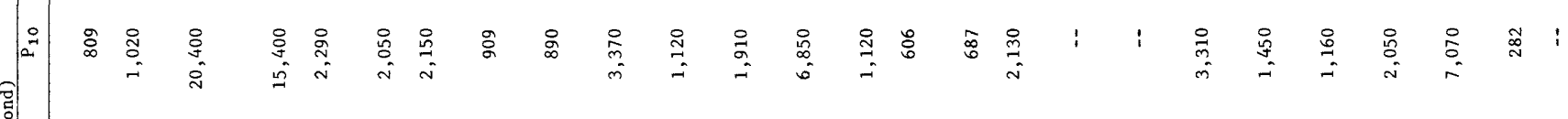

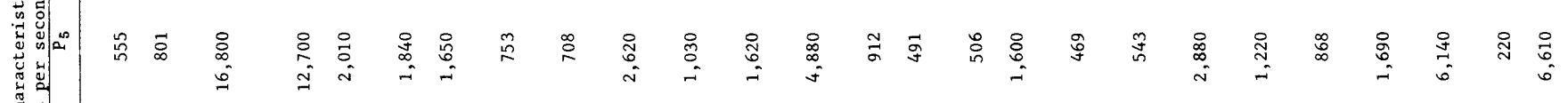

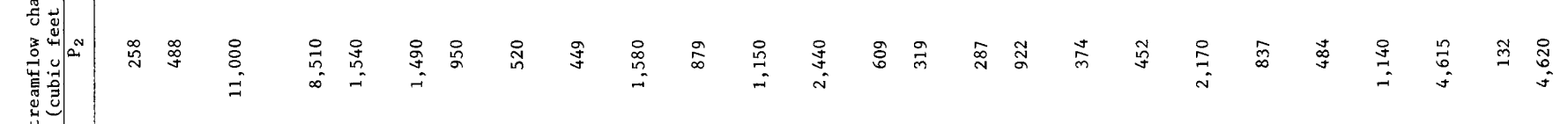

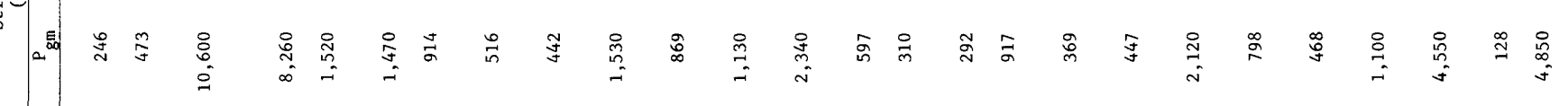

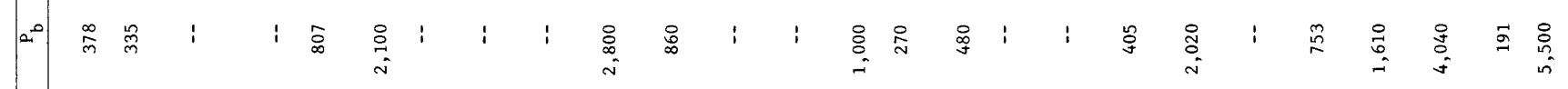

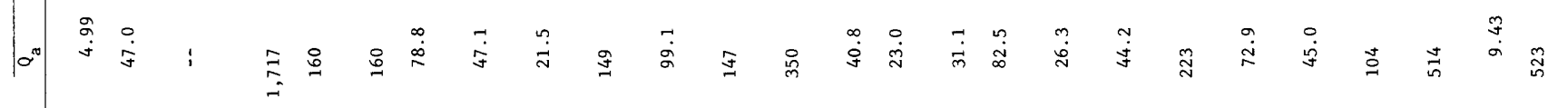

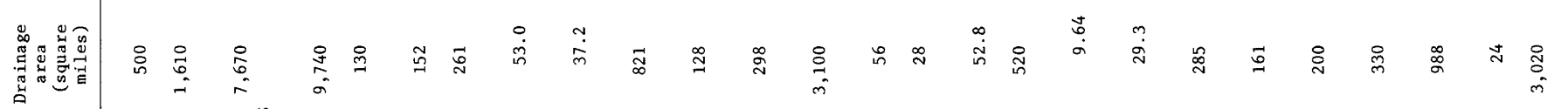

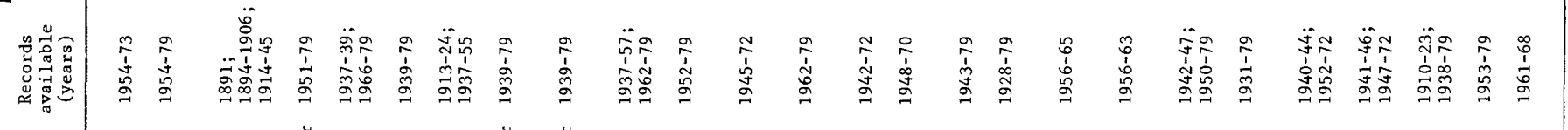

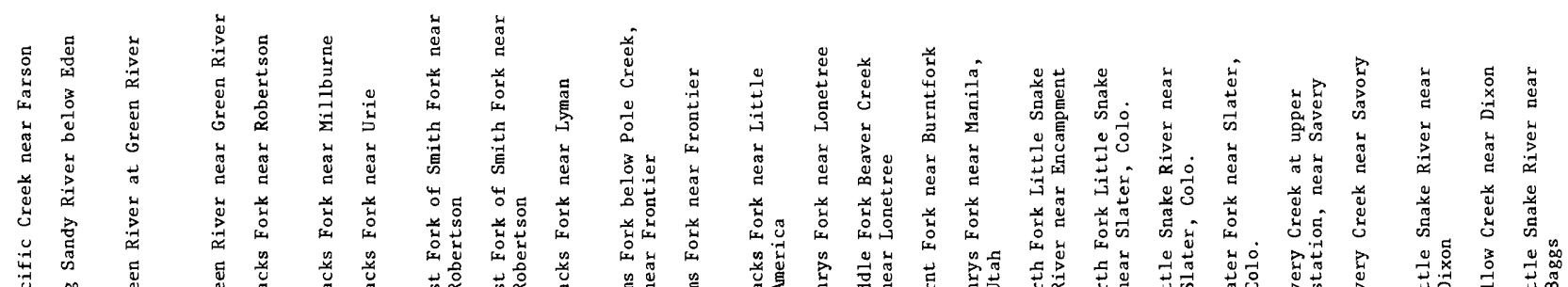

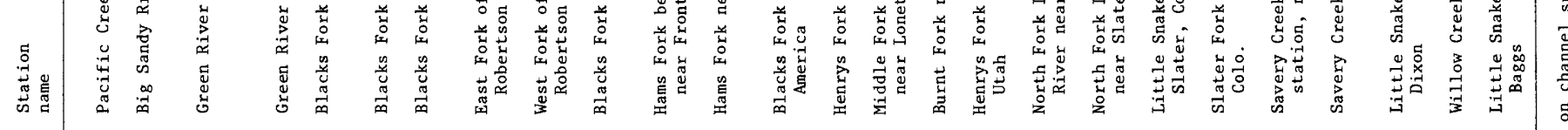
แaln 


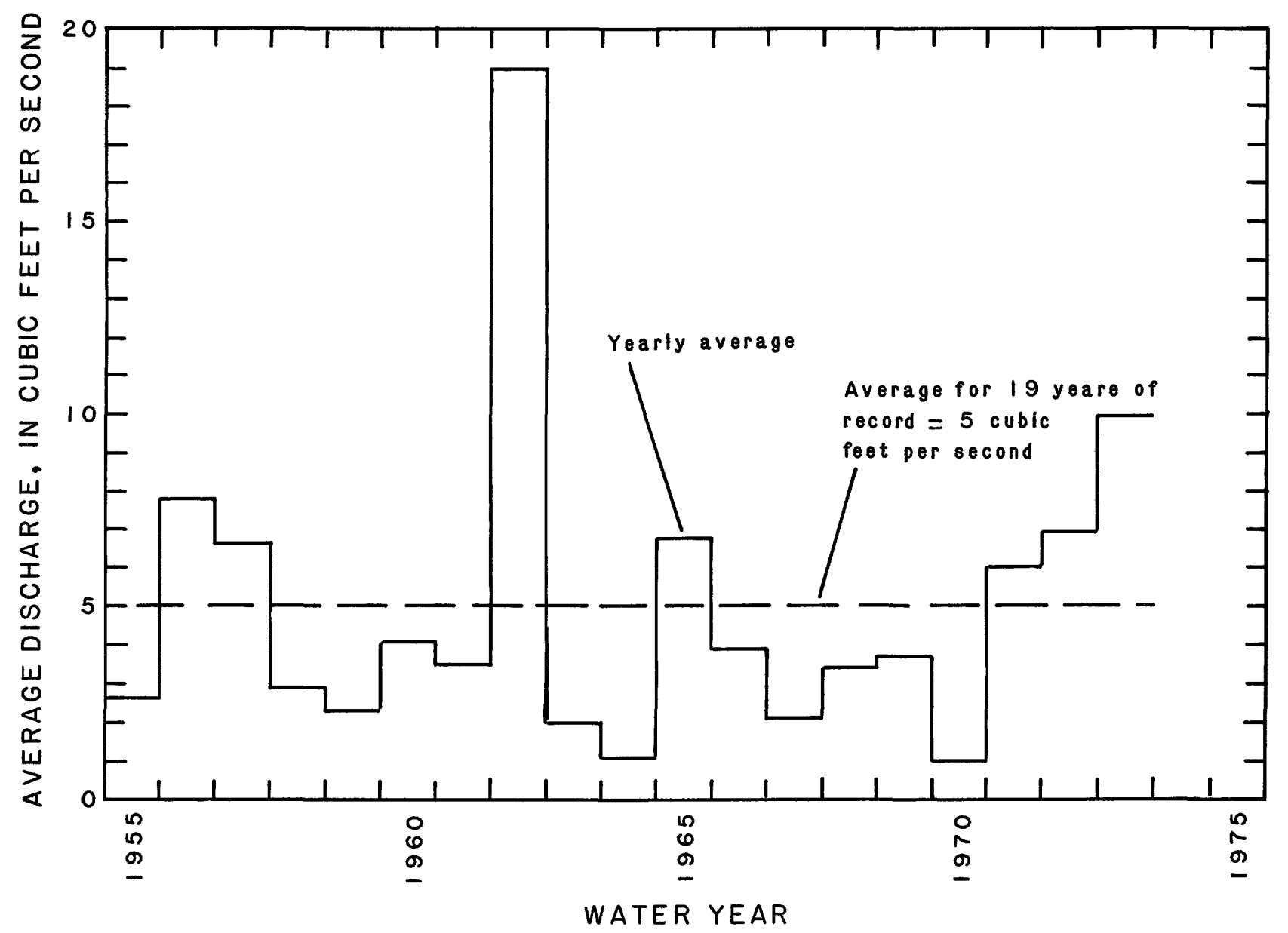

Figure 6.--Yearly and long-term average discharge (streamflowgaging station 09215000 , Pacific Creek near Farson). 


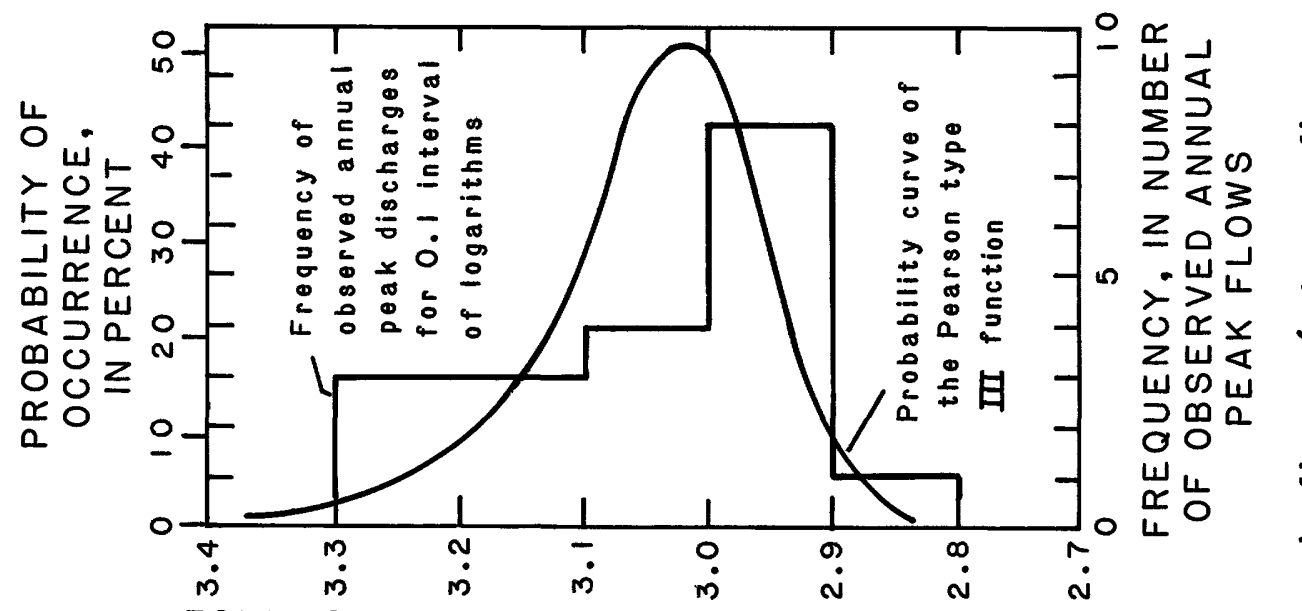

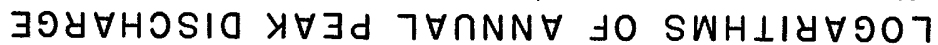

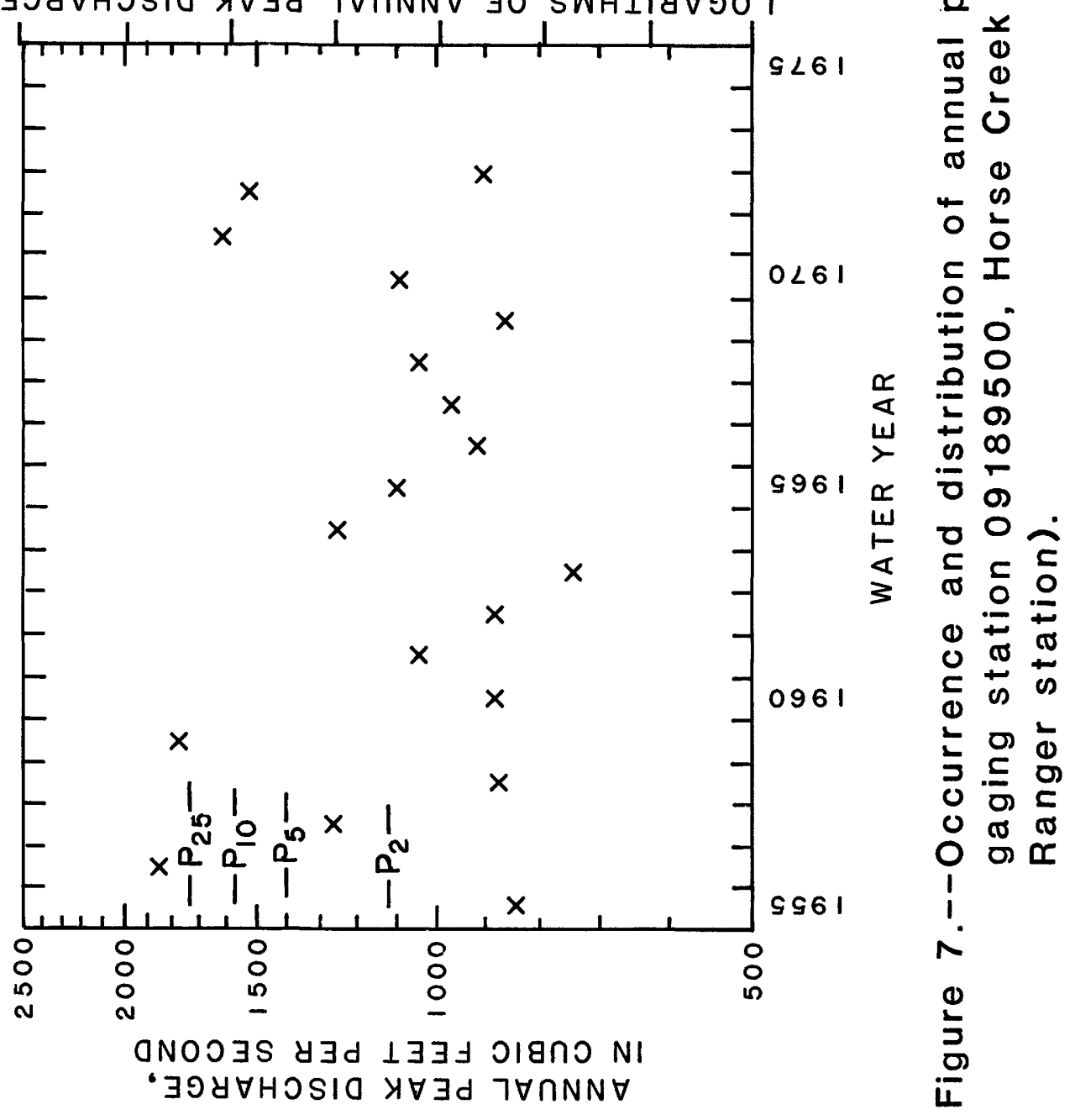




\section{HYDRAULIC CHARACTERISTICS}

As water moves downhill under the effect of gravity, it tends to collect and flow as a single stream. When a stream of water becomes large enough to move particles comprising the surface on which it is flowing, a channel is formed.

The size of a natural channel is an indication of flow magnitude. Large flows create large channels; smaller flows create smaller channels. In addition to size, other features of stream channels that are related to their flows include slope, shape, and meander characteristics.

As water flows in a channel, roughness features of the bed and banks tend to slow the movement. As a result, velocities across a stream vary as depicted by figure 8 . The fastest velocity generally is near the surface in the middle part of the stream; slower velocities occur near the banks and bed. The velocity (V) of equation $1(Q=A V)$ is the mean velocity of flow in a section.

As discharge of a stream varies, hydraulic characteristics also vary. For example, cross sections that are occupied by various flows of a typical perennial stream are illustrated in figure 9. Width, depth, and area of the cross section vary with magnitude of the discharge. As discharge increases, the average direction of flow of a stream straightens as shown in figure 10. In effect, this shortens the path of travel for the water and increases its slope, and average velocity increases.

\section{At-a-station Hydraulic Characteristics}

Mathematical relations can be developed that describe the hydraulic characteristics of flow in a channel. One of the most widely accepted studies of this type was made by Leopold and Maddock (1953). They showed that mean values of the width (W), depth (D), and velocity (V) of streamflow could be expressed as functions of discharge (Q), such that:

$$
\begin{aligned}
& W=a Q^{b}, \\
& D=c Q^{f}, \text { and } \\
& V=k Q^{m} \text {. }
\end{aligned}
$$

Data from current-meter discharge measurements described earlier were used to develop relations of the above type for each of the 51 gaged sites listed in table 1 . In addition, an equation for cross-sectional flow area (A) may be obtained by combining constants and coefficients for equations 2 and 3 , so that:

$$
A=(a \times c) Q^{(b+f)} .
$$

An example of these at-a-station relations showing changes in hydraulic characteristics with discharge is shown in figure 11. 
Channel cross section, showing velocity pattern

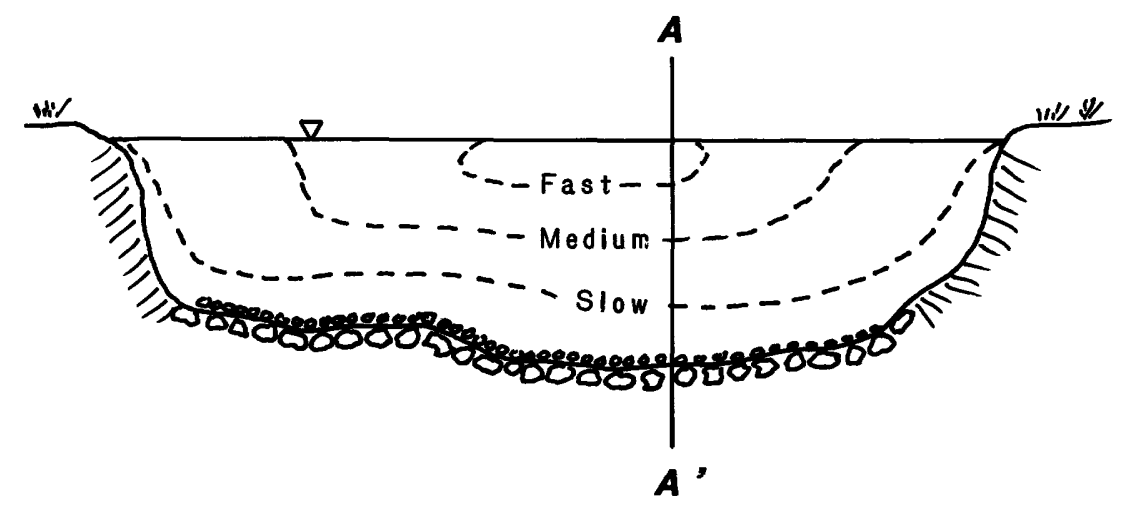

Vertical profile of section $\boldsymbol{A}-\boldsymbol{A}^{\prime}$, showing velocity distribution

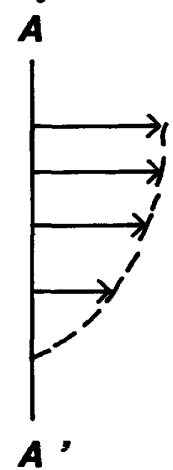

Figure 8.--Cross section and vertical profile of a stream, showing relative velocities. 


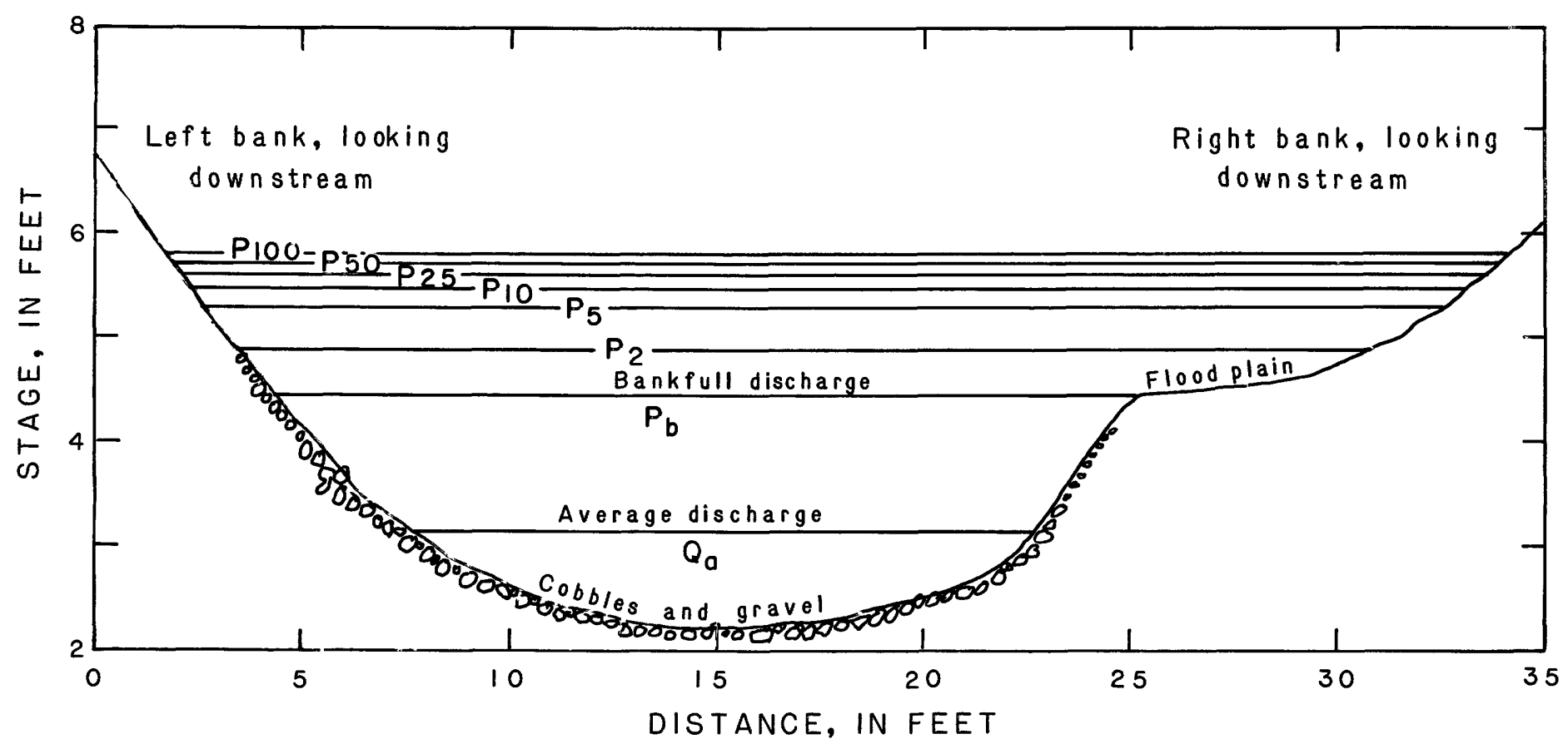

Figure 9.--Cross sections occupied by various flows of a perennial stream (streamflow-gaging station 09208000, La Barge Creek near La Barge Meadows Ranger station).

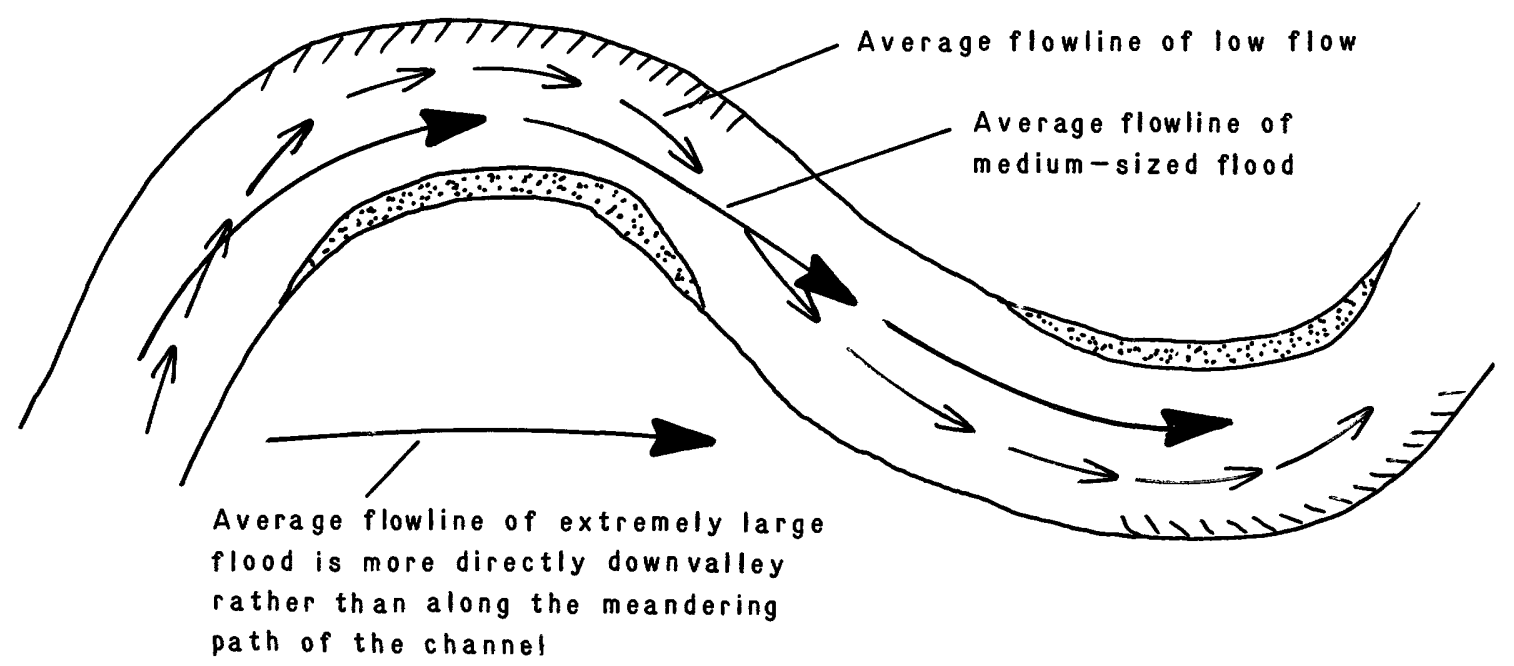

Figure 10.--Average direction of flow of stream at various discharges. For a meandering channel, the average flowline straightens with increasing discharge. This shortens the path of travel and increases the stream slope. 

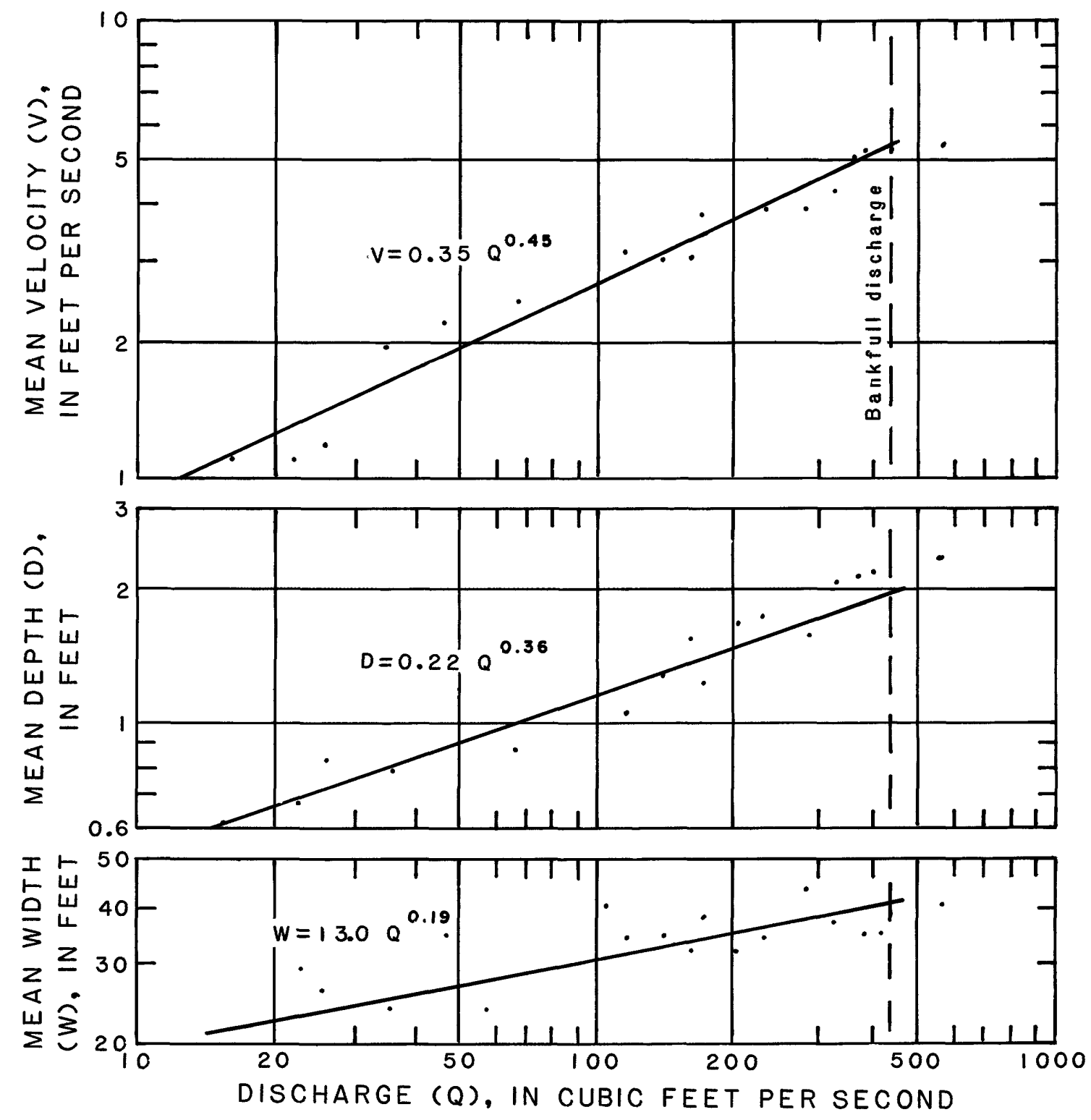

Figure 11.--Changes of mean width, depth, and velocity with discharge at a channel cross section (streamflow-gaging station 09205500 , North Piney Creek near Mason). 
The at-a-station characteristics, including the hydraulic relations, for the 51 gaged sites of this study are summarized in table 2 . The exponents and coefficients of the equations are different for each station depending on channel features unique to each site. The relations generally apply only to flows contained within the channel of the reach near each gaging station. When flow overtops the banks and spreads across the flood plain, a different set of hydraulic characteristics may prevail.

\section{Channel Formation}

Channel formation takes place mainly during floodflows when a stream has tremendous energy and is transporting large amounts of sediment. Erosion and deposition occur as the stream sculptures its channel to a size large enough to accommodate its flows.

In addition to flow magnitude, sediment load is important to channel formation. As discharge at a site increases, sediment concentration generally increases as well. This is because: (1) During runoff from snowmelt or rainstorms the washload of sediment eroded from the basin surface and transported by overland flows to the stream is greater, and (2) during high flows the stream has increased velocity and sufficient power to erode the bed and banks and transport this material along with the washload.

\section{Formative Discharge}

Floodflows cause channel formation and it is logical that an index of these flows would be related to channel size. Such an index could be used to develop regional relations between formative discharge and channel dimensions. These relations could then be used to study the characteristics of streams, and they would be especially valuable for analyzing possible effects of streamflow alteration on channels.

A review of literature concerning hydraulic characteristics reveals that several different parameters have been used as indices of stream discharge (K. L. Wahl, U.S. Geological Survey, written commun., 1974). Early studies, such as that by Leopold and Maddock (1953), used average discharge $\left(Q_{a}\right)$ to compare regional hydraulic characteristics. As noted by Leopold and others (1964, p. 242), average discharge was not considered responsible for channel size, but such data were readily available and simply reflected changes produced by more effective discharges. In subsequent studies, such as those by Wolman (1955), Nixon (1959), Brush (1961), Dury (1961), and Emmett (1972, 1975) bankfull discharge was used in the analyses. Bankfull discharge $\left(P_{b}\right)$ is the maximum streamflow that can be accommodated within a channel. As shown by figure 9, discharges greater than bankfull cause the stream to overtop the banks and spread onto the flood plain. 


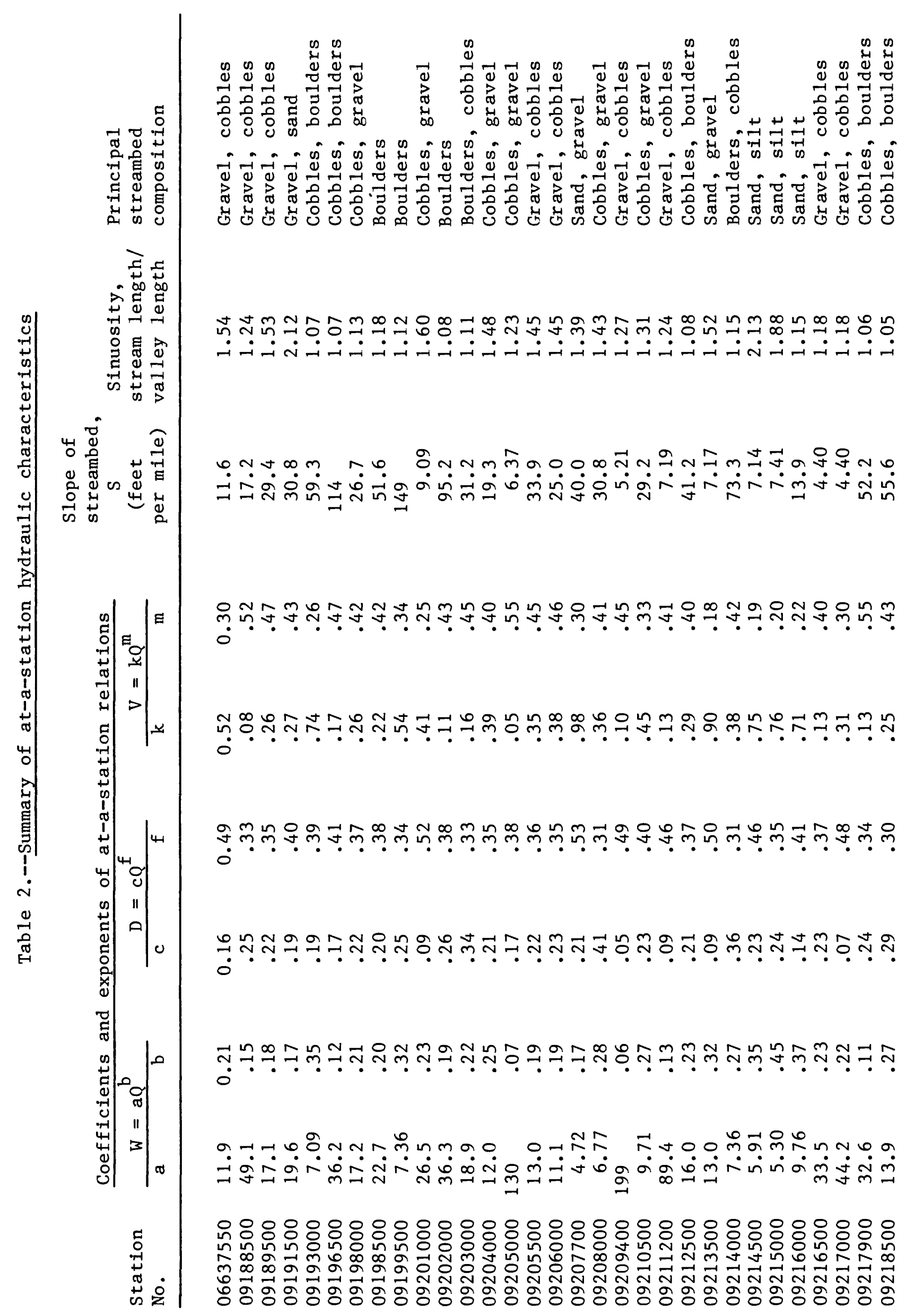




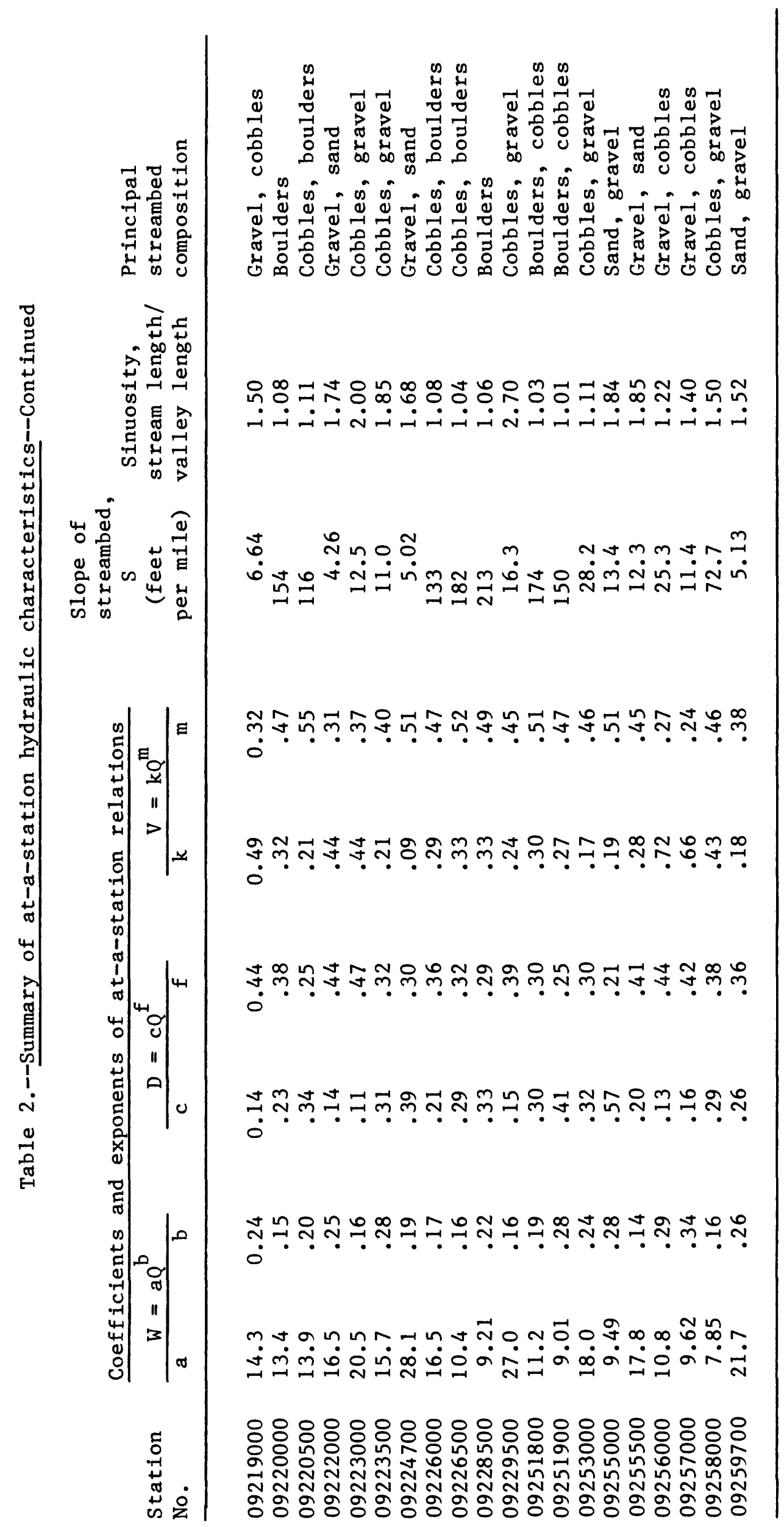


As determined by Wolman and Miller (1960), streamflows of about bankfull size seem to dominate channel formation. Although floods with discharges much greater than bankfull discharge $\left(P_{5}-P_{100}\right.$, for example) have the power necessary to form channels, such floods occur relatively infrequently. When such a flood does occur, channel size has already been established by the more frequent smaller discharges; hence, the larger flows tend to top the banks and flow along the flood plain. In many such floods, the established channel is left relatively unchanged by the overbank flow. In contrast, discharges less than bankfull commonly occur but have insufficient power to be effective in channel formation. Intermediate floodflows that just fill the available channel are thus believed to dominate channel formation. These streamflows have sufficient power and frequency of occurrence to form and maintain channel size and shape. This concept is illustrated in figure 12, where the momentary maximum discharge, or peak, is used to depict magnitude of the floodflow.

The frequency that a bankfull or greater discharge occurs has been found to be about the same for a large variety of streams. By conducting onsite surveys for a large number of gaged streams, several different investigators have independently found that bankfull discharge has an average recurrence interval of 1 to 2 years (Wolman and Leopold, 1957; Brush, 1961; Harvey, 1969; and Emmett, 1972, 1975). This means that, on the average, annual peak discharges of bankfull magnitude or greater would occur once every year or two.

To substantiate the recurrence interval of bankfull discharge for streams in the Green River basin, channel surveys were made at 30 of the gaged sites listed in table 1 . The median recurrence interval of bankfull discharge for those streams surveyed was found to be 1.7 years. Flow-duration statistics were reviewed for each station, and it was found that daily streamflows of bankfull magnitude or greater occur in the perennial streams about 0.6 percent of the time, or 2.2 days per year, on the average. The duration is less for intermittent and ephemeral streams, but a particular percentage could not be determined for them due to the insufficient amount of data available for such streams.

Williams (1978) analyzed data for 36 streams and reviewed works of previous investigators of $\mathrm{P}_{b}$. He concluded that $\mathrm{P}_{b}$ had a median recurrence interval of about $1.5^{\mathrm{b}}$ years for annual peaks, but there was a wide range and the magnitude of $P_{1.5}$ sometimes varied considerably from that of $P_{b}$. Thus, if $P_{b}$ is selected as a physical descriptor of formative discharge, there is likely to be some variation from site to site of any statistic describing such flows.

A physical basis is required for a particular statistic to be designated as an index of formative discharge. Peaks of about bankfull magnitude appear to dominate channel formation. However, it must be allowed that each and every high flow at a site affects channel formation to some degree. As proposed by Riley (1976, p. 545), $\mathrm{P}_{\mathrm{b}}$ is not the sole determinant of bankfull geometry, but rather, bankfull geometry may be affected by the whole spectrum of a stream's water and sediment discharges. This was realized by Wolman and Miller (1960); their proposal to use $P_{b}$ as an index of formative discharge was based on the concept that a large part of the "work" of sediment transport and, hence, channel formation is done by discharges of moderate magnitude which recur relatively frequent$1 y$, rather than by rare discharges of unusual magnitude. 


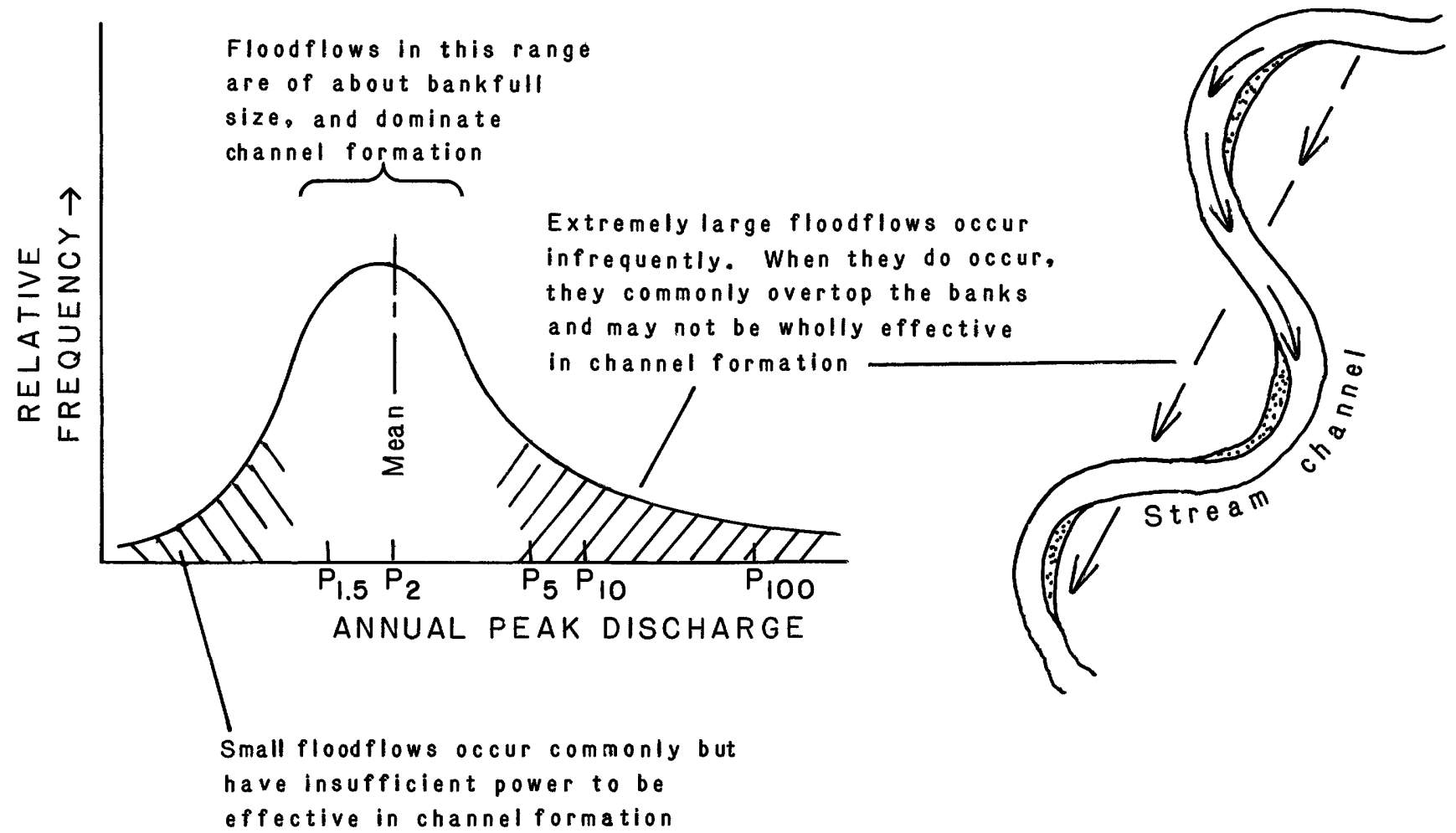

Figure 12.--Magnitude and frequency of flows dominating channel formation. 
In a study based on this concept, Andrews (1980) evaluated the sediment loads of streams at 15 gaged sites in Colorado and Wyoming. Increments were determined of the annual sediment loads transported by various discharges of the streams. For each of the sites studied, the discharge that transported the largest fraction of the sediment load throughout a number of years was nearly equal to the bankfull discharge.

Rather than designating a peak with a particular recurrence interval as dominant, a more basic descriptor of all high flows would be the mean of the annual peak-flow array. As described earlier, logarithms of annual peaks generally are used to compute peak-flow characteristics. The mean would, therefore, be that of a logarithmic array, and an antilog of this value would be the geometric mean. The geometric mean of annual peak flows $\left(P_{1}\right)$ is considered by the author to be a meaningful index of formative discharge because it represents relative magnitude of the complete array of peak flows for a site.

Technically, it matters little whether $\mathrm{P}_{\mathrm{b}}, \mathrm{P}_{\mathrm{gm}}$, or a peak with a recurrence interval of about 1.5 to 2.0 years is considered to be an index of formative discharge. There is generally little difference between magnitudes of the above indices when groups of stations are averaged.

For practical applications, the terminology used to designate dominant or formative discharge could have an advantage depending on its intended use, even though magnitudes of the above indices are about the same. $\quad P_{b}$ has a physical significance that is easily visualized, $P$ represents the complete array of annual peaks, and use of a flood with ${ }^{g m}$ particular frequency such as $P_{1.5}$ or $P_{2}$ exemplifies how often a significant channel-forming discharge occurs on the average.

The magnitude and range of flows that dominate channel formation vary from site to site depending on the particular distribution of high flows at the site and on individual basin characteristics. Channel formation is not controlled entirely by the forces of streamflow. The character of the bed material and sediment load are important, and other forces such as geology, vegetation, climate, wind deposits, the movement of wildlife and livestock, and developments of man also may affect channels. The net result of all such forces needs to be realized when a stream is examined. Vegetation is particularly important since its stabilizing effect prevents channels with erodible bed and bank material from adjusting their size with each high flow.

In summary, all high flows affect channel formation to some degree. $P_{b}$ is a physical index of the most dominant range of channel-forming flows; $P$ represents the relative magnitude of all high flows and under average Conditions it generally is about equal to $\mathrm{P}_{b} . \mathrm{P}_{\text {om }}$ is, therefore, considered to be a viable statistical index of channel-forming flows. A development that would alter streamflow and change the magnitude of this index might stimulate a corresponding change in the physical nature of a channel. Relations that could be used to appraise such cases are presented in following sections of the report. 
The at-a-station relations summarized in table 2 represent hydraulic characteristics that vary with discharge in channel reaches near each of the 51 gaging stations. Using these relations as a base, average hydraulic characteristics of the stream system may be determined. The analysis is made by using specific flow characteristics, such as $P$ or $\mathrm{P}_{2}$, to compare hydraulic features among the gaged streams. The resulting relations depict hydraulic characteristics of the streams on a regional basis. Provided the data base is representative of stream types throughout the region, the resulting relations may be assumed to apply to ungaged as well as gaged reaches. Such regional relations are sometimes referred to as downstream relations, as they allow comparison of hydraulic characteristics as stream size increases downstream due to tributary inflows.

Regional hydraulic relations for streams of the Green River basin in Wyoming are summarized in table 3. The relations for mean width, depth, and velocity versus discharge are shown graphically by figure 13 . The relations are drawn only for the range of data available from streamflow stations of this study. Separate relations were developed for $\mathrm{P}_{\mathrm{gm}}, \mathrm{P}_{2}$, and $Q_{a}$. Due to the closeness of the flow statistics, relations tor $P$ and $\mathrm{P}_{2}^{\mathrm{a}}$ are nearly identical. A comparison of data for the 30 sites tham were surveyed showed that the magnitude of $P_{b}$ generally is about the same as $\mathrm{P}_{\text {m }}$ or $\mathrm{P}_{2}$. The regional relations depicting $\mathrm{P}_{\text {om }}$ or $\mathrm{P}_{2}$, therefore, generally represent the hydraulic characteristics gm a stream flowing bankfull.

A large part of a stream's runoff occurs during its floodflows. If a stream has large floodflows, then it has a correspondingly large runoff. A comparison of $Q_{a}$ with $P$ is shown in figure 14 for perennial streams of the study. On the average, $Q_{a}$ for perennial streams is 10.6 percent of $P$. Because small streams have floodflows of shorter duration than lagme streams, the proportion of $Q_{\text {a }}$ to $P$ varies from about 9 percent for small streams to almost 13 percent for farge streams.

The relations for $Q_{\text {in }}$ table 3 and in figures 13 and 14 apply only to perennial streams of the study area. Data were lacking for developing relations for $Q$ of intermittent and ephemeral streams. Only two stations (09207700, Dry Piney Creek near Big Piney, and 09215000, Pacific Creek near Farson) were representative of intermittent streams. However, in a study using data for streams throughout Wyoming, the author (Lowham 1976 , p. 11) found that $Q_{a}$ ranged from less than 1 to about 4 percent of $\mathrm{P}_{\mathrm{gm}}$ for intermittent and ephemeral streams.

The regional relations show that cross-sectional flow area and stream velocity tend to increase with flow magnitude. For a stream whose discharge increases in the downstream direction as tributaries add flow, channel size and stream velocity also will increase. However, exceptions to the downstream increase in discharge may occur. For example, streams with channel beds having large infiltration rates may lose significant amounts of flow. Red Creek, located in the northeastern part of the study area, is such a stream. (See fig. 1 for location.) Nearly all of its runoff originates in low hills of its headwaters. Flows from tributaries draining the hills collect into a main channel that crosses a 
Table 3.--Summary of regional hydraulic relations

\section{Regression} equation (inch-pound units)

$W=1.17 \mathrm{P}_{\mathrm{gm}}^{0.61}$

$\mathrm{W}=1.15 \mathrm{P}_{2}^{0.61}$

$W=2.95 Q_{a}^{0.60}$

$D=0.35 \mathrm{P}_{\mathrm{gm}} 0.30$

$\mathrm{D}=0.35 \mathrm{P}_{2}^{0.30}$

$D=0.34 Q_{a}^{0.28}$

$\mathrm{V}=2.45 \mathrm{P}_{\mathrm{gm}}^{0.09}$

$V=2.48 \mathrm{P}_{2}^{0.09}$

$V=1.01 Q_{a}^{0.12}$

$\mathrm{A}=0.41 \mathrm{P}_{\mathrm{gm}} 0.91$

$A=0.40 P_{2}^{0.91}$

$A=0.99 Q_{a}^{0.88}$

N R

$\frac{\text { SE }}{\text { Log units Average percent }}$

51

0.96

0.097

22.5

51

.96

.096

22.3

47

.97

.081

18.8

51

.91

.075

17.4

51

.90

.076

17.6

47

.91

.067

15.5

51

.37

.114

26.6

51

.36

.115

26.8

47

.58

.090

20.9

51

.97

.114

26.6

51

.97

.115

26.8

47

.98

.090

20.9 


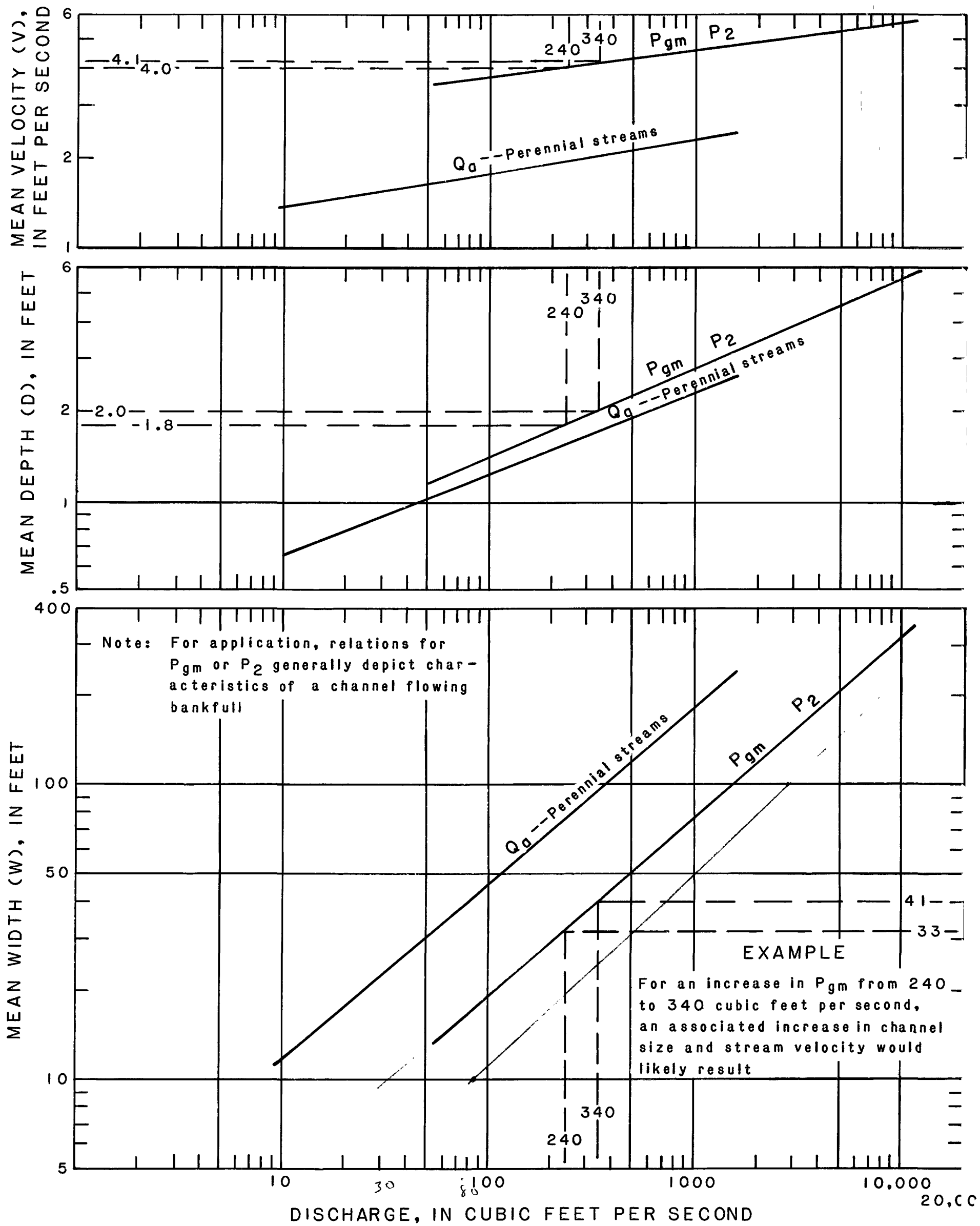

Figure 13.--Regional hydraulic relations for streams. 


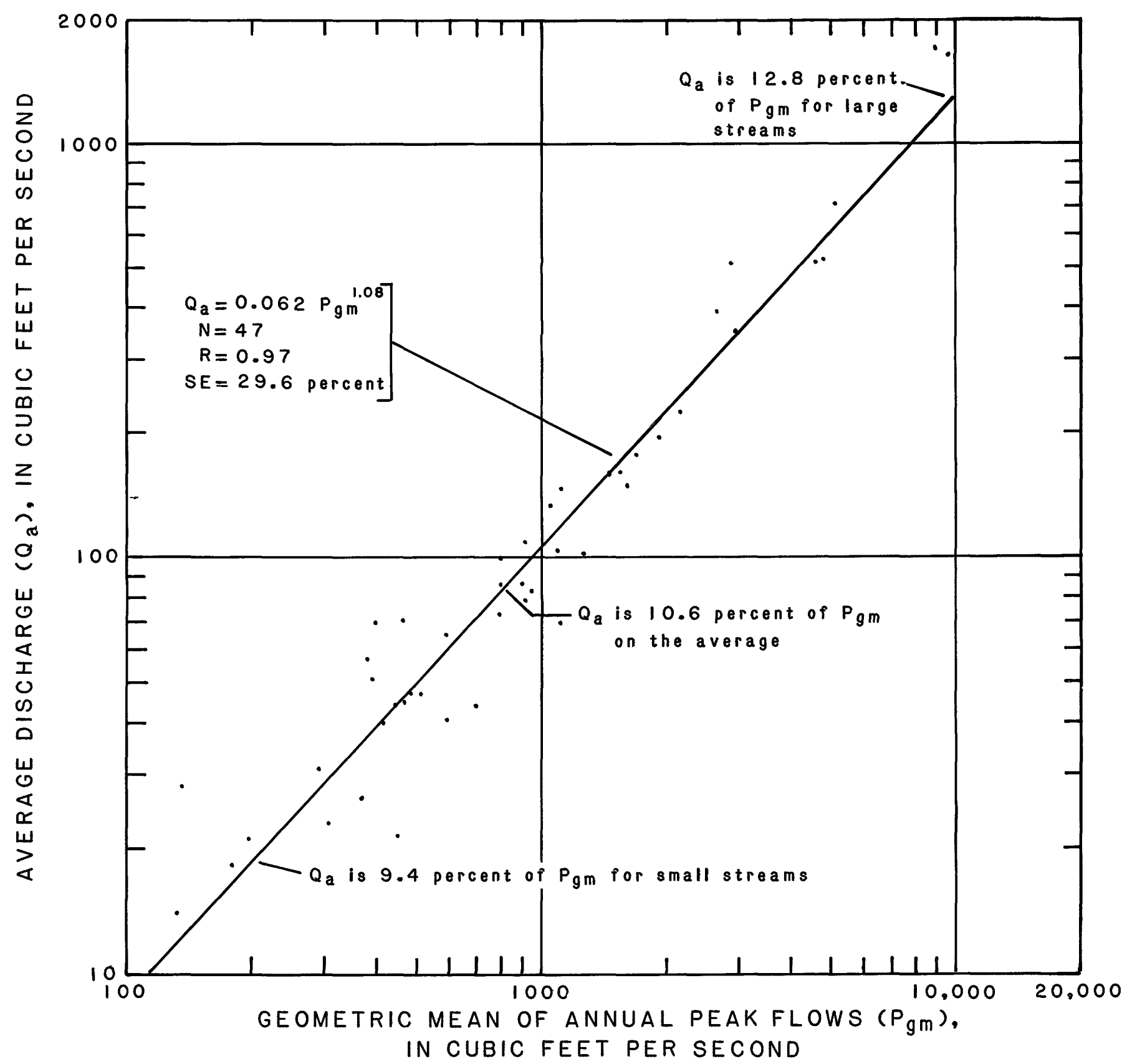

Figure 14.--Relation of $Q_{a}$ versus $P_{g m}$ for perennial streams. 
sandy plain. Very few tributaries enter the main channel in the plain due to the small yield of water there. Due to seepage loss and attenuation of flood waves, discharge and channel size decrease in the downstream direction. The slower flow rates have less capability for transporting sediments; thus, part of the sediment load is deposited, and an alluvial fan has developed near a landmark known as Five Fingers Butte, with the main channel of Red Creek split into numerous distributary channels that spread water onto the plain. The alluvial deposits have formed a very broad and flat plain. During high flows, water from Red Creek merges with that of Bear Creek, a similar drainage just to the south. The small distributary channels regroup at the end of the fan to form a main channel for each stream.

\section{Channe1 Shape}

The shape of a stream channel generally is about parabolic, as was shown by the example cross section in figure 9. The size of a channel increases with magnitude of channel-forming discharges; however, large streams are relatively wider in relation to depth than small streams. This feature may be examined by comparing the width/depth ratio (W/D) of the streams in relation to $P$, which is used as an index of channelforming flows. As shown by the data in figure 15, the width/depth ratio varies with $P$ from about 13 for 100 cubic feet per second to about 53 for 10,000 cubic feet per second.

Considerable scatter occurs about the relation of figure 15, and much of this scatter is attributed to the nature of the sediment loads carried by the streams. Channels are formed of materials carried by them, and the percentage of silt and clay in the bed and banks was found by Schumm (1960) to have a significant effect on channel shape. Stream channels with large percentages of silt and clay tend to have small width/depth ratios. Schumm (1977, p. 121) also notes that vegetation may affect channel shape. If within-channel bars that are deposited during relatively small floods become vegetated, they may resist erosion by relatively larger floods. The greater discharge might then be accommodated by scouring of the channel rather than widening; thus, the width/ depth ratio would be decreased.

\section{Channel Slope and Pattern}

The slope of a stream generally shows a decrease in the downstream direction that is associated with an increase in discharge and a decrease in size of sediments (Shulits, 1941; Lane, 1955). As an example, figure 16 shows the streambed profile of the Big Sandy River. Changes in surface geology also are noted in the figure, and it is evident that geology affects the channel slope. Streambeds and banks are composed of materials that the stream flows through or transports. Bedrock and coarse materials resist erosion and will support steeper slopes than fine materials. Relatively small amounts of fine materials (sand, silt, and clay) are available for erosion in the mountainous headwaters of the Big Sandy River. Tributaries originating in the plains and entering the main channel at lower altitudes contribute most of the fine materials transported by the Big Sandy River (Kircher, 1982). The median size of the 


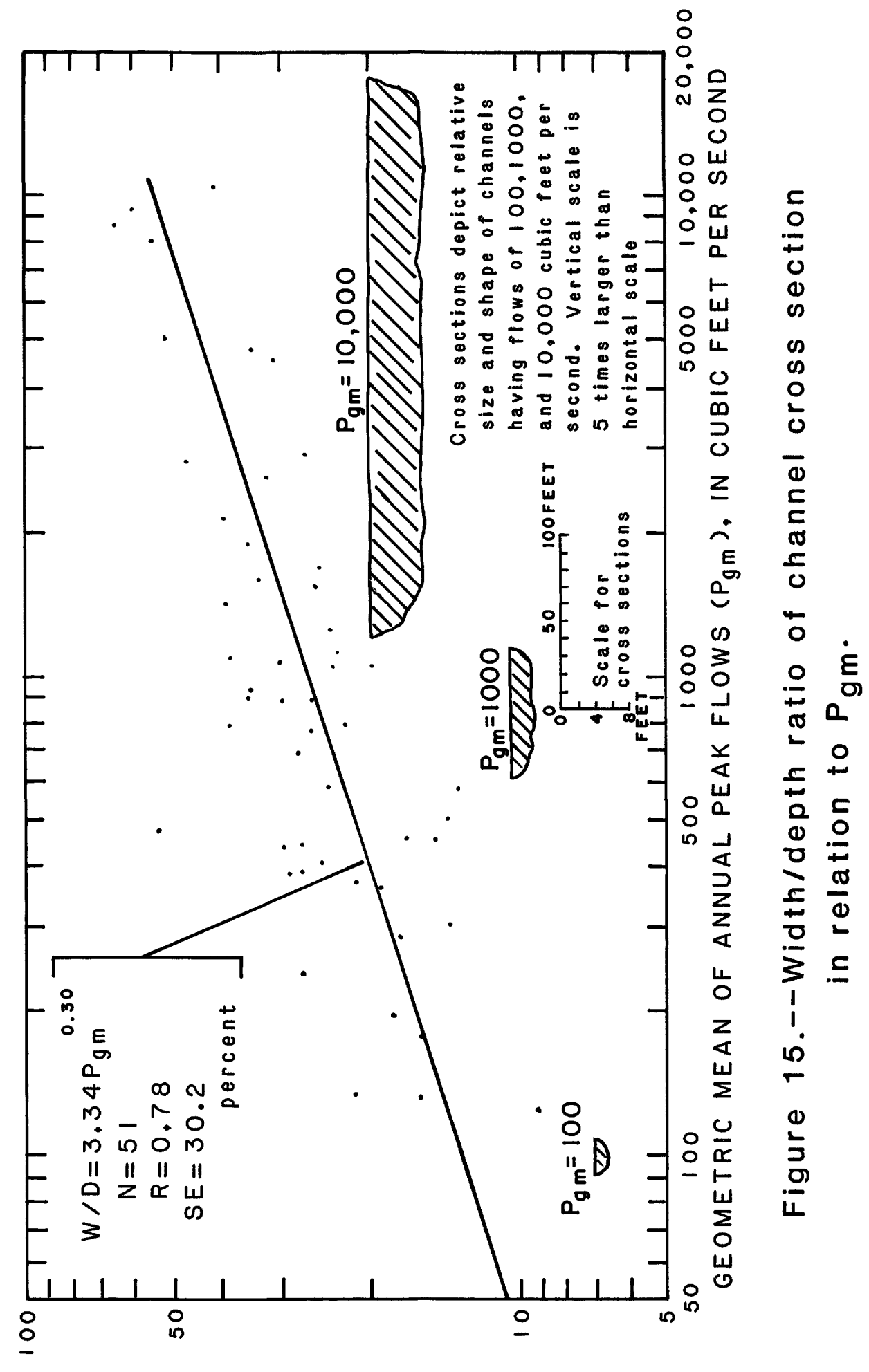

$(O / M) O I \perp \forall Y H \perp d \exists O / H \perp O I M$ 

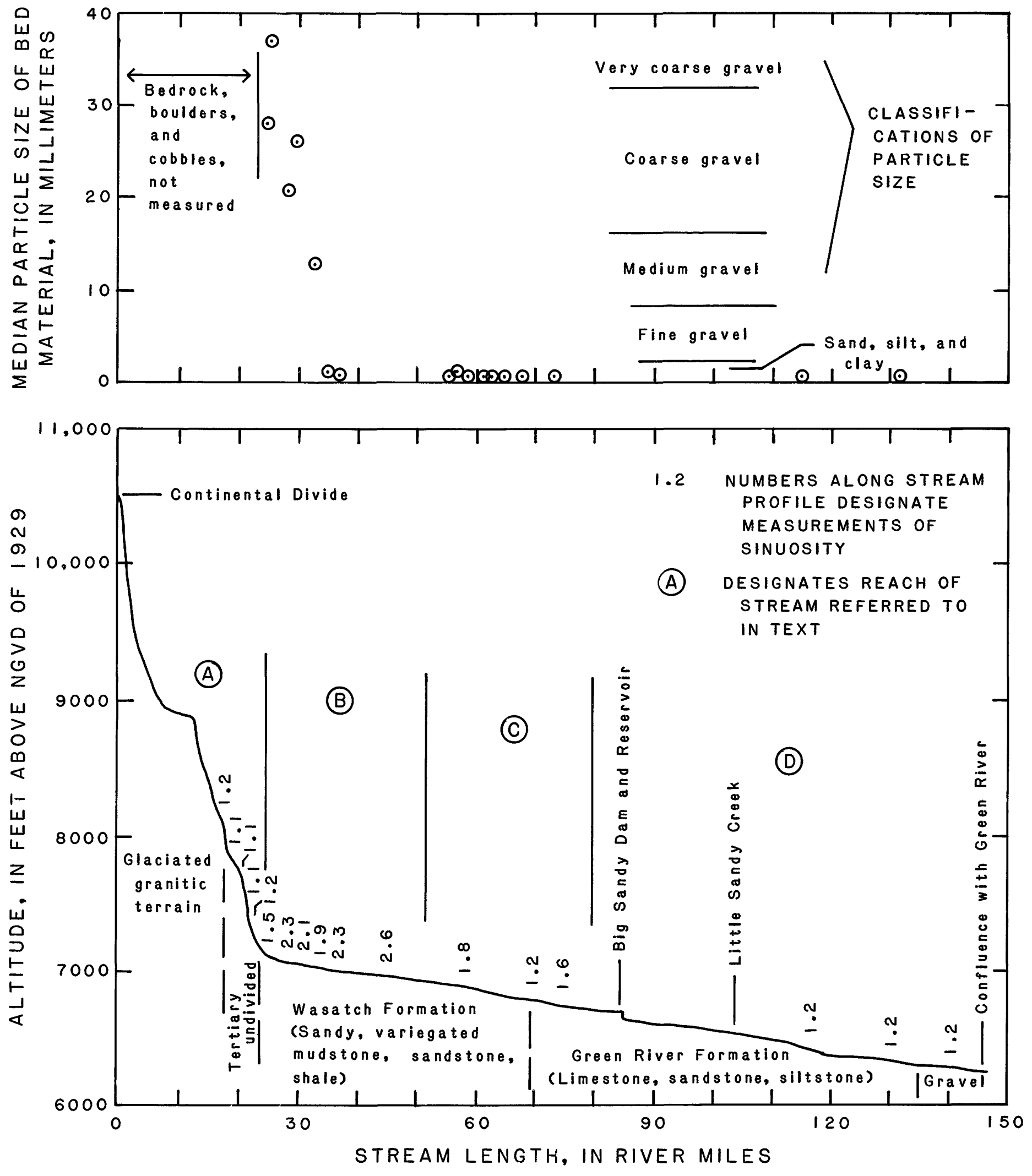

Figure 16.--Altitude of streambed and size of bed material in relation to downstream distance for the Big Sandy River. 
bed material decreases in the downstream direction as shown by the upper graph of figure 16. The bed material samples were obtained in June 1978 during high flows. Runoff during this time was occurring mainly from snowmelt in the mountainous area above about 8,000 feet altitude. Very little runoff was being contributed by tributaries originating in the lower altitudes. As a consequence, the stream was observed to be starved for sediment, as noted by the absence of within-channel bars and relatively low sediment load.

A graph of channel slope (S) versus $P$ for sites of this study is shown in figure 17. The slope data were degermined from 1:24,000-scale topographic maps for channel reaches in the vicinity of the gaged sites. The data are plotted with a symbol designating the type of bed material present in the vicinity of each streamflow station. The trend of data points shows that slope decreases with increasing discharge, and that type of bed material also is important.

The slope of a channel is important to its stability. Steep channels commonly are straight or braided and have small sinuosity (defined as stream length divided by valley length); whereas, channels with shallower slopes tend to be meandering and have a large sinuosity. Leopold and Wolman (1957, p. 59,60) developed a relation showing a distinction between braided and stable channels as:

$$
\mathrm{S}=317 \mathrm{P}_{\mathrm{b}}^{-0.44} \text {. }
$$

Streams plotting above this relation tended to be straight or braided; streams plotting below it tended to be meandering (defined as having a sinuosity of 1.5 or more). The above relation is shown in figure 17 . Leopold and Wolman (1957) used bankfull discharge whereas figure 17 uses the geometric mean of annual peak flows; however, these two indices generally are about synonymous as was explained earlier. A review of the graph supports the validity of the above relation, as most of the sites plotting above the relation have sinuosities less than 1.5 .

As shown in figure 17, the group of sites having streambeds of boulders or cobbles all have relatively steep slopes and have sinuousities less than 1.2. Although they are relatively straight, these streams generally are stable due to the immovable nature of their streambed material. Application of equation 6 in defining which stream conditions are likely to be unstable and, hence braided, is therefore limited to streams where the size of the bed material is small enough to be readily moved by channel-forming flows. Regression relations were investigated that analyzed slope as a function of discharge, sinuosity, and bedmaterial size. Fair results were obtained for the resulting relations; however, a review of the data indicated that spurious correlation, due to the large number of sites with steep slopes and small sinuosities, could be affecting the analysis. The relations were, therefore, suspect and are not presented in this report.

The sinuosity and slope of a stream are affected by a complex interaction of several variables. Regionalizing these channel characteristics by comparing a number of different sites provides only a general picture of what to expect at other sites. The pattern of a particular stream commonly may be studied more accurately by developing a relation between 


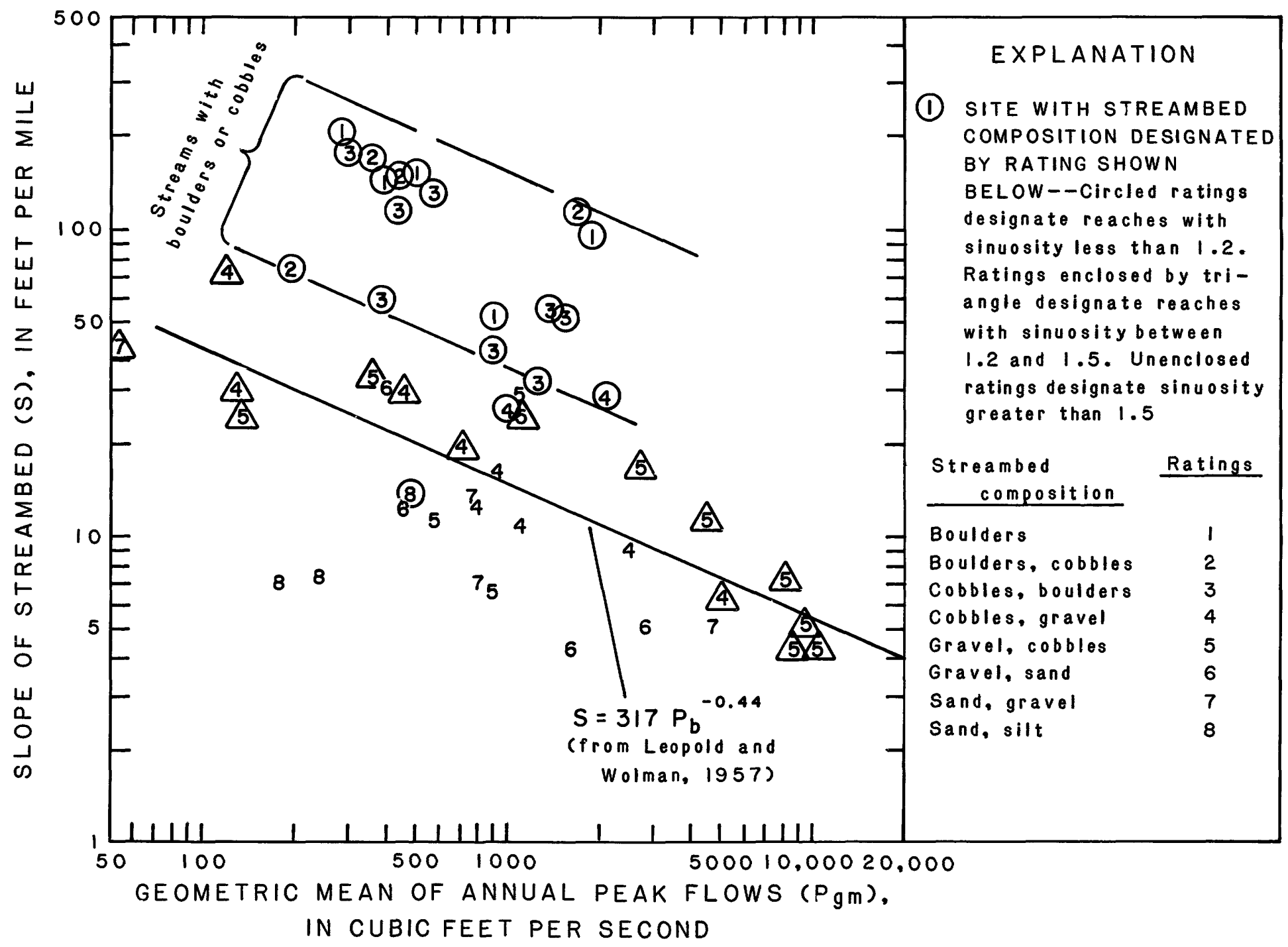

Figure 17.--Slope of streambed in relation to $\mathrm{Pgm}_{\mathrm{gm}}$, type of bed material, and sinuosity. 
sinuosity and valley slope as is shown in figure 18. The sinuosity and slope of a stream are known to be affected by valley slope (Schumm, 1977, p. 137-149). For a reach of stream having approximately the same channel-forming discharge throughout, an optimum valley slope exists for maximum sinuosity. In addition to the control imposed by surface geology, variations of valley slope can be caused by slight uplift, by depression or tilting of the valley, and by a great difference in the sediment loads carried by tributaries versus the main stream.

In the mountainous upper reach of the Big Sandy River (designated A in fig. 16), the valley slope generally is greater than 40 feet per mile, and sinuosities are 1.2 or less (fig. 18). The pattern of the stream is significantly affected by variations in bedrock. The valley slope is too steep for the stream to form or maintain a sinuous channel except in isolated meadow areas where valley slope is less.

As the stream emerges from the mountains onto the plain (reach B), the valley slope decreases and sinuosity increases. Sinuosities greater than 2.0 occur when the valley slope is between 15 to 25 feet per mile.

As the stream continues its course across the plain (reach $C$ ), the valley slope decreases to about 10 to 15 feet per mile. Sinuosity also decreases from that of reach $B$. Tributaries entering the Big Sandy River in reaches $B$ and $C$ contribute a relatively large sediment load but very little water. Coupled with the decrease in valley slope, the stream must therefore straighten to maintain a slope that will provide a velocity sufficient to transport the increased sediment load.

Discharge of the stream, including total runoff and peak flows, is decreased by storage in the Big Sandy Reservoir and by associated consumptive use of water due to irrigation. Much of the sediment load also is trapped and removed by the reservoir; however, Little Sandy Creek contributes a considerable sediment load a short distance downstream. The valley slope in reach $D$ is about 7 to 11 feet per mile, which is the least for the whole stream. A comparison of stream pattern in reach $D$ with that in reaches $B$ and $C$ is not wholly equitable due to the decrease in discharge. However, it appears that the continued downstream decrease in sinuosity is of necessity for the stream to have a slope that can transport a large sediment load through a relatively flat valley.

An analysis of stream pattern such as was done for the Big Sandy River provides a base for determining possible effects to a channel by a development. A meandering stream with large sinuosity commonly is regarded as being stable and in equilibrium with its discharge and sediment load. However, in the instance of alluvial reaches of the Big Sandy River, the channel apparently requires a relatively small sinuosity in places where the valley slope is shallow and the sediment load is large. In reach $D$, the channel probably meanders about all it can without decreasing its slope and associated velocity of flow to the critical limits where aggradation occurs. It appears unlikely that the pattern of the stream in reach $D$ could be induced into a more meandering one without causing aggradation, unless there were associated changes in discharge or sediment load. If a development resulted in a further decrease in discharge without an associated decrease in sediment load, aggradation and straightening of the existing channel appear likely to occur. A decrease 


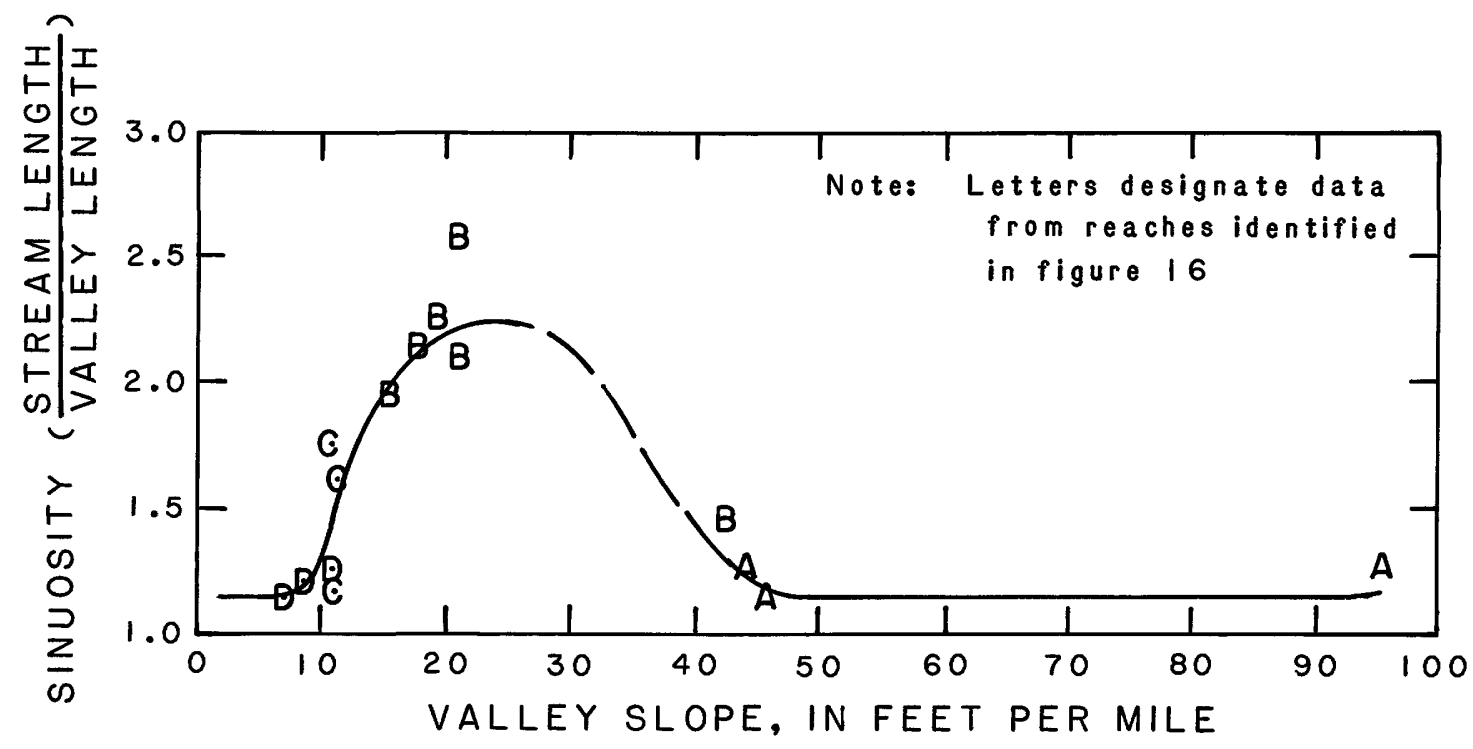

Figure 18.--Sinuosity versus valley slope, Big Sandy River. 
in sediment load with no change in discharge might cause the formation of a more sinuous channel; however, some erosion of the streambed and banks also would occur.

\section{Channel Geometry For Estimating Streamflow}

A common requirement in the planning of water-related projects is the need for streamflow information. If a streamflow station has not been operated near the site where information is needed, estimates of streamflow quantities generally are made. Because channel size is an indication of flow magnitude, methods using measurements of channel geometry can be developed that provide estimates of streamflow. Such methods are useful because of their simplicity. Channel width is the most common channel characteristic to be used because it is easy to obtain and it correlates well with flow characteristics. Relations of the form:

$$
Q=a W_{*}^{b}
$$

are developed by using streamflow information and width measurements for gaged sites; the relations may then be applied to ungaged sites. Application of the relations requires a measurement of channel width $\left(W_{*}\right)$ at the site where streamflow estimates (Q) are needed.

The author (Lowham, 1976) has developed relations of the above form for estimating average discharge and peak flows of Wyoming streams. The channel measurement used in those relations differs from width of flow used earlier in this report for hydraulic characteristics. The width (W) of flow for discharge that was depicted by the hydraulic relations is the mean width of flow in a stream reach. The channel-geometry relations developed for estimating streamflow use a width measurement $\left(W_{f}\right)$ made of the main channel at a site where the channel is stable and narrowest. Stable, narrow reaches usually occur just downstream from curves or rapids where energy has been dissipated and the stream has minimum erosive potential. The complete set of estimating relations are not presented in this report, and the reader is referred to Lowham (1976).

A useful tool for purposes of predicting channel response to streamflow alteration would be a relation that could be used to estimate formative discharge at ungaged sites. Using data from Lowham (1976), a relation was developed to estimate $P_{\text {m }}$, which is considered to be a meaningful index of formative discharge. ${ }^{\mathrm{gm}}$ The relation is:

$$
\mathrm{P}_{\mathrm{gm}}=2.32 \mathrm{~W}_{\star}{ }^{1.55}
$$

and it is based on data for 155 gaged sites throughout Wyoming, including 34 sites in the Green River basin. The correlation coefficient is 0.96 and the average standard error of estimate is 47 percent. The above relation is applicable to all types of streams, including perennial, intermittent, and ephemeral types of either the mountains or plains, provided the channel is stable and has been formed by the hydraulic forces of floodflows. The width measurement $\left(W_{f}\right)$ is made of the main 
channel between the breaks in slope where the banks end and the flood plains begin. The narrowest section of a stable reach is selected for measurement, and measurements of several such sections are made to obtain an average for the reach. An example of the use of the relation is presented in the following section of this report.

\section{Application of Relations}

A stream naturally strives toward a state of equilibrium as depicted in part by the foregoing hydraulic relations. When either a natural or man-caused alteration of streamflow or sediment character takes place, a corresponding response is likely to occur to the channel, although the changes may be subtle and take several years or more to complete.

Relations presented in this report can be used for predicting resulting hydraulic characteristics and possible channel response to either a natural or man-caused alteration of streamflow. Example applications follow that illustrate several possible uses of the relations.

Alteration of streamflow.--Assume that a proposal is made for transbasin diversion of flow, with the water to be diverted from one stream, transported by a canal across the basin divide, and spilled into a second stream for use some distance downstream. From the discussion of formative discharge and the regional hydraulic relations, it is evident that there may be an associated increase in channel size of the receiving stream if the diversion adds significant amounts of water during periods of floodflow. If the receiving stream is ungaged, equation 8 can be used to determine its formative discharge. Assume that width measurements $\left(W_{*}\right)$ averaged 20 feet. Then, using equation $8, P_{\text {m }}=2.32(20)^{1.55}=240$ cubic feet per second. Assume the diversion is p panned to be throughout the spring and summer months at a rate of 100 cubic feet per second. The new value of $P_{\text {om }}$ for the receiving stream will be about 340 cubic feet per second. Arfassociated change in channel size will likely occur for this increase in discharge, and the new hydraulic characteristics can be predicted from the relations for $P_{\text {m }}$ in table 3 and figure 13. A summary of the values before and after diversion follows:

\begin{tabular}{lccc}
\hline $\begin{array}{c}\mathrm{P}_{\mathrm{gm}} \\
\begin{array}{c}\text { cubic feet } \\
\text { per second) }\end{array}\end{array}$ & $\begin{array}{c}\mathrm{W}=1.17 \mathrm{P}_{\mathrm{gm}}{ }^{0.61} \\
\text { (feet) }\end{array}$ & $\begin{array}{c}\mathrm{D}=0.35 \mathrm{P}_{\mathrm{gm}}^{0.30} \\
\text { (feet) }\end{array}$ & $\begin{array}{c}\mathrm{V}=2.45 \mathrm{P}_{\text {gm }}{ }^{0.09} \\
\text { (feet per second) }\end{array}$ \\
\hline $\begin{array}{l}\text { (before) } 240 \\
\text { (after) } 340\end{array}$ & 33 & 1.8 & 4.0 \\
\end{tabular}

Note that the mean channel width (W) of 33 feet is larger than the measurement $\left(W_{*}\right)$ of 20 feet of the narrowest sections.

The increased flow will have potential for moving greater quantities of larger streambed material; thus, the channel might be susceptible to downcutting. Scour and bedload-transport equations are not presented in this report, but are available for such determinations. For example, Emmett (1972, p. 22-27) applied hydraulic relations to compute depth of 
channel scour and bedload discharge for streams in Alaska. In addition, equation 6 and figure 17 can be consulted to estimate the stability related to slope. Clearly, the assumed example is an exaggerated case. Mitigating measures such as decreasing the diverted flows during periods of expected large runoff could decrease the channel changes that were predicted.

Weather modification.--As a second example of streamflow alteration, consider the possibility of a man-induced climatic change. Cloud seeding is sometimes considered for areas short of water. From a review of figure 14 it is apparent that if a snowpack is artificially increased to produce greater annual runoff, peak flows also will increase. Again, mitigating measures such as retention or detention dams could be implemented to control peak flows and minimize channel degradation.

Fishery habitat.--A number of streams in the Green River basin provide excellent fisheries and other recreational opportunities. One of the most popular streams is the lower Green River. (See fig. 1 for location.) This 73-mile reach between Fontenelle and Flaming Gorge Reservoirs is classified as a Blue Ribbon (the highest rating) trout habitat by the Wyoming Game and Fish Department. Studies by the Game and Fish Department have resulted in their recommendation for minimum flows of 800 cubic feet per second during the spring and summer months when fish are growing most rapidly, and 500 cubic feet per second during the fall and winter months (Wiley, 1977, p. 29). In addition, a minimum of 300 cubic feet per second was proposed as a short-time survival flow. Although existing water withdrawals and operation of Fontenelle Reservoir provide sufficient releases to provide minimum recommended flows, future water demands and diversions may change this. The lower Green River is only an example reach; the problem of providing minimum streamflows exists or will exist on a number of other streams.

The amount of water necessary for fish habitat includes not just that necessary to provide cover for the fish. It also includes the flow necessary to cover a suitable area of the substrate, which provides food (primarily benthic organisms) for the fish. If the substrate is dry for even a short time, many aquatic organisms die; thus, the effect of a dry period on the food supply of the fish is felt for some time.

Every stream has individual characteristics based on its natural flow regimen and channel configuration. Minimum streamflow requirements for fish habitat thus vary from stream to stream depending on their size and shape (Wesche, 1978). While a relatively small flow may provide an excellent habitat in a very small stream, it would be inadequate in a large stream such as the Green River. Thus, an analysis of flow requirements for aquatic life requires that the size and shape of the stream channel be considered along with its flow characteristics.

Streamflows for fish habitat in the Green River and other perennial streams will be a frequent issue as surplus waters of the area are considered for diversion and consumption. Rather than relying strictly on first-hand observations and opinion, effects of streamflow alteration on aquatic habitat can be simulated and documented through the use of mathematical models. For example, several techniques for hydraulic simulation are presented by Bovee and Milhous (1978). The hydraulic relations of 
this report can be used as an aid to the development of such models. As an example, at-a-station relations for streamflow stations 09211200 and 09216500 are used to represent hydraulic characteristics of the lower Green River. An average of these relations shows characteristics vary with selected flow rates as shown below:

\begin{tabular}{|c|c|c|c|}
\hline $\begin{array}{c}\text { Discharge } \\
Q \\
\text { (cubic feet per second) }\end{array}$ & $\begin{array}{l}\text { Mean } \\
\text { width } \\
W \\
\text { (feet) }\end{array}$ & $\begin{array}{l}\text { Mean } \\
\text { depth } \\
\text { D } \\
\text { (feet) }\end{array}$ & $\begin{array}{c}\text { Mean } \\
\text { velocity } \\
V \\
\text { (feet per second) }\end{array}$ \\
\hline $\begin{array}{r}5,000 \\
1,500 \\
800 \\
500 \\
300\end{array}$ & $\begin{array}{l}260 \\
210 \\
185 \\
170 \\
160\end{array}$ & $\begin{array}{l}5.0 \\
3.0 \\
2.5 \\
2.0 \\
1.6\end{array}$ & $\begin{array}{l}3.9 \\
2.4 \\
1.7 \\
1.5 \\
1.2\end{array}$ \\
\hline
\end{tabular}

An inspection of the values in the above table shows that factors affecting fish habitat, especially depth, rapidly decrease at flows less than 800 cubic feet per second. The long-term average flow $\left(Q_{a}\right)$ of the river at station 09217000 is 1,717 cubic feet per second. Fontenelle Reservoir began storage of water during August 1963. From 1952-63 the smallest daily flow recorded at station 09217000 was 170 cubic feet per second on November 16, 1955. Since the reservoir began operation, the smallest daily flow recorded was 245 cubic feet per second on January 13, 1968 . Low flows have been augmented by the reservoir.

\section{Case Histories}

The discussion of channel formation and regional relations of this report provide a general characterization of flows in natural channels. The examples showed several applications whereby the hydraulic relations could be used to aid planning and design of proposed developments. The example situations were fairly simple with channel response or hydraulic characteristics being affected by significant alterations of streamflow. However, channel response is a complex feature, and when a more complicated situation than just a change in streamflow occurs, accurate mathematical formulation may be difficult to apply. For example, downstream effects of land-use changes or channelization present more complicated situations that, with the present state of knowledge, are difficult to predict quantitatively. When a situation warrants a thorough study, physical models sometimes are constructed and tested to simulate watershed or channel response. Such models generally are quite expensive and time consuming, especially when long-term response is investigated. Guides for predicting channel change are, therefore, commonly derived from case histories of similar situations.

To illustrate the experience that can be gained from case histories, two examples of stream-related developments in the Green River basin are discussed. Locations of the sites are shown in figure 1. 
Pole Creek.--Just east of Pinedale, Pole Creek flows out of the Wind River Mountains, across some relatively flat glacial terraces, and into the New Fork River (fig. 19). The downstream reach of Pole Creek has a well-developed flood plain that is used for irrigated hay meadows. As reported by Kuntz (1977), a problem began in 1968 when unused irrigation water diverted from nearby Pine Creek was spilled into Pole Creek through Airport Arroyo. The terrace through which Airport Arroyo has cut is composed of fine gravel. The gravel washed into Pole Creek and clogged its channel. Overbank flows and gravel deposits then threatened to destroy some downstream hay meadows of the Fayette Ranch. To save the hay meadows, the ranch employees cut a new channel through several oxbows just downstream from where Airport Arroyo enters Pole Creek.

What was intended to be an improvement of the stream turned into a disaster. The channelization increased the velocity of the flow so much that three additional oxbows were cut and serious bank erosion occurred downstream. In addition, a headcut began at the U.S. Highway 187 bridge and eroded upstream nearly a mile until it was stopped by a diversion structure. Besides the economic loss of a 56-acre hay meadow that has been ruined by gravel deposits, the ranch owner spent more than $\$ 20,000$ trying to restore the stream channel (Kuntz, 1977, p. 10).

But the ranch personnel learned by their experience and rather than continue attempts to repair the stream through channelization, they alleviated the original cause of the problem. According to Fayette Ranch foreman Murland Morss (oral commun., 1979), the ranch obtained a water right for the surplus irrigation water in Airport Arroyo, and now uses it to irrigate pasture lands to the north of the highway in section 30 . (See fig. 19.) This eliminated the gravels that were washing into the channel, and during the past 3 years the stream appears to be stabilizing.

Bitter Creek.--Deep gullies are a striking feature of Bitter Creek, an intermittent stream that drains arid plains east of Rock Springs (fig. 20). Climatic change and natural erosion have caused some gullying, but it is evident that much gullying also has resulted from land-use practices of the past, including:

1. Channelization of Bitter Creek to accommodate construction of a highway and railroad. The channelization involved straightening and shortening the stream. This increased the slope of the streambed, resulting in higher stream velocities and subsequent erosion of the channel. A channelized reach where the gully has incised 26 feet (vertical distance, terrace to flood plain) is shown in figure 21 .

2. Dewatering of underground coal mines with the water released into tributaries of Bitter Creek. The site of an old dewatering well for a coal mine (now abandoned) at Superior is shown in figure 22. Large-scale underground mining took place in this area during the early $1900^{\prime} \mathrm{s}$, and wells were used to rid the mines of water. Flows from the wells were spilled into Horsethief Canyon, an ephemeral tributary of Bitter Creek. The introduction of perennial flow to a formerly ephemeral stream will induce channel erosion when, as 


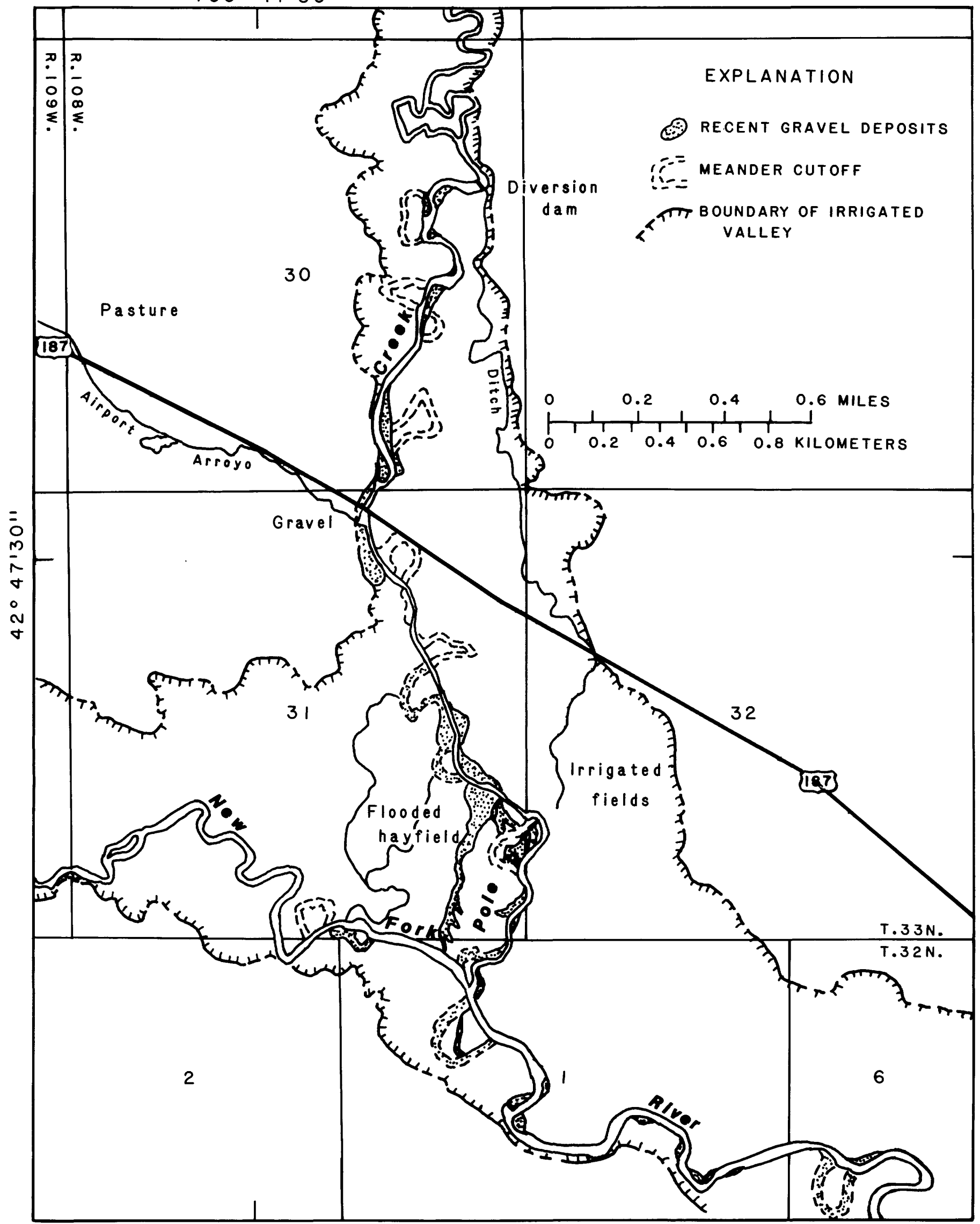

Base from U.S. Geological Survey aerial photograph, July 1074.

Figure 19 .--Downstream reach of Pole Creek. 


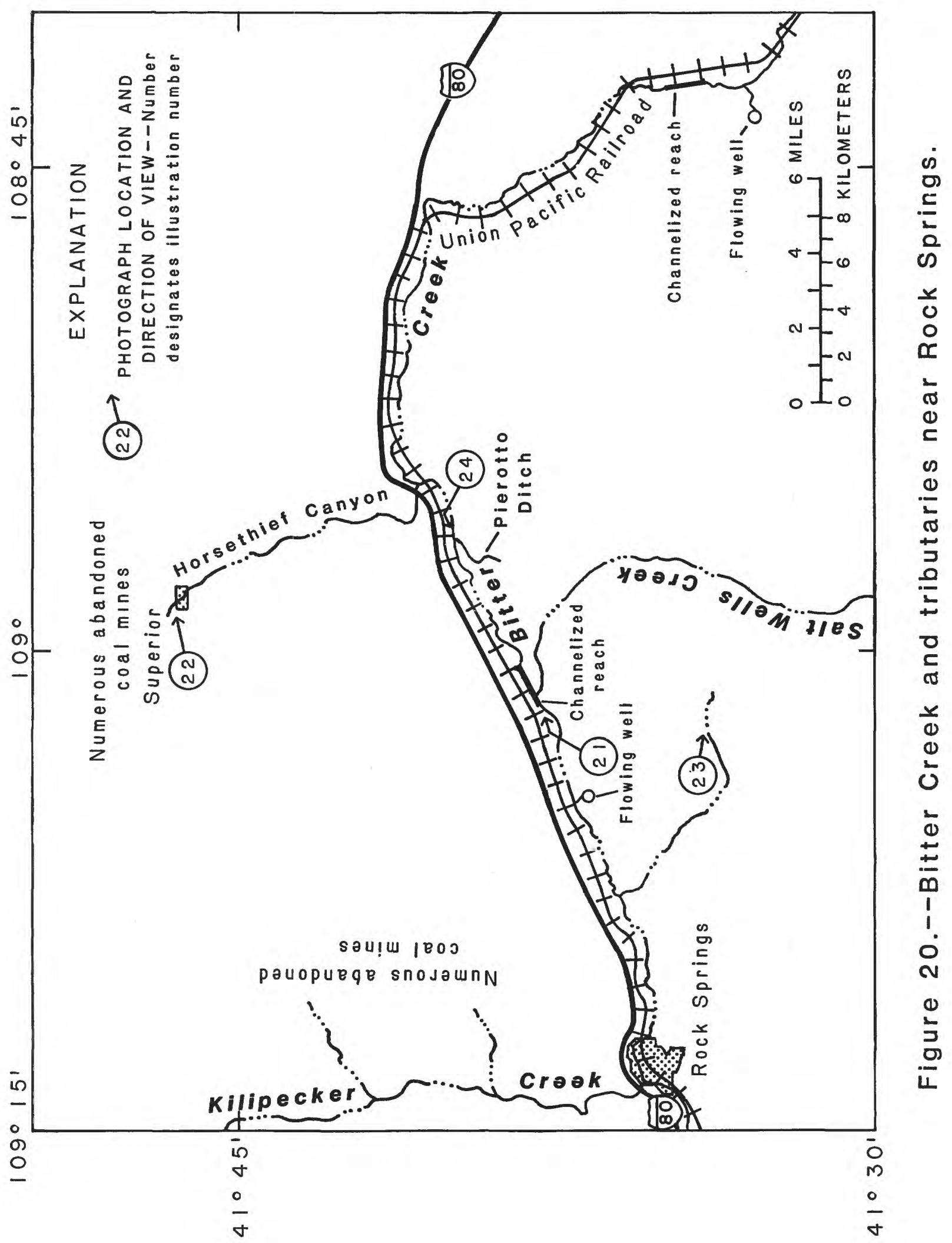




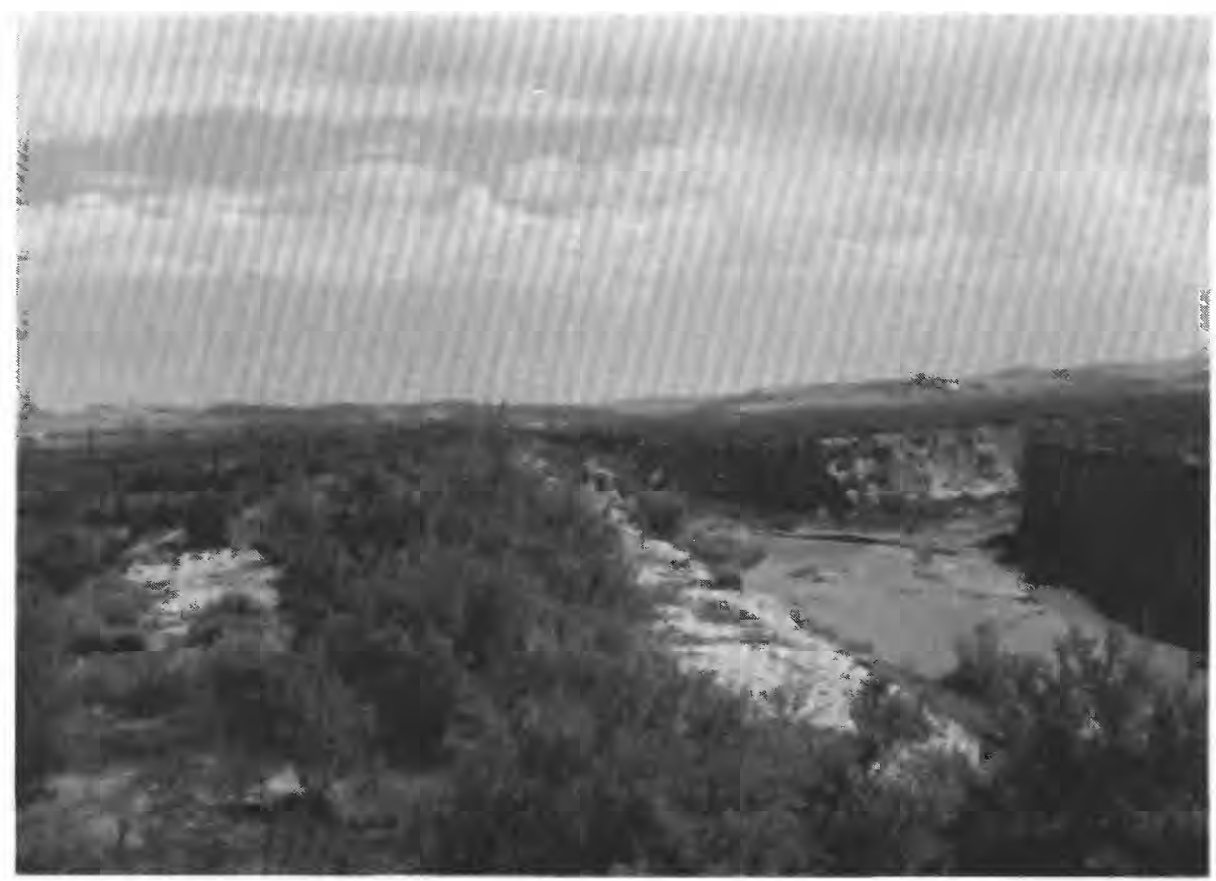

Figure 21.--Gully of Bitter Creek. View is upstream at channelized reach about 10 miles east of Rock Springs. The mouth of Salt Wells Creek, a major tributary, is at the right of the photograph. The railroad is at the left. 


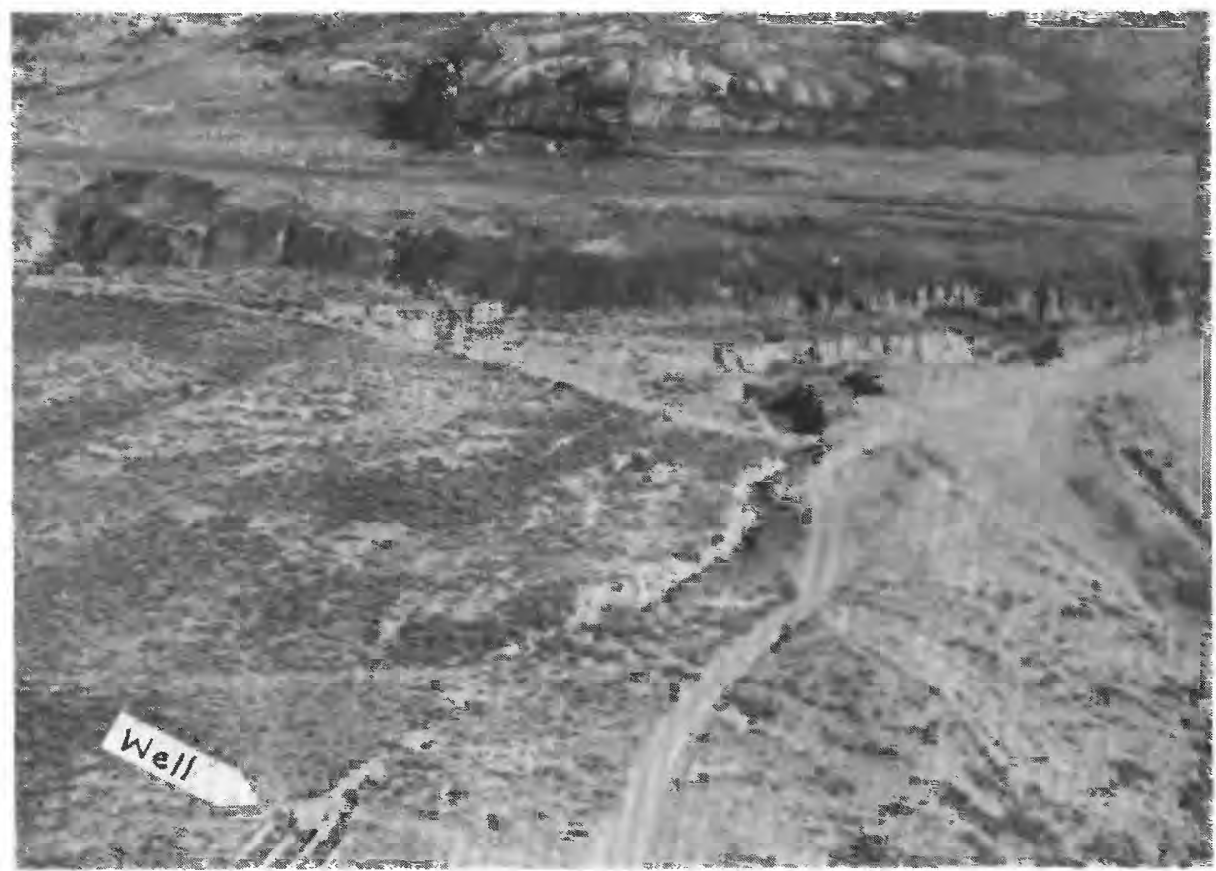

Figure 22.--Dewatering well for coal mine (now abandoned) at Superior. Water from several such wells was released into Horsethief Canyon and Killpecker Creek, tributaries of Bitter Creek. 
is the case here, the streambed is composed largely of sand and smaller-sized material. Because the flow is added without a washload, there is no replacement of eroded bed material and the channel downcuts. Horsethief Canyon has incised as much as 25 feet in the reach downstream from Superior, and it is evident that much of the erosion has resulted from the dewatering. Similar erosion has resulted in Killpecker Creek as a result of such flows.

3. Oil and gas exploration wells left unplugged and allowed to flow water unregulated under artesian conditions into Bitter Creek. This produces the same erosive conditions as dewatering of the coal mines. However, the unplugged oil and gas wells are spread about a large area and are not concentrated on just one or two tributaries as was the dewatering of coal mines.

4. Overgrazing by livestock and wildlife during late $1800^{\prime}$ s and early $1900^{\prime} \mathrm{s}$. Extensive grazing by cattle and sheep began in the area about 1890 . Depletion of vegetative cover by overgrazing results in less retardation of overland flows, causing higher peak flows that have increased potential for channel erosion. Overgrazing may have initiated some gullying, especially if it was coupled with several large floods.

Gullies are undesirable because they accelerate erosion of the watershed, contribute to degradation of downstream water quality, and cause lowered ground-water levels in the valleys. When a channel such as Bitter Creek downcuts, tributaries entering the lowered reach must adjust levels of their streambeds accordingly. This results in headcutting as is shown in figure 23. Headcutting and erosion of an effected tributary spread upstream until the entire watershed has reached equilibrium with the new base level. On Bitter Creek, the accelerated erosion is causing increased sediment and salt loads to be washed from the basin into the Green River and Flaming Gorge Reservoir.

The drainage of Bitter Creek is having continued erosion and gully development even though man-induced causes of the problem have ended. Existing regulations restrict spillage of water into streams by mining and oil and gas developments. Also, the U.S. Bureau of Land Management and private land owners in the basin watch livestock operations closely to avoid the possibility of overgrazing; however, even with these improved management practices, additional erosion and headcutting are likely to occur as the drainage adjusts to the lowered streambeds of existing gullys. The problem is intensified by the fact that large-scale energy development (currently two coal strip mines and a steam powerplant, with more development planned) is occurring in the basin. Rehabilitation of tributaries affected by the gullying is a possible alternative. The rehabilitation of watersheds has been successful in similar basins. For example, Heede (1977) described a case study on Alkali Creek in Colorado where check dams were used to convert gullies to vegetationlined waterways. By stabilizing the gullies, erosion rates were decreased to one-fifth of those for gullies not treated. 


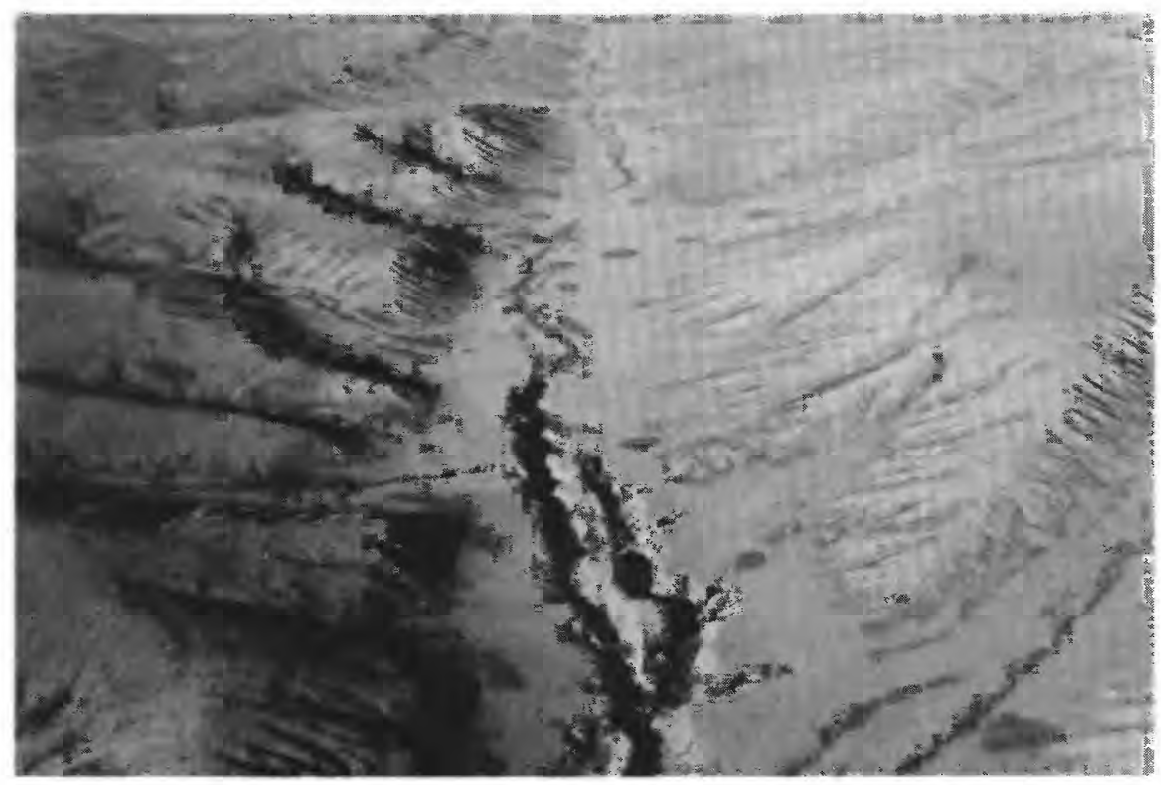

Figure 23.--Progressive headcutting of small tributary of Bitter Creek. Gully at bottom of photograph is about 12-feet deep. 
Gullying and erosion of Bitter Creek would be much worse if it were not for the diversion structure for Pierotto Ditch that is located at an erosion-resistant shale outcrop on the stream about 13 miles east of Rock Springs (fig. 24). The diversion is located several miles upstream from the channelized reach shown in figure 21. As shown in figure 24, the structure and rock outcrop have prevented the gully of Bitter Creek from extending upstream.

The right bank of the channel just upstream from the diversion structure appears to be in danger of washing out and allowing the stream to be captured by the gulley during an overbank flood. If this occurs, a headcut will erode back up the stream. This could further damage the watershed, as well as pose a threat to the railroad embankment and several bridge structures.

\section{Dye Studies}

Regression statistics in table 3 indicate that regional velocity relations are relatively inaccurate. The use of dye tracers provides a more accurate means than current-meter measurements for determining velocity in a stream reach. Fluorescent dyes and tracing techniques were used to determine velocities for various reaches of six streams in the study area. The streams measured included the Green, East Fork, Big Sandy, and Little Snake Rivers, Horse Creek, and Blacks Fork. Location of the reaches where stream velocity was measured by dye tracing are shown in figures 25 and 26.

The dye studies were made by injecting a small amount of dye into the stream and tracing the shape and speed of the resultant dye cloud as it moved downstream. Dye acts as a solute when injected into water; that is, it mixes completely with the water and moves in the same manner as the water molecules themselves.

The velocity of flow through a reach is determined by measuring the time for movement of the dye cloud from the injection site to one or more downstream sampling sites. Soon after it is injected, the dye disperses and becomes invisible. But the dye is fluorescent and samples of water collected at each site were tested for presence of dye using a fluorometer. A fluorometer is an instrument that accurately measures fluorescence so that very small concentrations of dye can be detected. The amount of fluorescence measured is directly proportional to the concentration of dye in each sample.

Plots of concentration versus time define the passage of the dye cloud at each sampling site. As the dye cloud moves downstream, it takes longer to pass each successive site and the peak concentration decreases. As an example, a graph and sketch depicting the downstream movement and dispersion of a dye cloud in the Little Snake River are shown in figure 27. As shown in the sketch, dye particles in the center of the stream travel faster than those near the banks. Concentrations of the dye cloud shown in figure 27 were determined from samples collected near the center of the stream. 


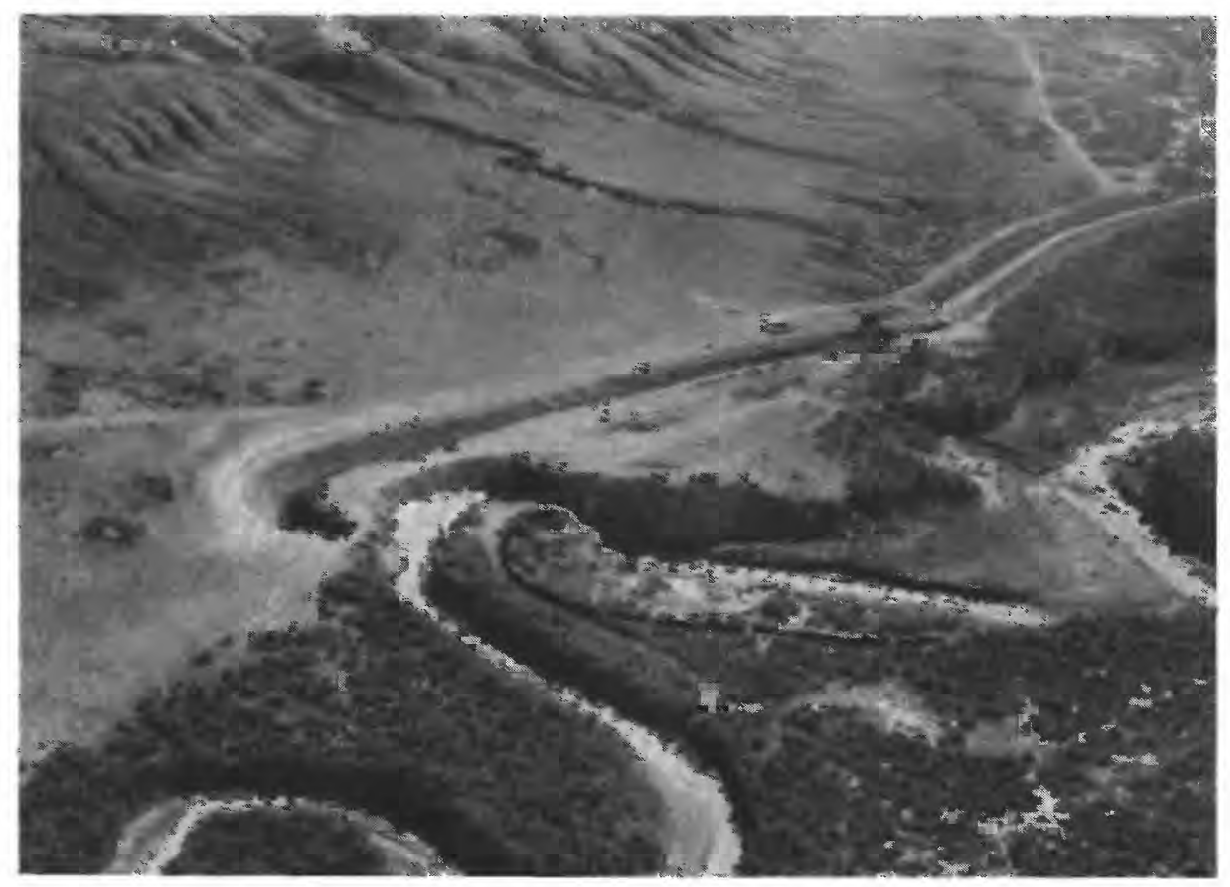

Figure 24.--Diversion structure for Pierotto Ditch on Bitter Creek, about 3 river miles downstream from Horsethief Canyon. View is downstream. During high flows, the right bank overtops upstream from the structure and allows flow to cascade into the gully. The eroding gully wall is within about 20 feet of capturing the stream (in the area of the dotted lines). 


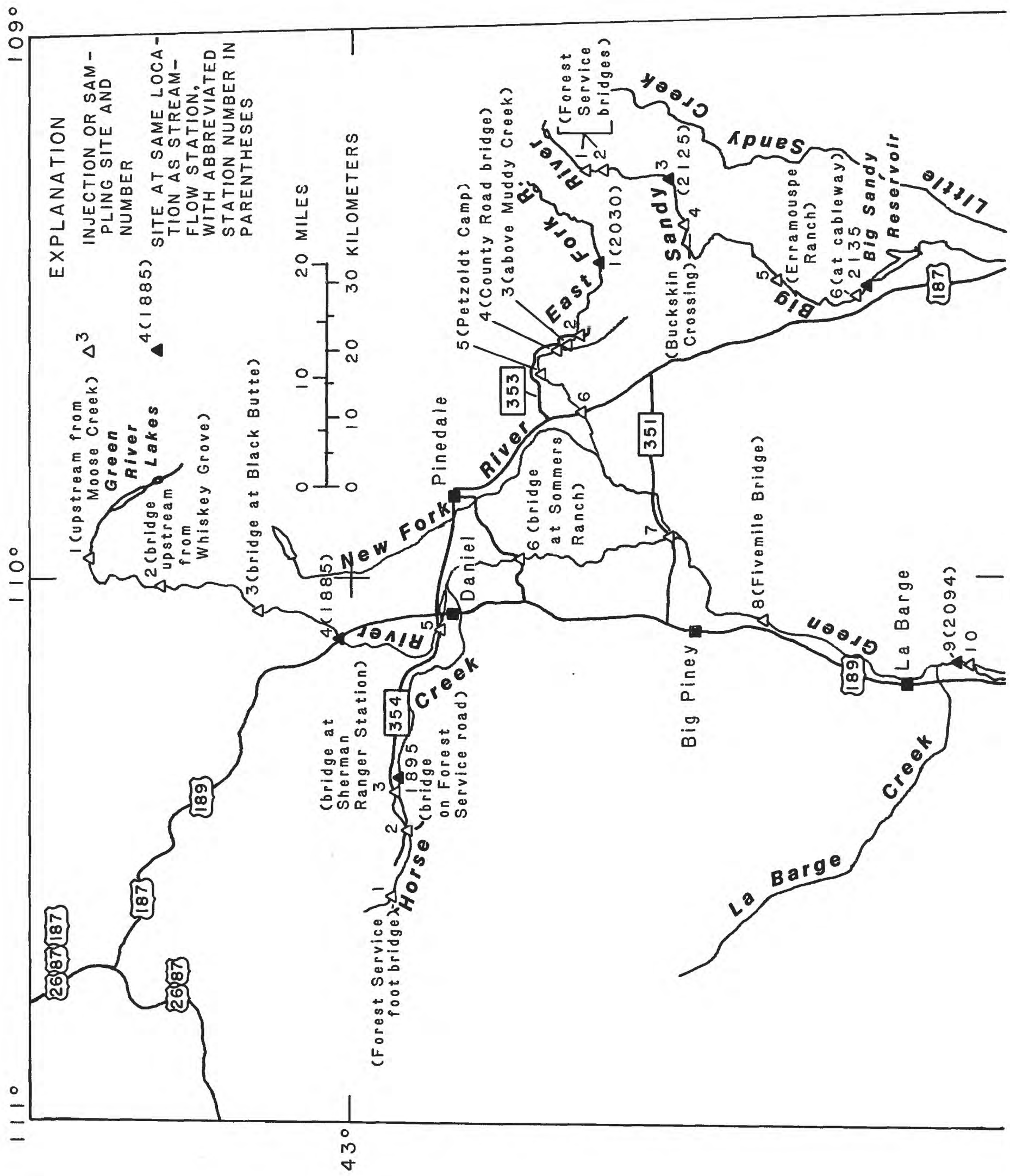




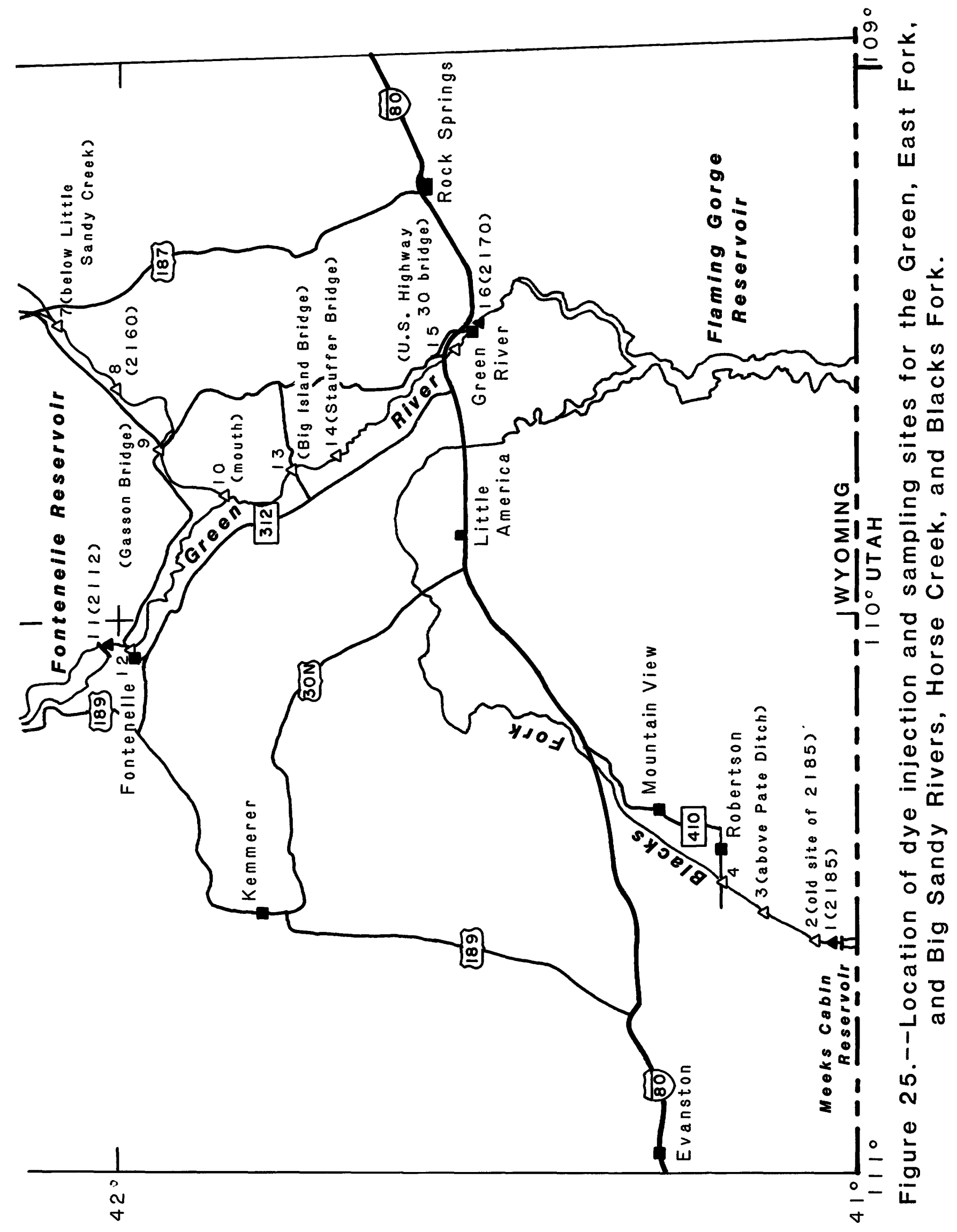




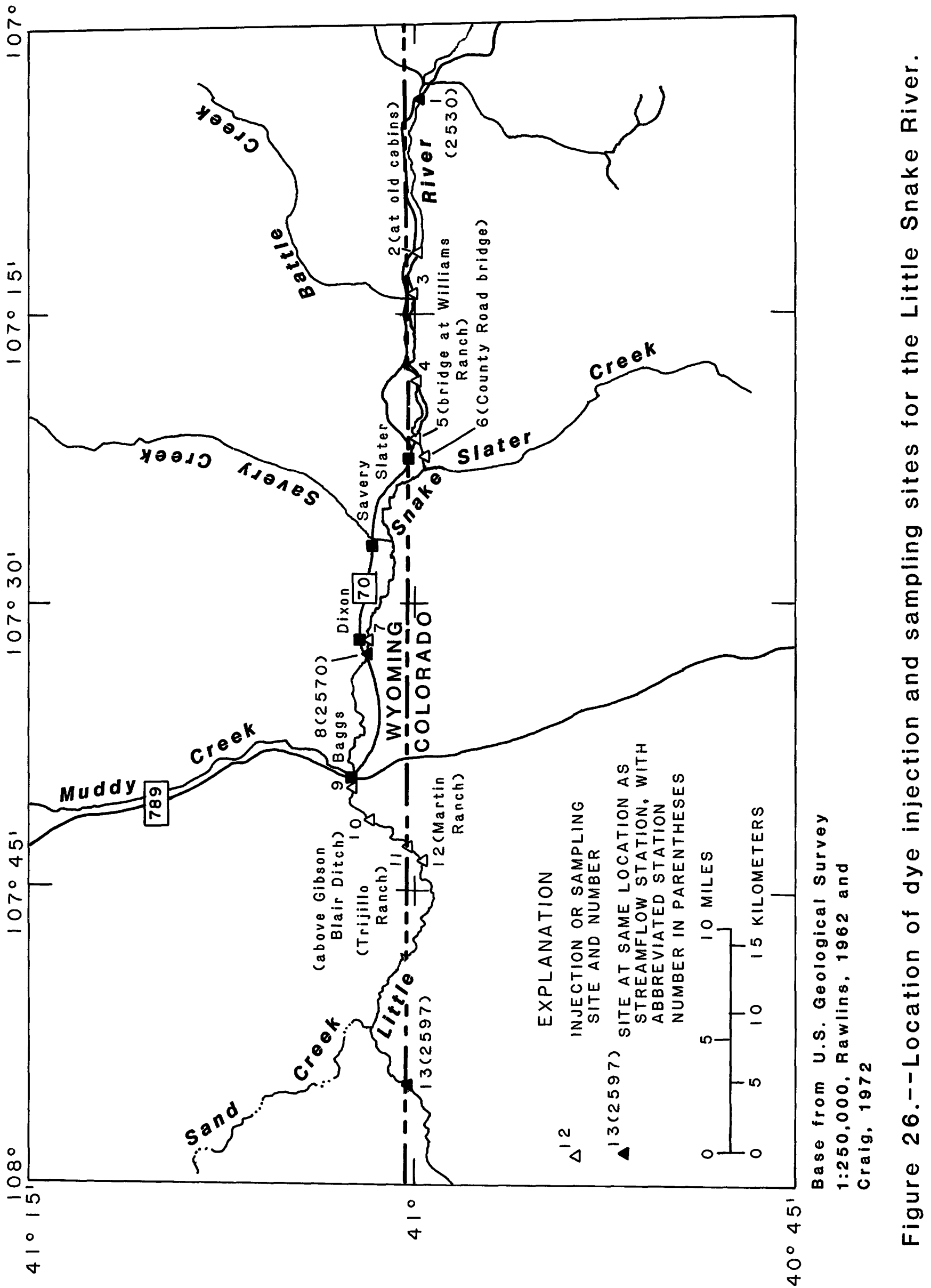




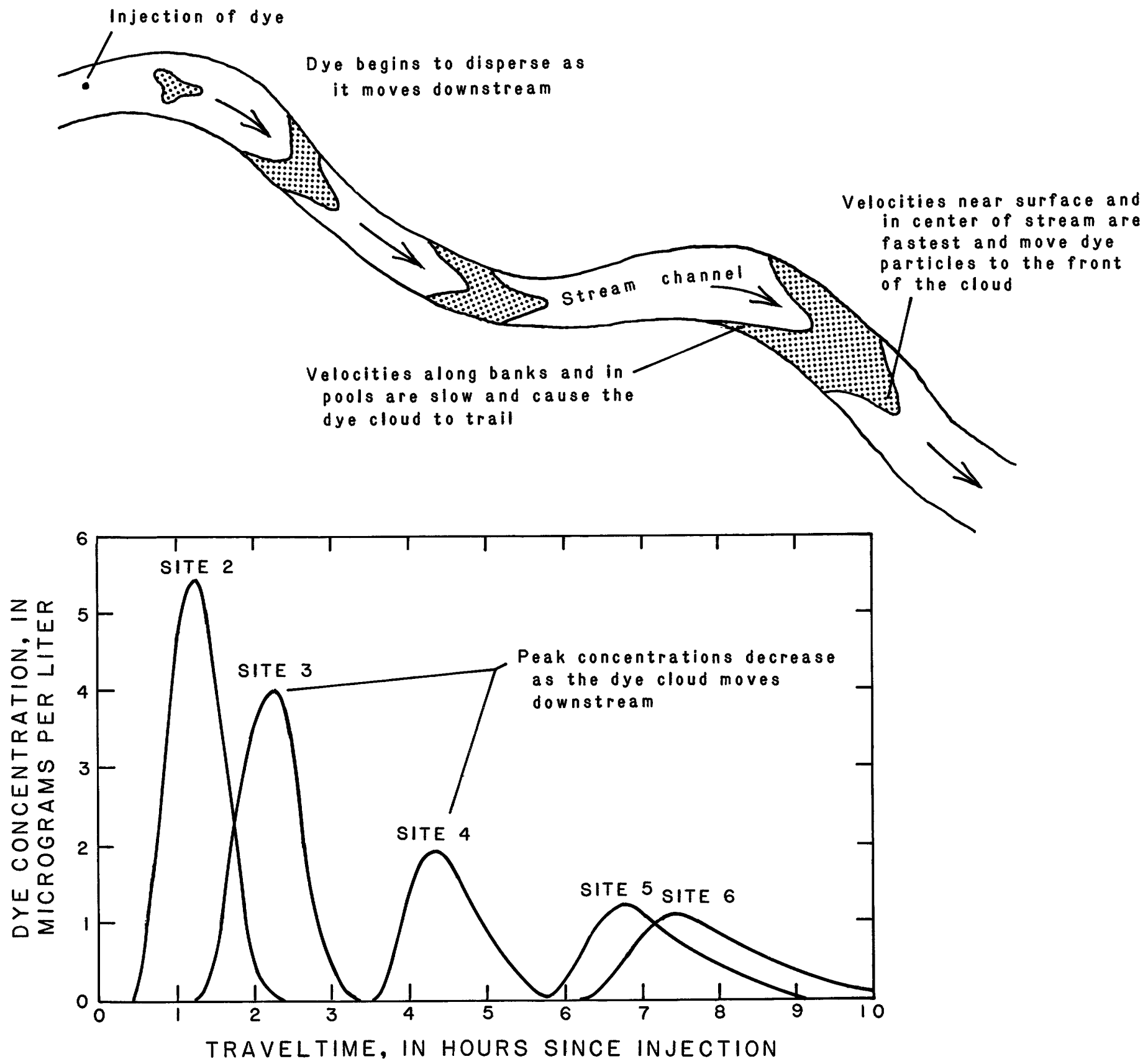

Figure 27.--Downstream movement and dispersion of dye cloud, Little Snake River, May 18, 1977. 
Graphs similar to figure 27 were constructed for results of each of the dye studies. The graphs were then used to determine traveltimes of the leading edge, peak concentration, centroid, and trailing edge of the dye clouds. Data for the dye studies are summarized in table 4 . The concentration distribution of a dye cloud is not symmetrical, and the velocity of the centroid rather than the peak was used to depict mean velocity between sites.

Velocity varies with magnitude of discharge; therefore, several measurements at different discharges were made to define velocity through a useful range of flows. As an example, mean velocity between sites for various discharges of the Green River is shown in figure 28 .

\section{Velocity Relations}

Data obtained from the dye studies were used to develop relations that show mean velocity versus discharge for the six streams measured (figs. 29-34). The relations show that for a given discharge differences in mean velocities occur for different reaches of the streams. For example, velocity of the Green River is faster between sites 4 to 8 than in other reaches of the stream. This is the result of differences in channel properties among the reaches.

At-a-station relations developed from current-meter measurements at streamflow-gaging stations also are shown in figures 29-34 to allow comparison of velocity determination by the two methods. Most of the at-a-station relations compare fairly close to relations determined by the dye studies for the adjacent reaches. Relations for site 3 (streamflow-gaging station 09212500) on the Big Sandy River, site 3 (streamflow-gaging station 09189500) on Horse Creek, and site 13 (streamflow-gaging station 09259700) on the Little Snake River are markedly different from those of the dye studies for the adjacent reaches. The differences are attributed to the gaged reaches not being representative of the longer adjacent reaches measured by the dye studies.

Some inaccuracies in the velocity relations developed from the dye studies might be present due to errors inherent to measuring distance between stream sites. Topographic maps with a scale of 1:24,000 were used for measuring stream distance. The measurements are considered to be fairly accurate when the stream is flowing about bankfull; however, as was shown by figure 10 , the average flowline of a stream changes with discharge. The path of travel is therefore longer at a low discharge than at a high discharge. This could cause the computed velocity relations based on the dye studies to have steeper slopes than actually occur; that is, for low discharges velocities of the streams might be slightly faster than depicted in figures 29-34. A more accurate determination of stream length at low discharge would require either an onsite survey or aerial photographs taken of the stream during such conditions. 


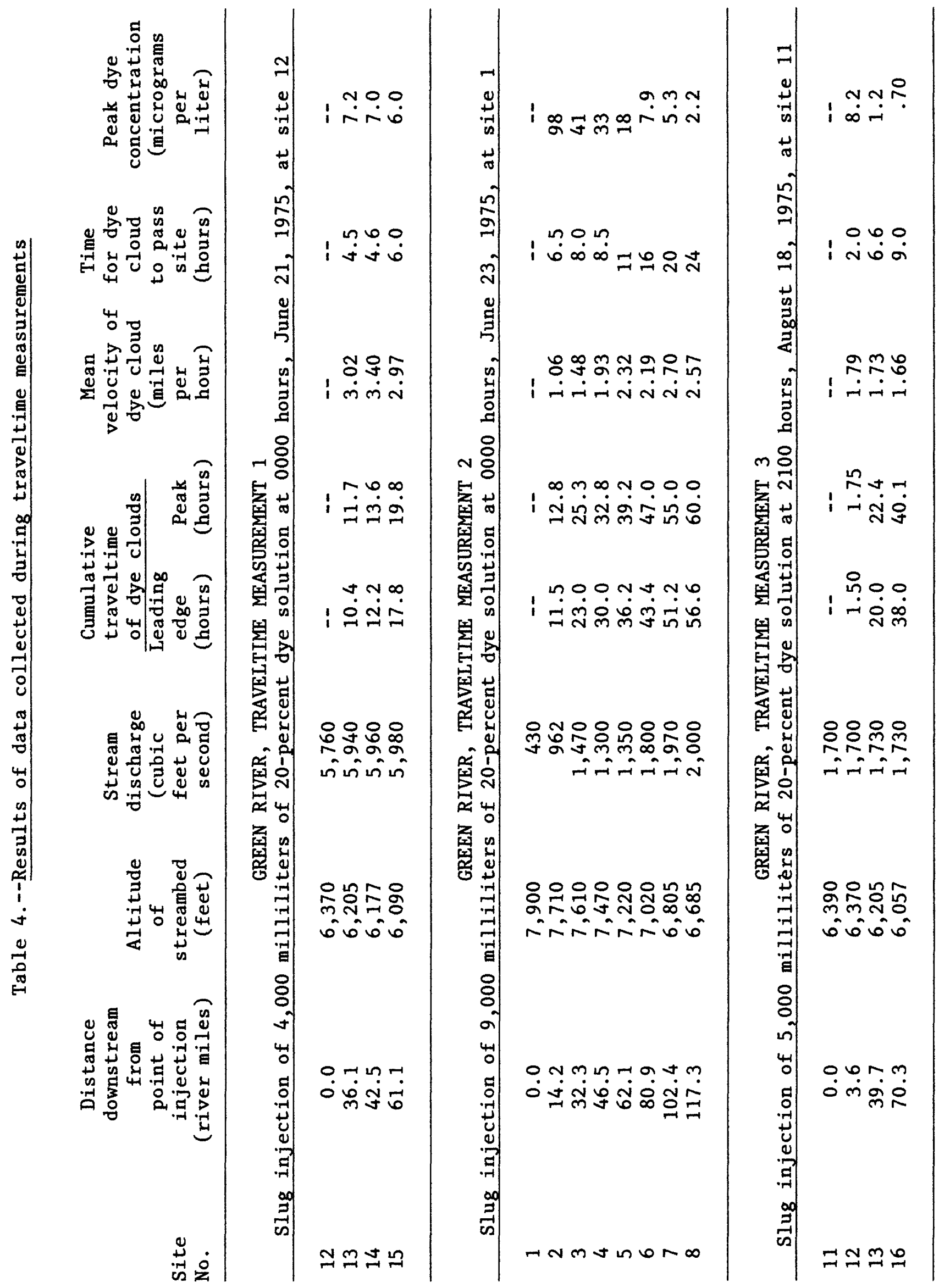




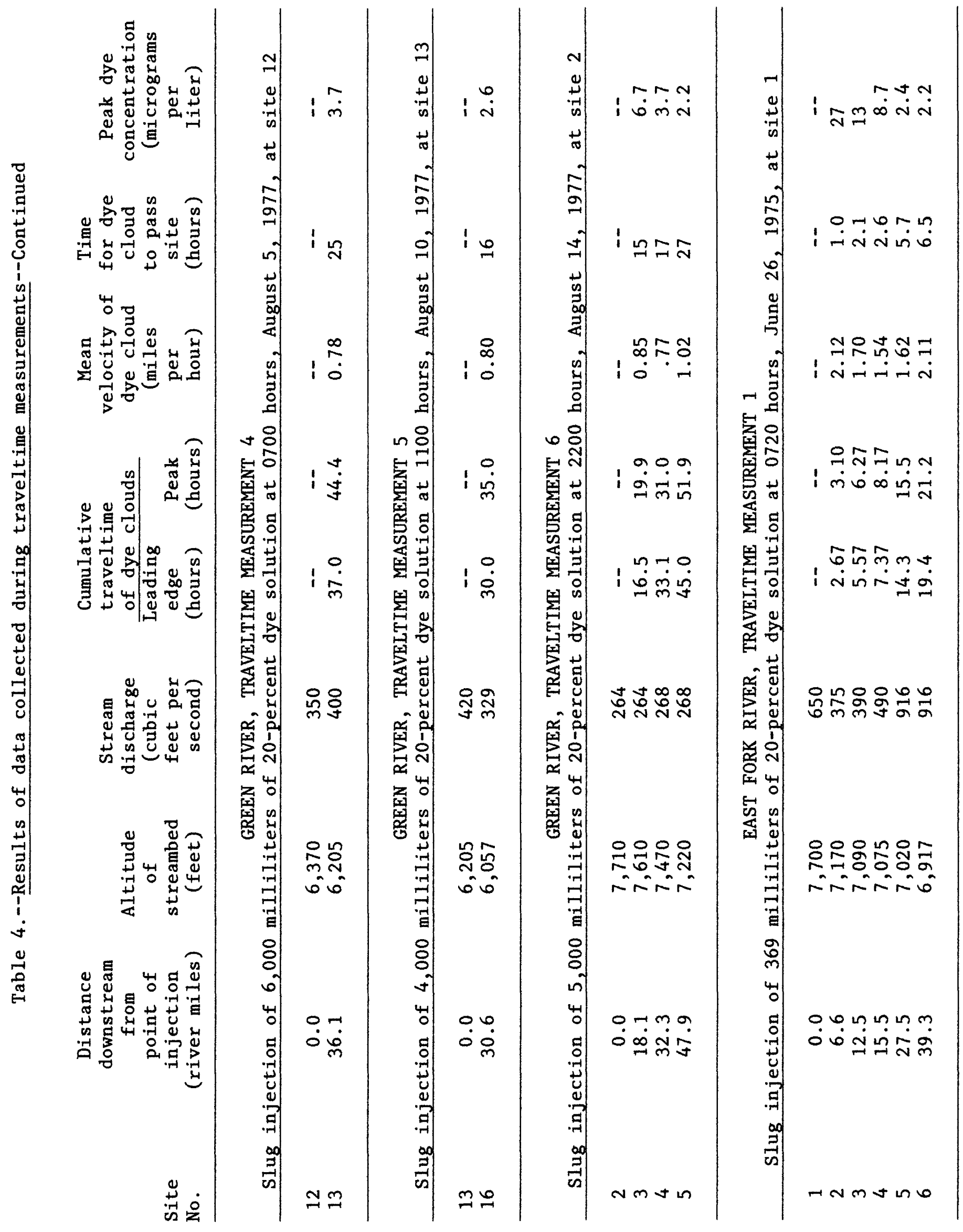




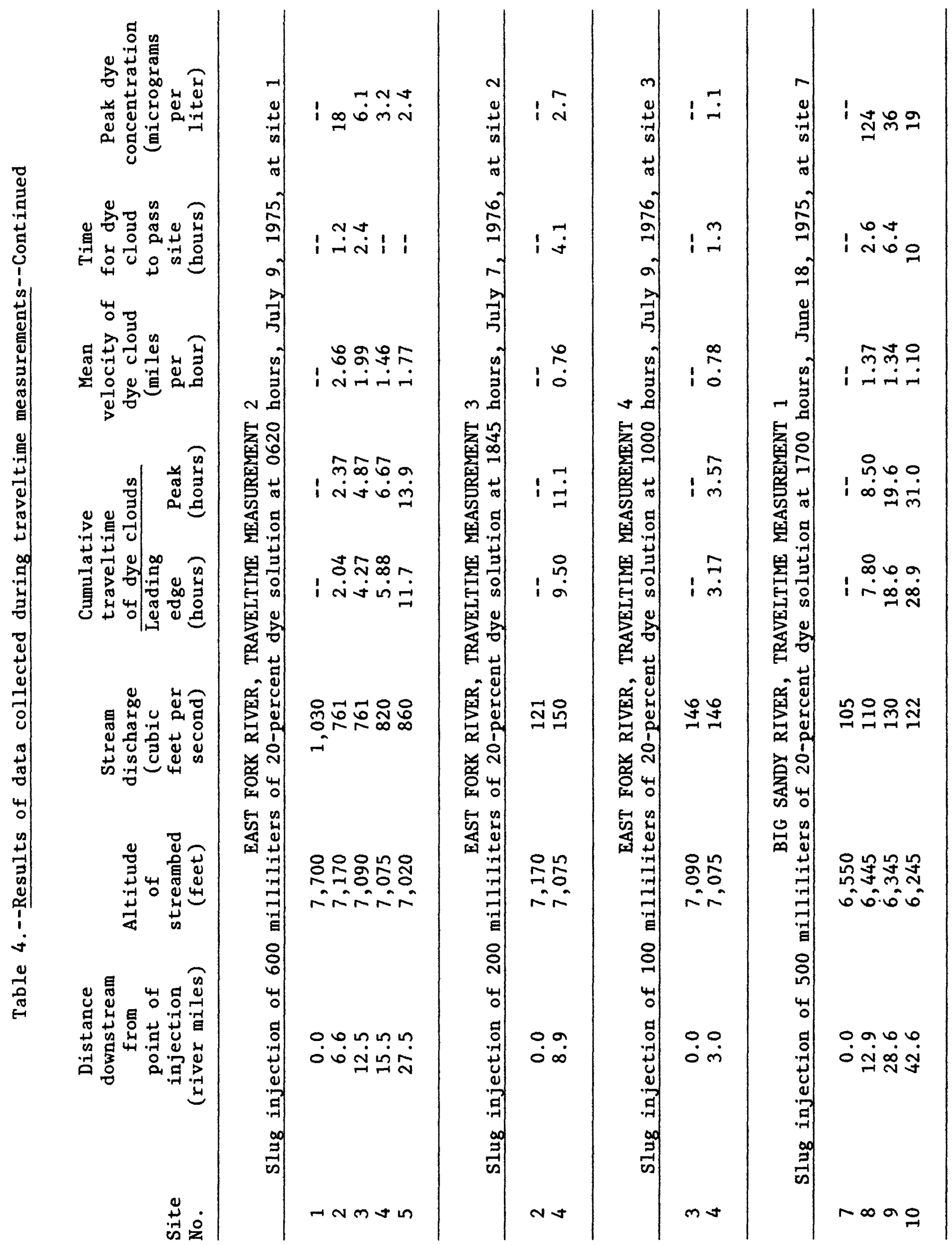




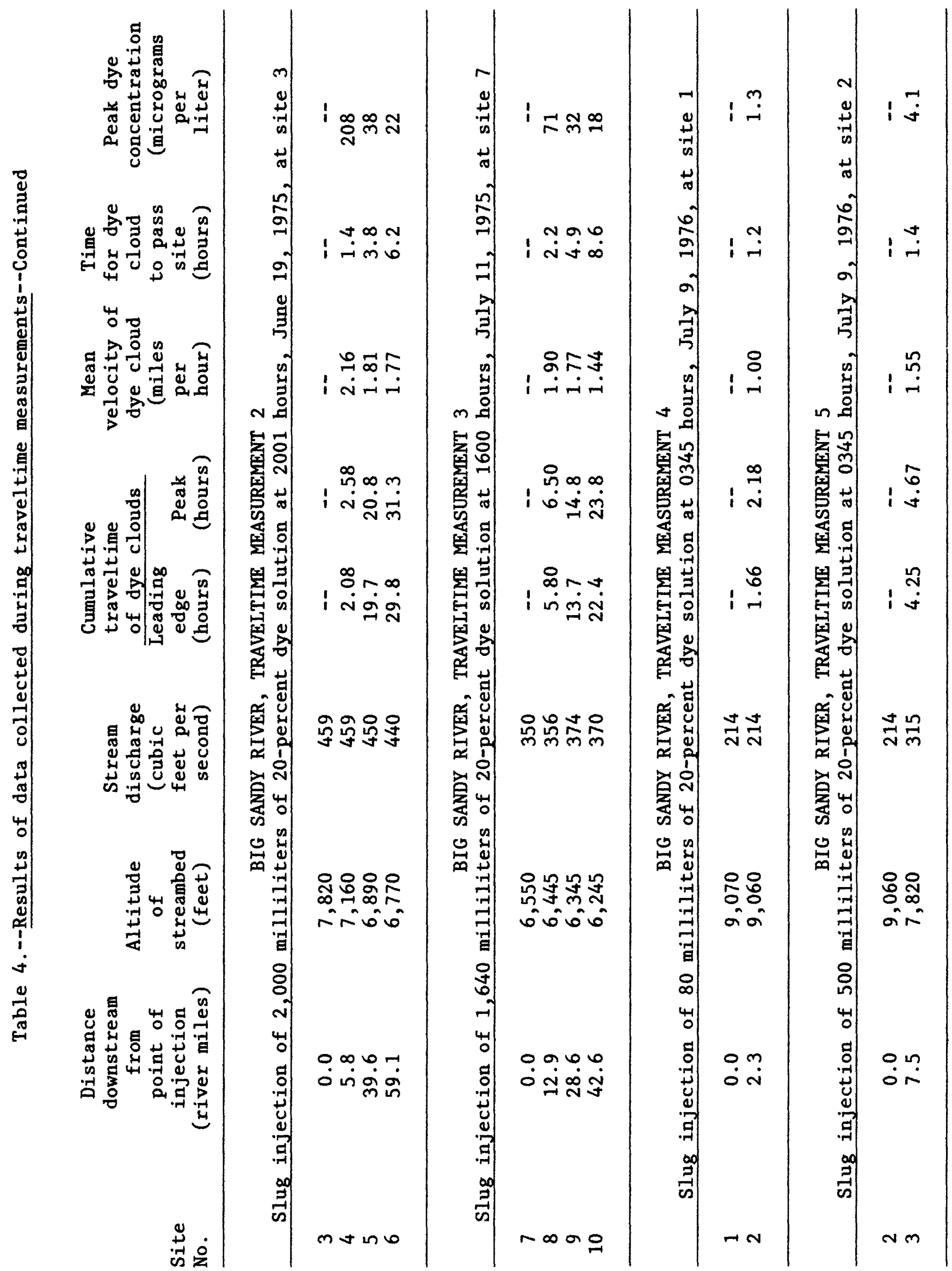




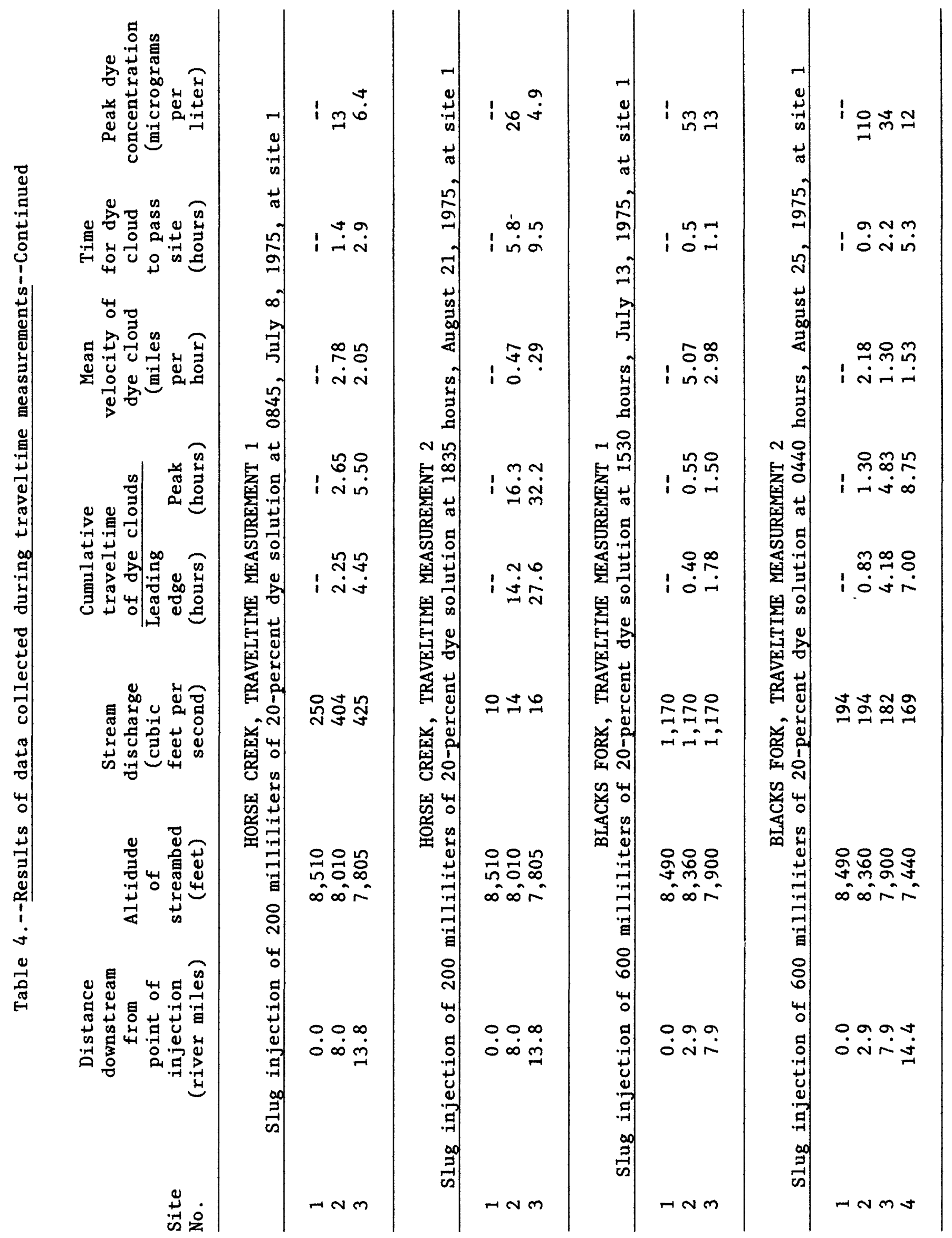




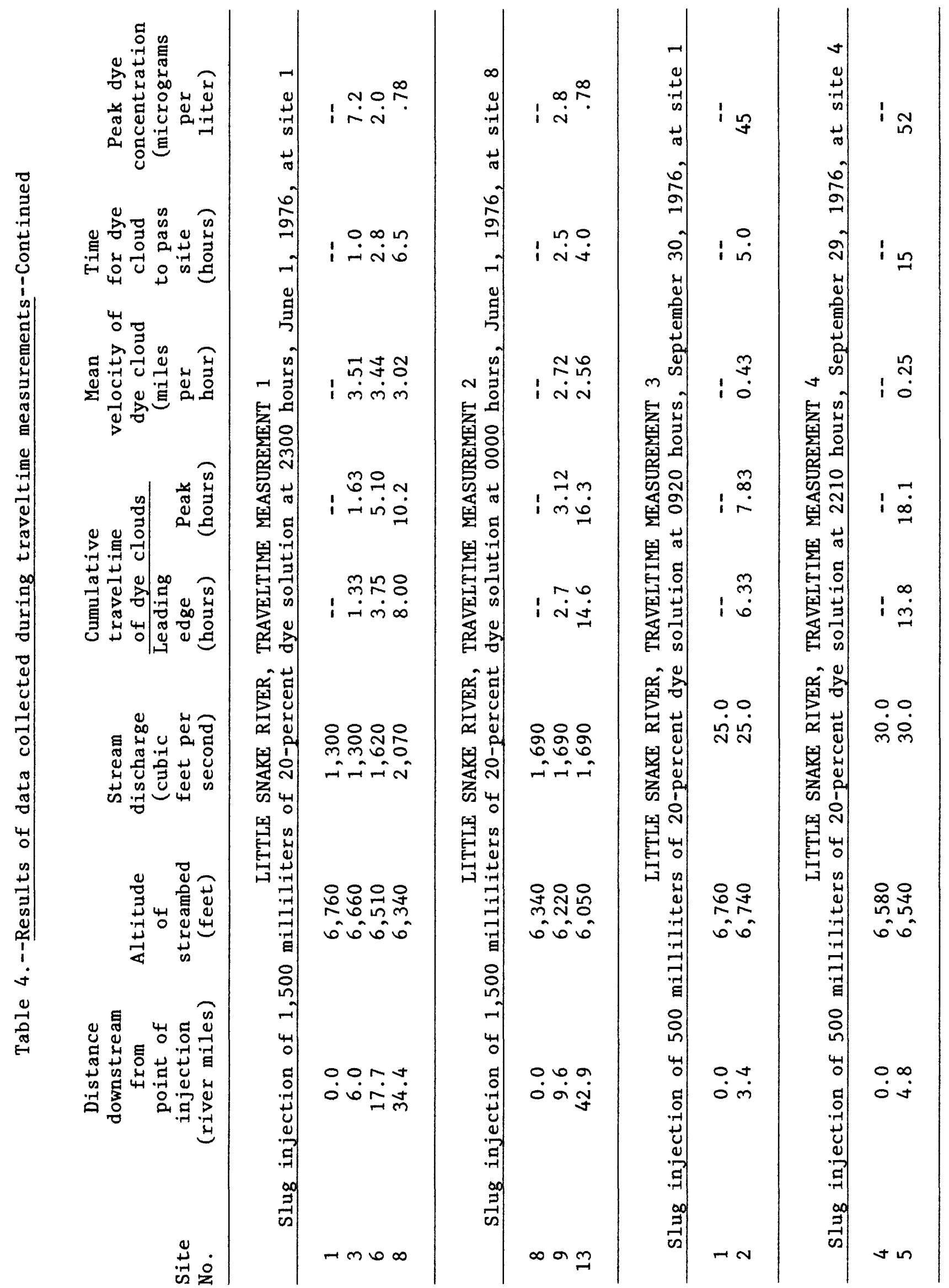




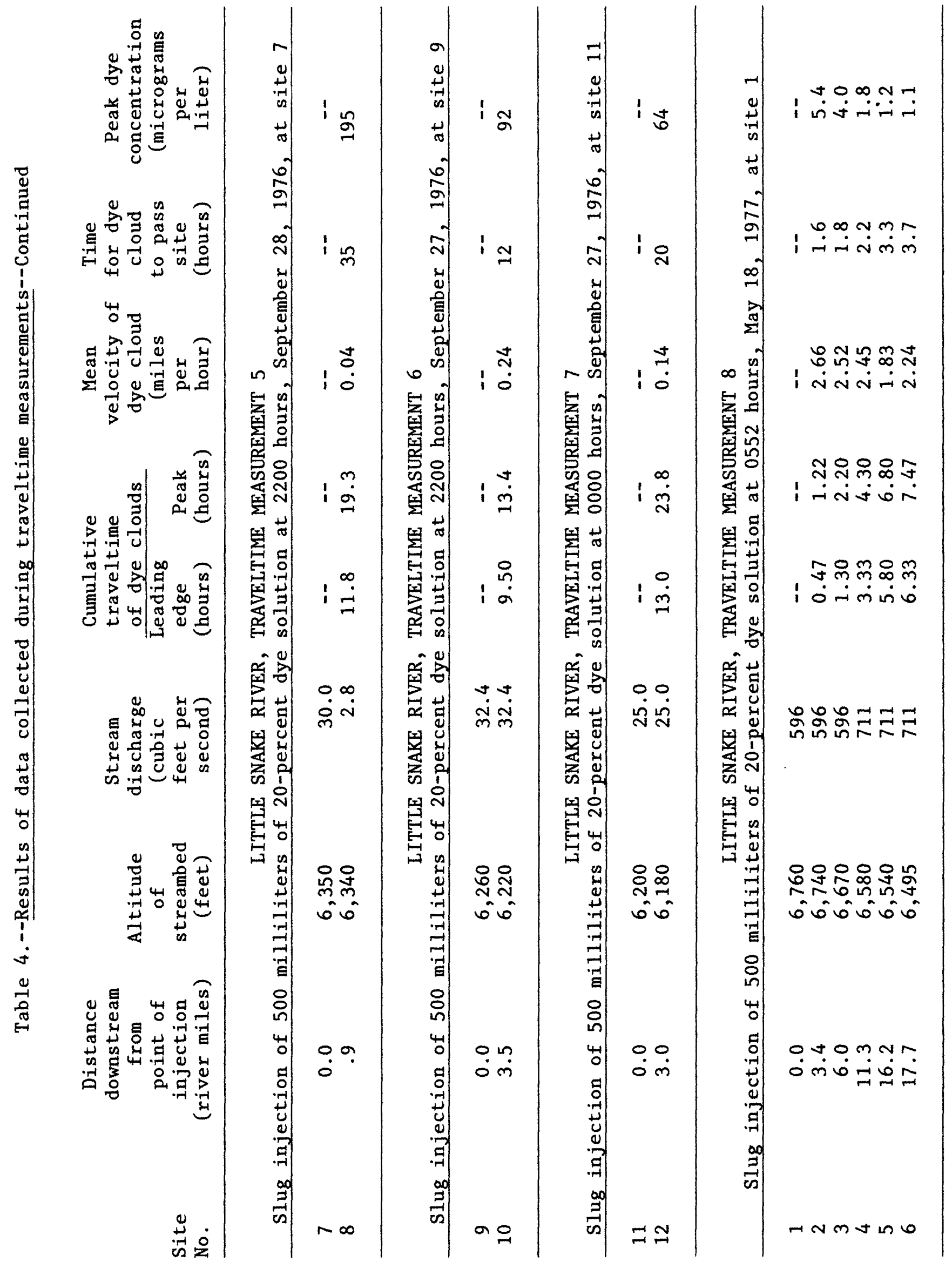




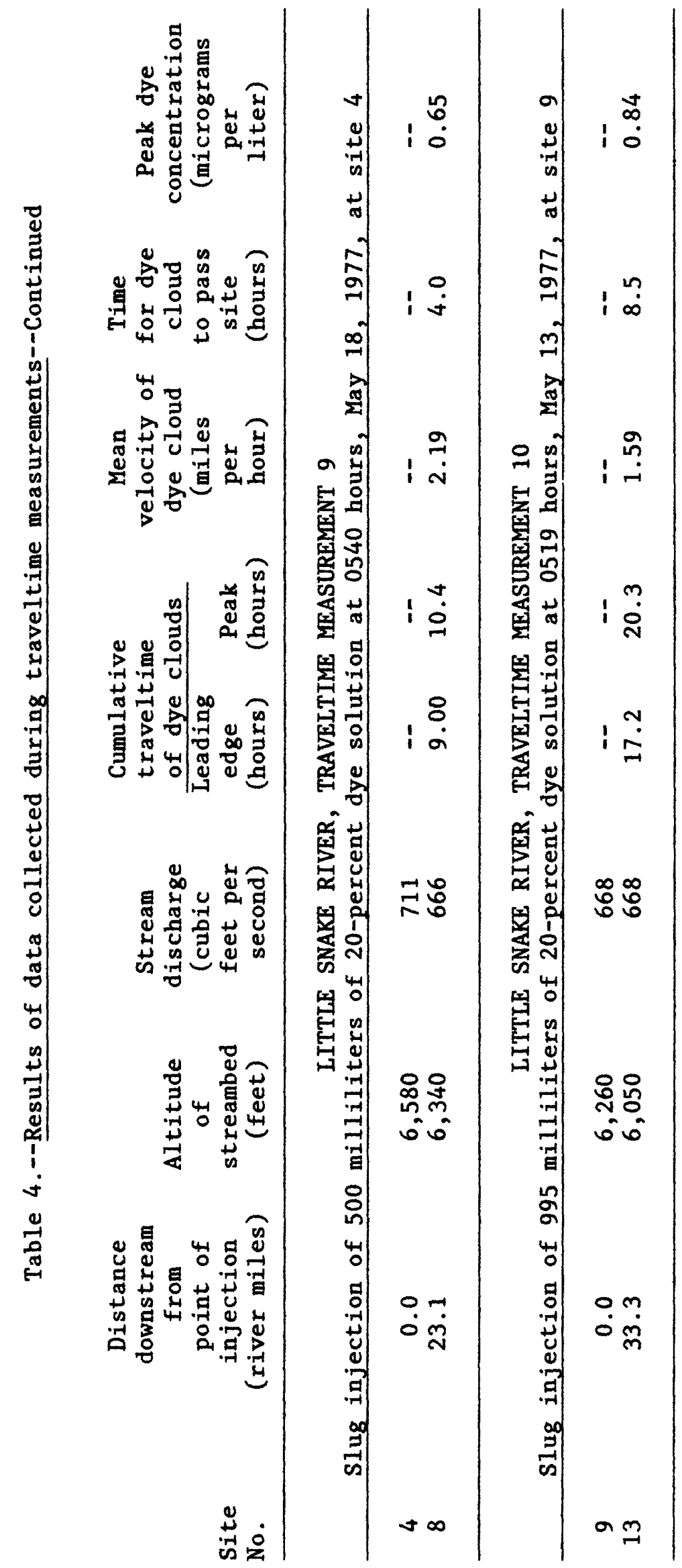



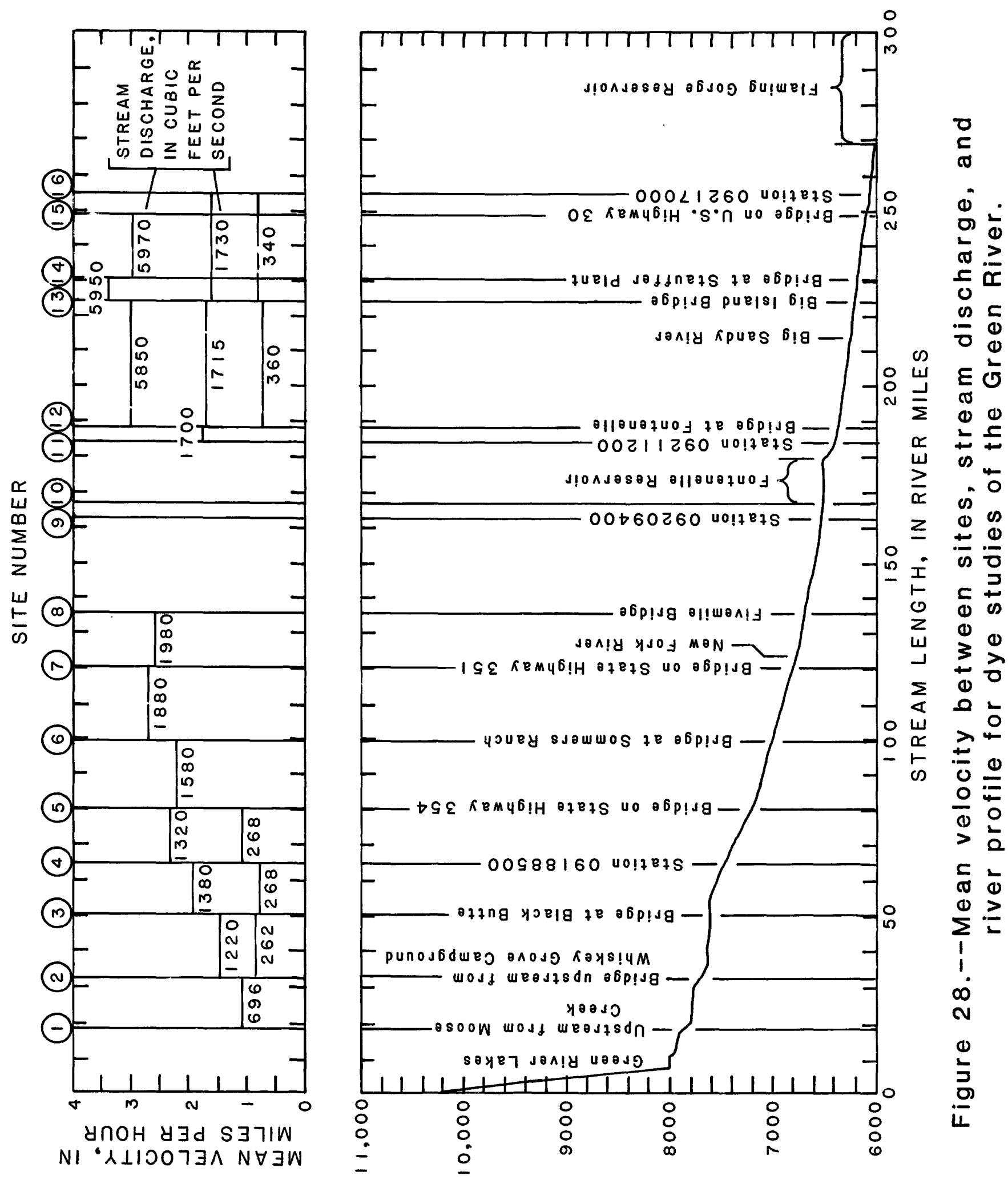

$6 己 6 । \pm 00 \wedge 9 N \exists \wedge O 8 \forall$

$\perp \exists \exists \sqsupset N I \cdot \exists 0 n \perp I \perp \neg \forall 0 \exists g N \forall \exists y \perp S$ 


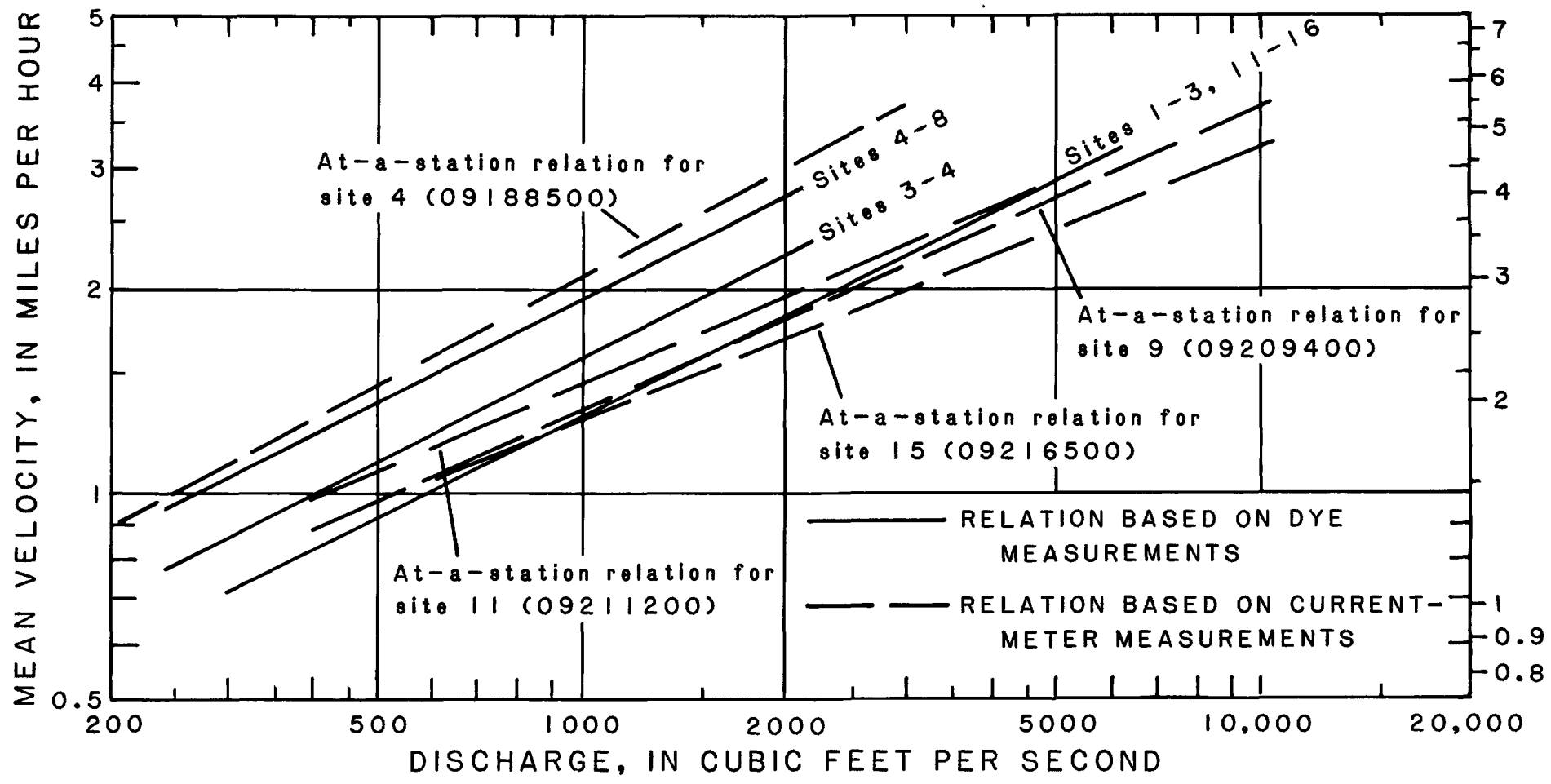

Figure 29.--Mean velocity versus discharge for the Green River.

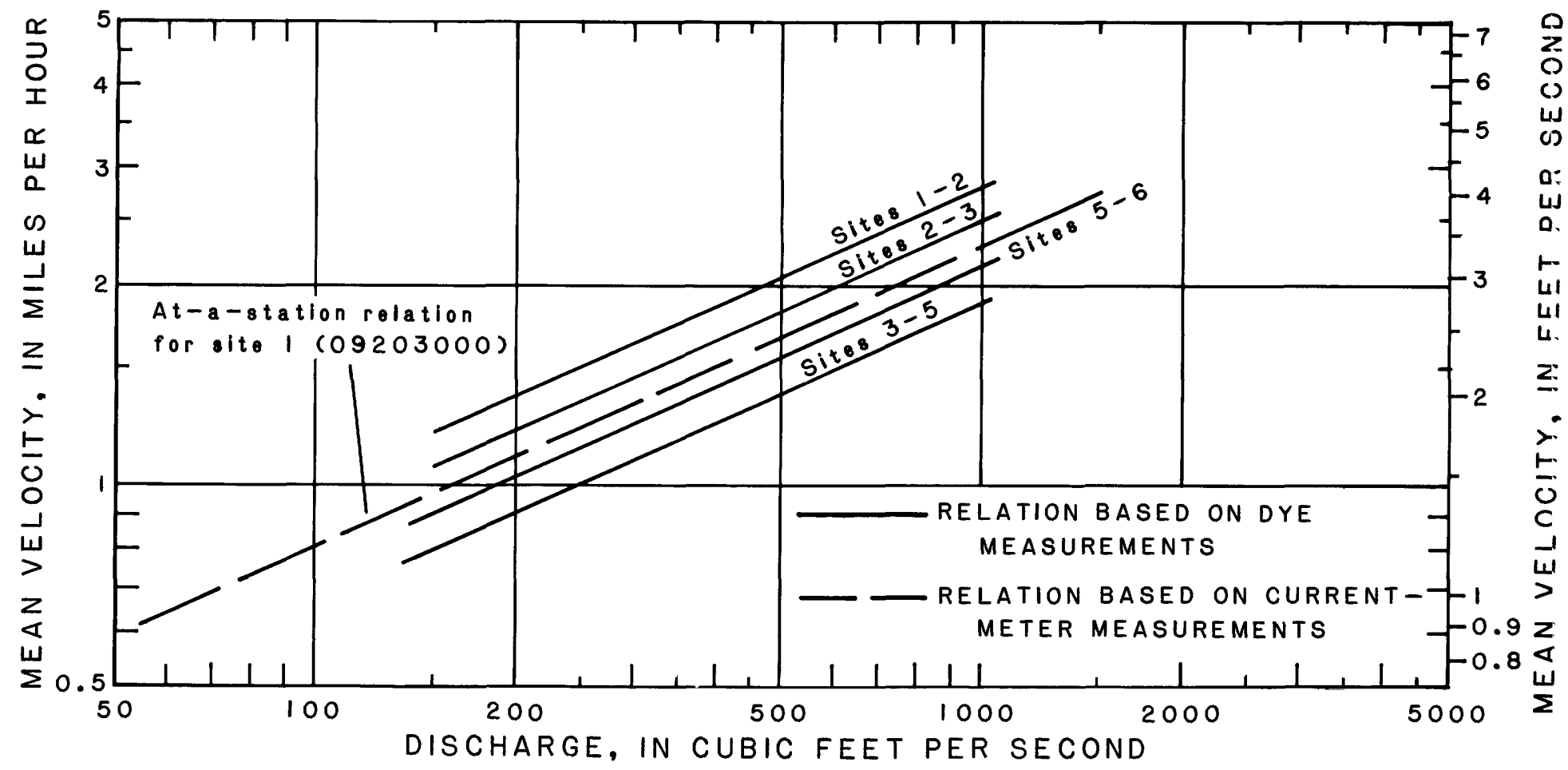

Figure 30.--Mean velocity versus discharge for the East Fork River. 


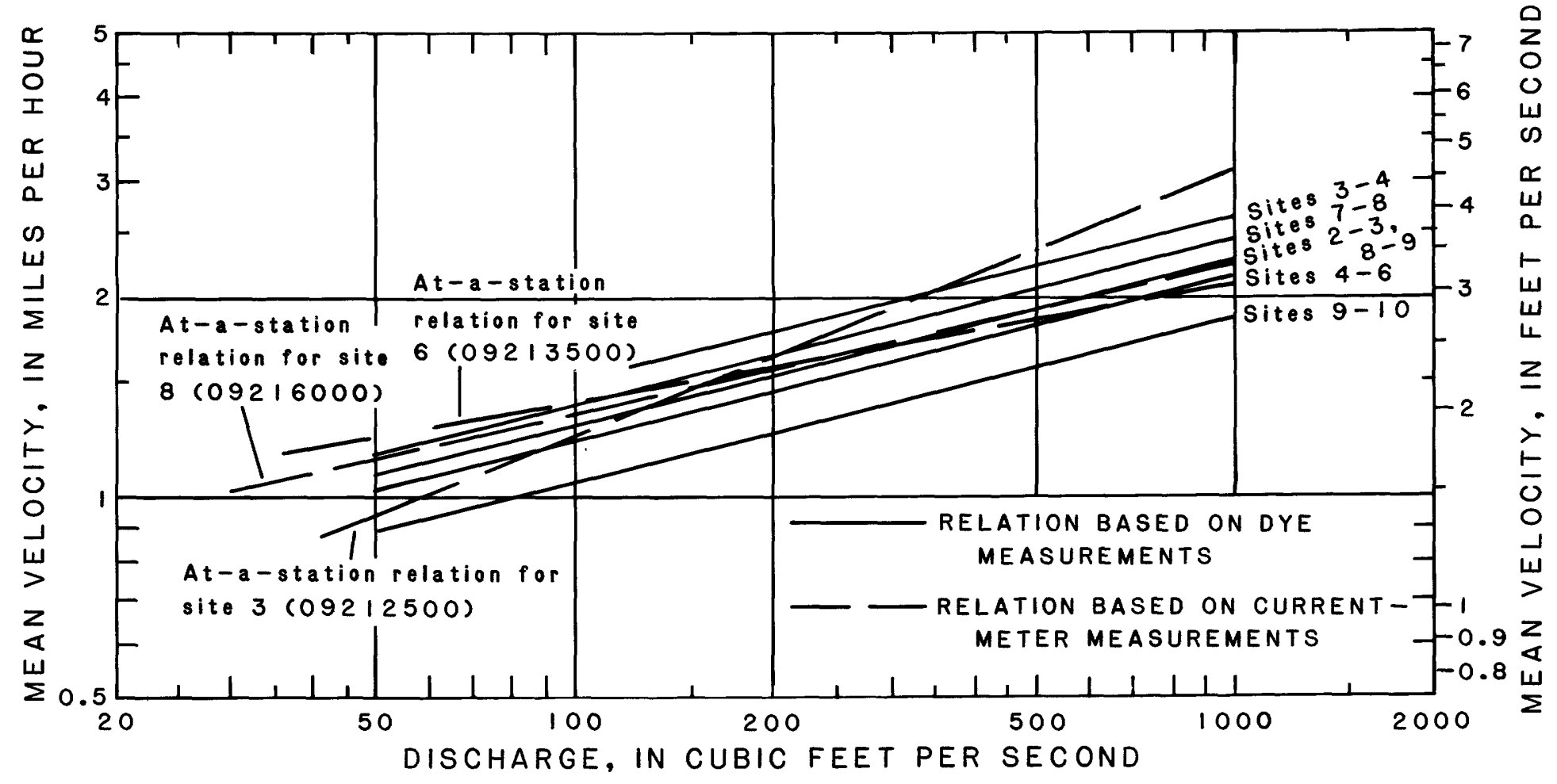

Figure 31.--Mean velocity versus discharge for the Big Sandy River.

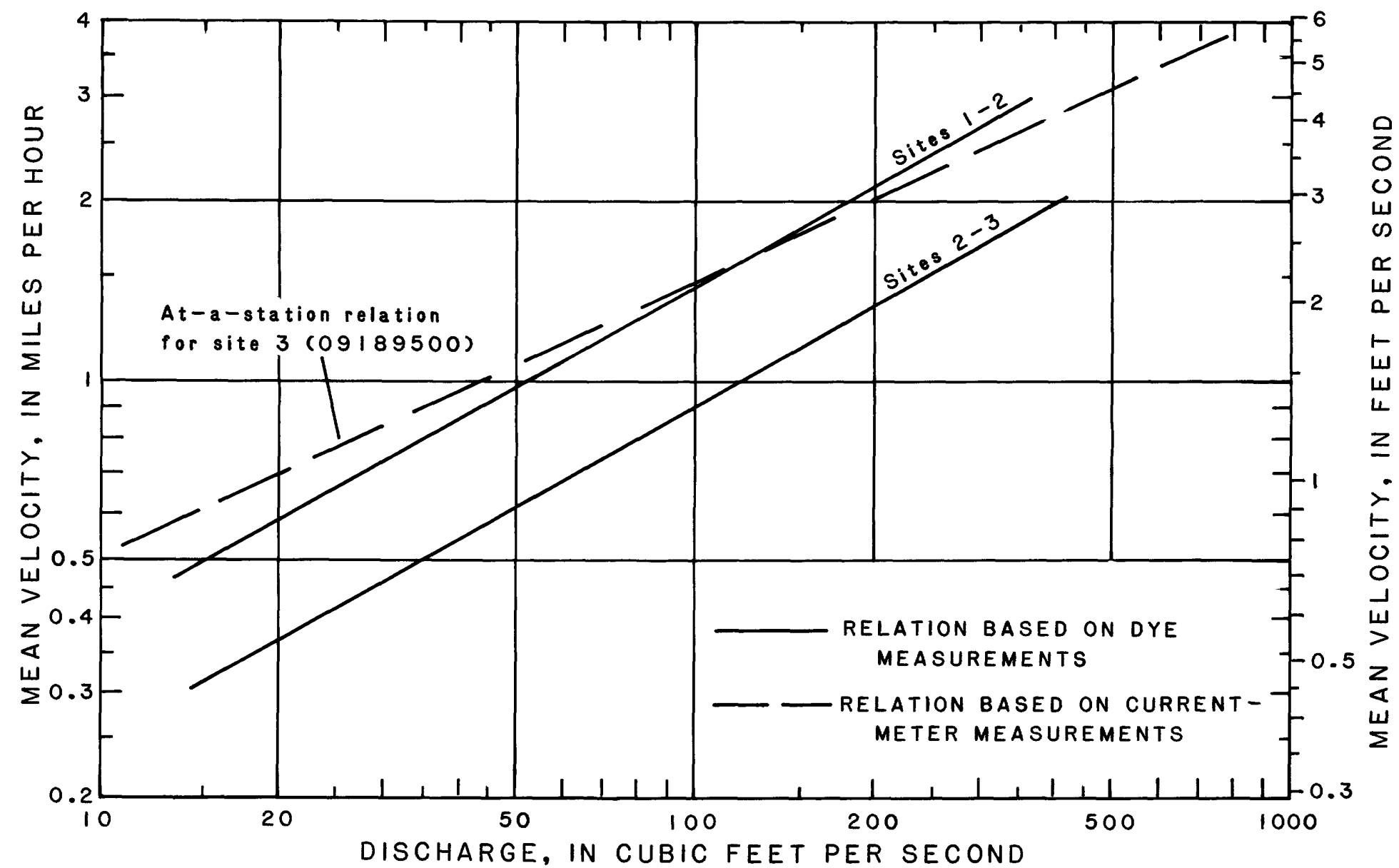

Figure 32.--Mean velocity versus discharge for Horse Creek. 


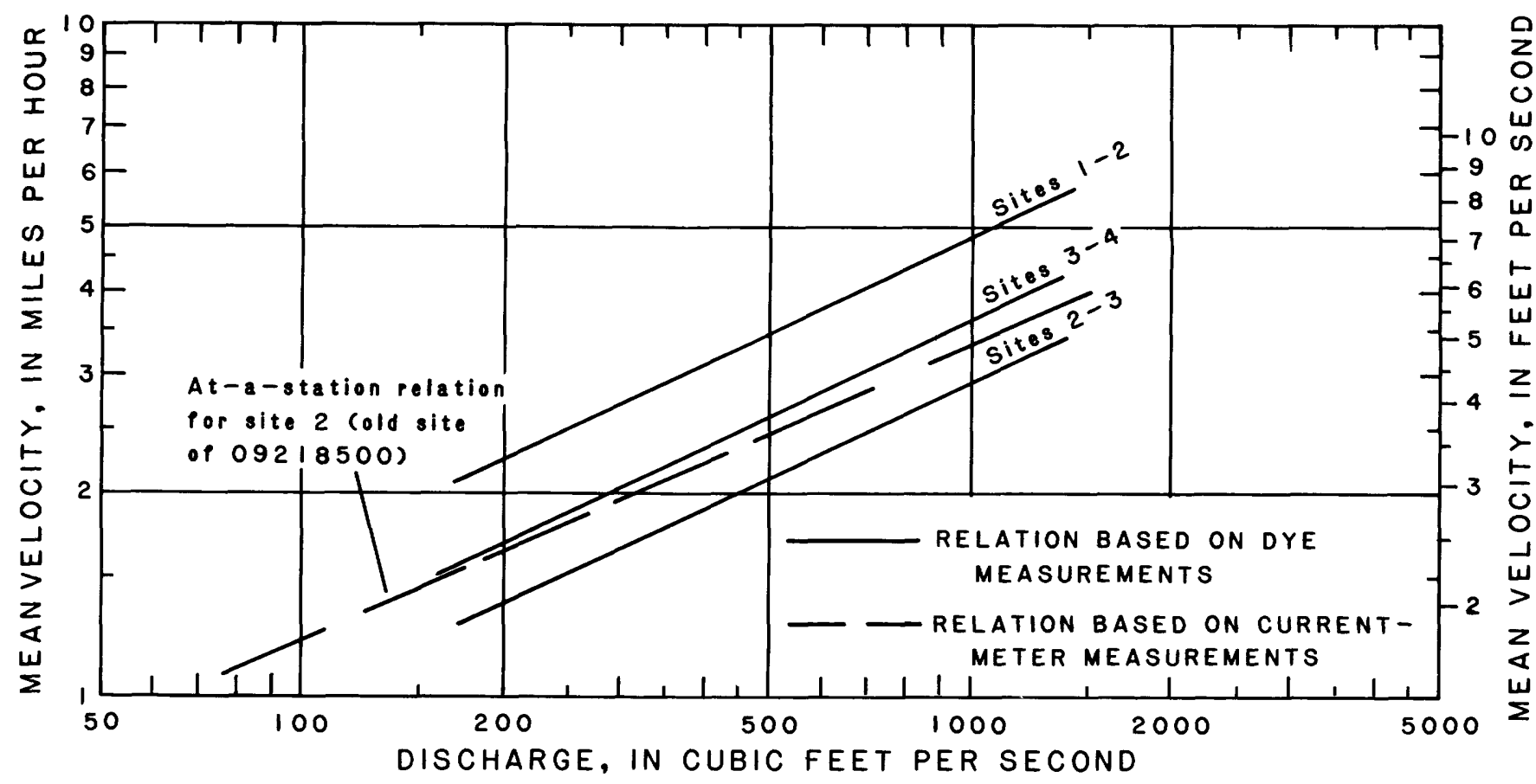

Figure 33.--Mean velocity versus discharge for Blacks Fork.

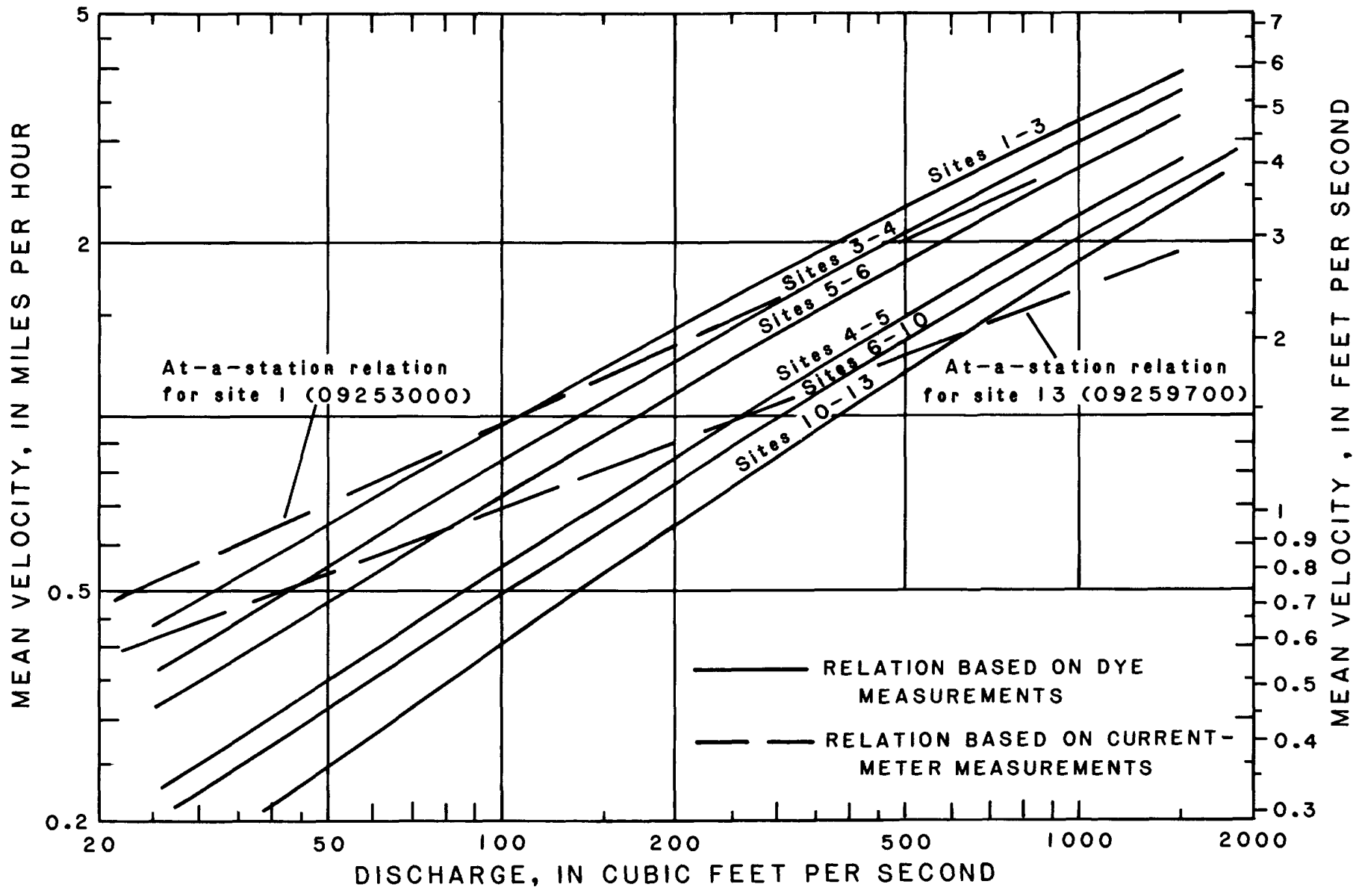

Figure 34.--Mean velocity versus discharge for the Little Snake River. 


\section{Traveltime Prediction}

Dye studies are especially useful in determining the traveltime of soluble contaminants that might be accidentally spilled into a stream. By knowing the traveltime of a pollutant in a stream, a quick and efficient plan could be made to protect downstream water users. Emergency situations have occurred as a result of spills into streams in other States, and when traveltime was known it helped decrease the downstream danger. For example, Moore and Kin (1969) described an emergency situation that occurred in Indiana when a train wreck caused an estimated 1,200 gallons of contaminant containing cyanide to be spilled into Buck Creek and the White River. Traveltime estimates were made and efforts were taken to decrease toxicity of the cyanide by treating it in the stream with a hypochlorite solution.

Traveltime relations for the Green River are shown in figures 35 and 36. Similiar relations for the Little Snake River are presented in a report by Bauer and others $(1979$, p. 29, 30). The graphs are constructed so that traveltime between any two designated sites may be determined. An exception is the reach between sites 10 and 11, which is occupied by Fontenelle Reservoir. Any spill upstream from site 10 would be contained and diluted by storage in the reservoir.

To determine traveltime between two sites, the stream discharge in the reach needs to be known. Streamflow stations located at sites 4, 9 , 11 , or 16 can be used to provide a quick determination of discharge in case of a spill. The U.S. Geological Survey at Cheyenne or Green River can provide this information. In addition, the U.S. Bureau of Reclamation at Fontenelle can provide quick information regarding discharges at sites 9 and 11 .

The relations of figures 35 and 36 depict traveltime expected for the peak concentration of a soluble contaminant. The variation in velocity across a stream causes the leading edge of contamination to travel faster than the peak. Based on the traveltime measurements made for this study, velocity of the leading edge is 1.12 times faster than velocity of the peak, on the average. The expected traveltime of the leading edge can, therefore, be estimated by the relation:

$$
\mathrm{T}_{1}=\frac{\mathrm{T}_{\mathrm{p}}}{1.12}
$$

To illustrate an application of the traveltime relations, assume that a tank accidentally ruptures and spills its content of a soluble contaminant into the Green River at site 12. Streamflow station 09211200 at site 11 can be used to determine the prevailing discharge of the stream. Assume the discharge is 1,500 cubic feet per second. From figure 36, traveltime of the peak concentration from sites 12 to 13 is 22 hours. The leading edge of the solute can be expected to arrive at site 13 in about $22 / 1.12=20$ hours (equation 9). Assume there is little inflow from Big Sandy and other tributaries, and that discharge of the Green River downstream remains at about 1,500 cubic feet per second. Peak traveltime from site 12 to site 15 (town of Green River) is 37 hours. The leading edge can be expected to arrive in about $37 / 1.12=33$ hours. 


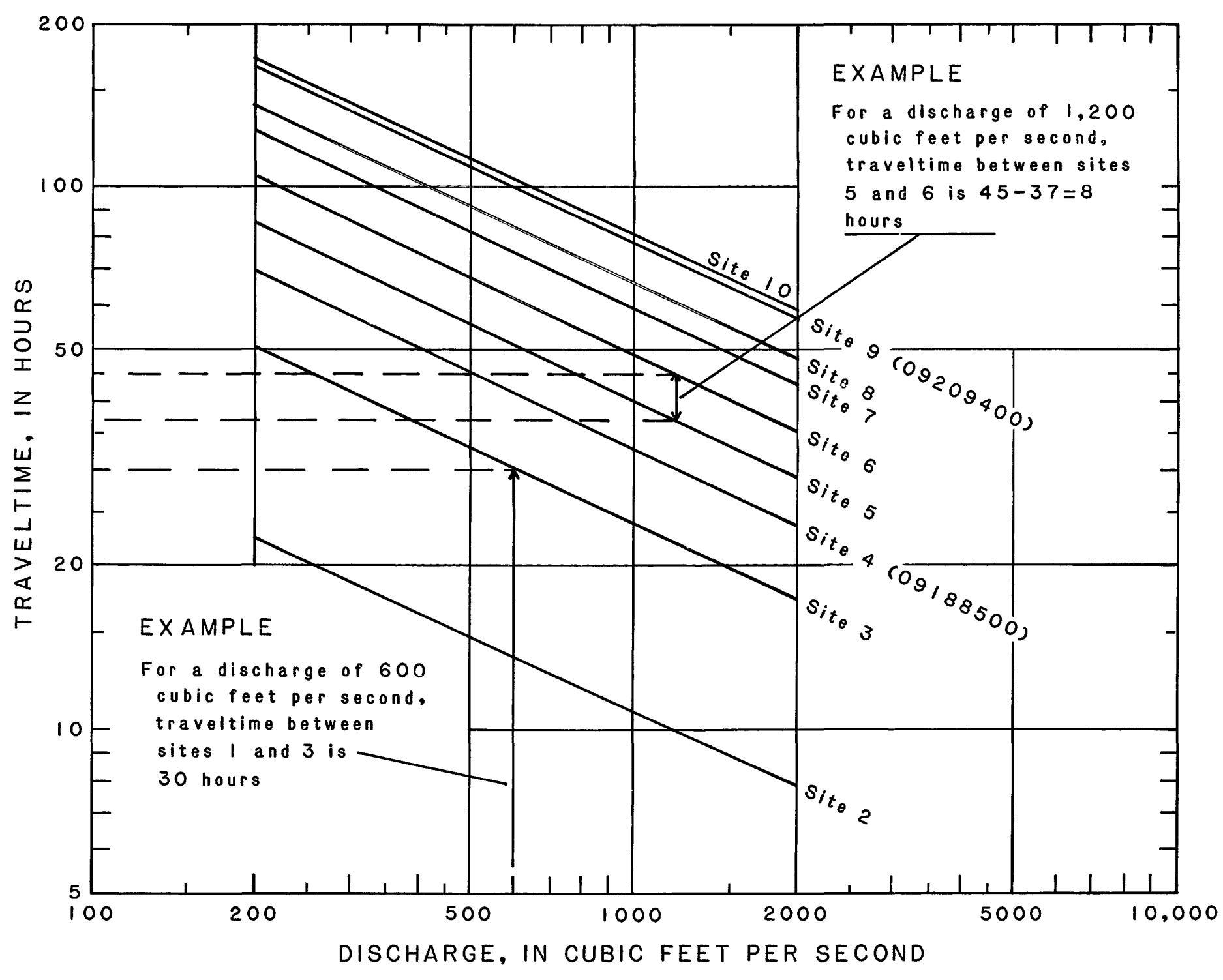

Figure 35.--Cumulative traveltime for the Green River between sites 1 and 10 . 


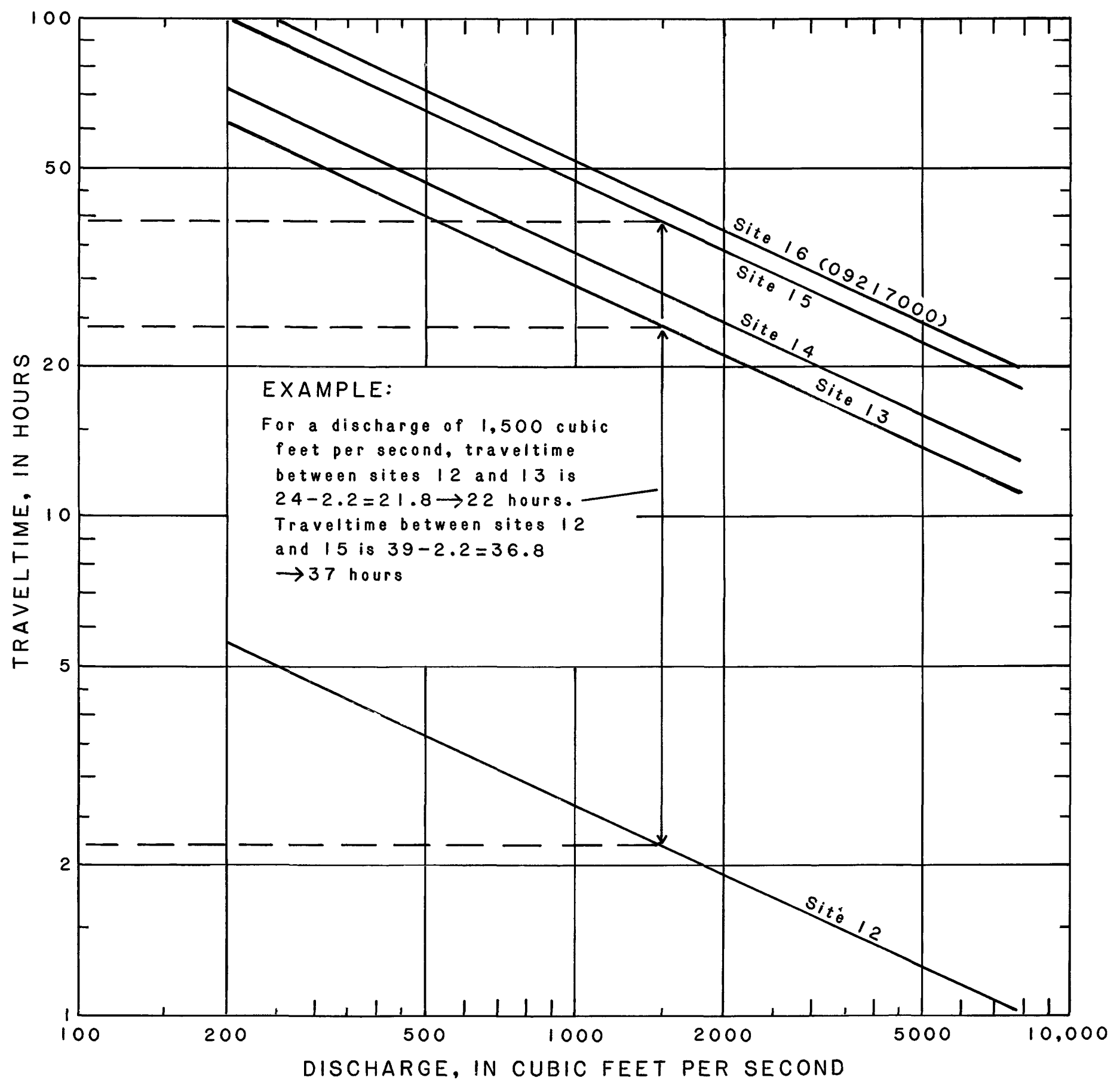

Figure 36.--Cumulative traveltime for the Green River between sites 11 and 16 . 
Another application of the relations is to predict average trave1times for water released from Fontenelle Reservoir to locations downstream. For such applications it should be noted that a large abrupt release of flow causes a flood wave in the stream channel. Flood waves generally travel about 1.5 to 2.0 times faster than the actual mean velocity of the water.

The Green River is used for recreational activities. A practical use of this report for persons making, float trips on the river is to estimate their traveltime before the trip. Such planning may help them decide where to put in and get out, depending on the length of time they desire to be on the river. For example, the traveltime between sites 12 and 13 for a discharge of 1,500 cubic feet per second is 22 hours. If the boat is kept in the faster velocities near the center of the stream, traveltime will be about 1.12 times less, or 20 hours, assuming the participants do not paddle or use a motor to propel them faster than the current. Consideration also needs to be given to wind conditions, as a canoe or rubber raft can be stopped by an upstream wind, especially during low-flow conditions.

\section{SUMMARY}

Owing to a variety of extensive mineral resources that are in the Green River basin of Wyoming, development of the area is expected to increase. As developments proceed, water use commonly will be a central issue.

Streamflows are available in the area for new uses. A variety of stream types exist in the area due to wide ranges in climatic, geologic, and orographic conditions. Perennial streams, whose headwaters drain mountainous areas, provide the greatest quantities of runoff. The major part of runoff in these streams occurs during spring and early summer as a result of snowmelt.

When developments involve streams, hydraulic characteristics of the flow commonly need to be considered in the planning and design. Information concerning these characteristics is vital to the design of sound structures and may also be useful for environmental considerations.

At-a-station relations using records of current-meter measurements made at gaging-station sites were developed for 51 stream sites in or near the study area. These relations show changes in width, depth, and velocity of flow as discharge of the stream varies. The relations define flows that are contained within the channel; during floods when a major part of the flow is overbank, the relations may not apply.

Channel formation is the result of streamflow magnitude and sediment character. High flows affect channel formation, and a representation of such flows is the array of annual peak flows. The geometric mean of this array is considered to be a meaningful index of channel-forming flows as it represents relative magnitude of all high flows at a site. The geometric mean was found to closely represent flows of bankfull size; thus, it is considered to be a statistical index that will approximately equate with bankfull discharge, on the average. Some variations in magnitude of 
bankfull discharge may occur due to differences in the basins such as surface geology, climate, vegetation, and bank activity by wildlife and livestock.

A stream naturally strives toward an equilibrium state in which the channel can efficiently transport its flow and sediment load. Hydraulic characteristics of streams in a region commonly are similar and can be portrayed through the use of regional relations, which are sometimes referred to as downstream relations. Using the at-a-station relations as a base, downstream relations were developed that depict mean width, depth, cross-sectional area, and velocity of flow for several characteristics of within-channel flows.

Channel shape varies with stream size, and the geometric mean of annual peak flows was used as an index of formative discharge to examine the width/depth ratio of the gaged streams. The width/depth ratio of channels increases with magnitude of channel-forming flow. Vegetation and sediment character also have significant effects on channel shape.

The slopes of streams generally decrease in the downstream direction as channel-forming discharge increases and bed-material size decreases. A relation developed by Leopold and Wolman (1957) depicting channel slope and stability was found to be applicable to streams of the study area.

Channel size is related to magnitude of channel-forming flows, and channel-geometry relations use this concept to provide estimates of streamflow at ungaged sites. A relation depicting the geometric mean of annual peak flows versus main-channel width was presented that can be used in conjunction with the hydraulic relations to predict channel response to a development that causes streamflow alteration. The geometric mean is considered to be an index of channel-forming flows. If this index was increased or decreased, a change in channel features would occur as depicted by the regional hydraulic relations.

The velocity (or traveltime) of flow in a reach may be accurately measured through the use of dye tracing. Dye studies were made of six streams, and relations showing mean velocity versus discharge were presented for different reaches of the streams. A comparison of these relations with the at-a-station velocity relations showed fair agreement. In cases where they were not similar, the difference was attributed to: (1) The gaged reach not being representative of the adjacent reaches measured by the dye studies, or (2) inaccuracies in the dye-velocity computation for low flow because the path of travel for low flow is longer than that for high flow. Stream distance was determined by measuring main-channel length from topographic maps. The distance measurements represent path of travel for relatively high flows.

Results from dye studies are particularly useful for predicting traveltime of a spilled contaminant to downstream sites. Traveltime relations were presented for the Green River that enable arrival times of both the leading edge and peak concentration of a soluble contaminant to be predicted. A second application is the estimation of traveltime for reservoir water released for downstream uses. A third application is for recreation purposes, to help plan expected time on the river during a float trip. 


\section{REFERENCES}

Andrews, E. D., 1980, Effective and bankfull discharges in the Yampa River basin, Colorado and Wyoming: Journal of Hydrology, 46 (1980), p. 311-330.

Bauer, D. P., Rathburn, R. E., and Lowham, H. W., 1978, Traveltime, unit-concentration, longitudinal-dispersion, and reaeration characteristics of upstream reaches of the Yampa and Little Snake Rivers, Colorado and Wyoming: U.S. Geological Survey Water-Resources Investigations 78-122, $66 \mathrm{p}$.

Bovee, K. D., and Milhous, R. T., 1978, Hydraulic simulation in instream flow studies: theory and techniques: U.S. Fish and Wildlife Service Instream Flow Information Paper No. 5, 131 p.

Brush, L., M., Jr., 1961, Drainage basins, channels, and flow characteristics of selected steams in central Pennsylvania: U.S. Geological Survey Professional Paper 282-F, p. 145-181.

Dury, G. H., 1961, Bankfull discharge: an example of its statistical relationships: Bulletin of the International Association of Scientific Hydrologists, v. 6, no. 3, p. 48-55.

Emmett, W. W., 1972, The hydraulic geometry of some Alaskan streams south of the Yukon River: U.S. Geological Survey open-file report, 44 p.

1975, The channels and waters of the upper Salmon River area, Idaho: U.S. Geological Survey Professional Paper 870-A, $116 \mathrm{p}$.

Harvey, A. M., 1969, Channel capacity and the adjustment of streams to hydrologic regime: Journal of Hydrology, v. 8, no. 1, p. 82-98.

Heede, R. H., 1977, Case study of a watershed rehabilitation project: Alkali Creek, Colorado: U.S. Forest Service Research Paper RM-189, $18 \mathrm{p}$.

Kircher, J. E., 1982, Sediment transport and source areas of sediment and runoff, Big Sandy River basin, Wyoming: U.S. Geological Survey Water-Resources Investigations $81-72,51 \mathrm{p}$.

Kuntz, Bernie, 1977, Malady at Pole Creek: Wyoming Wildlife, v. 41, no. 3 , p. 10-13.

Lane, E. W., 1955, The importance of fluvial morphology in hydraulic engineering: Proceedings of the American Society of Civil Engineers, v. 81, no. 745,17 p.

Leopold, L. B., and Maddock, T., Jr., 1953, The hydraulic geometry of stream channels and some physiographic implications: U.S. Geological Survey Professional Paper 252, 56 p.

Leopold, L. B., and Wolman, M. G., 1957, River channel patterns; braided, meandering and straight: U.S. Geological Survey Professional Paper 282-B, p. 39-85. 


\section{REFERENCES--Continued}

Leopold, I. B. Wolman, M. G., and Miller, J. P. 1964, Fluvial processes in geomorphology: San Francisco, W. H. Freeman and Co., 522 p.

Lowham, H. W., 1976, Techniques for estimating flow characteristics of Wyoming streams: U.S. Geological Survey Water-Resources Investigations $76-112,83 \mathrm{p}$.

Moore, S. L., and Kin, S. R., 1969, Train wreck causes cyanide pollution: Water and Sewage Works, v. 116, p. 35-40.

Nixon, Marshall, 1959, A study of the bankfull discharges of rivers in England and Wales: London, Proceedings of the Institution of Civil Engineers, v. 12, p. 157-174.

Riley, S. J., 1976, Aspects of bankfull geometry in a distributary system of eastern Australia: Hydrologic Sciences Bulletin, v. 21, no. 4, p. 545-560.

Schumm, S. A., 1960, The shape of alluvial channels in relation to sediment type: U.S. Geological Survey Professional Paper 352-B, p. 17-30.

1977, The fluvial system: New York, John Wiley, 338 p.

Shulits, Samuel, 1941, Rational equation of river-bed profile: Transactions of the American Geophysical Union, v. 22, p. 522-631.

Wesche, Thomas, 1978, Minimum stream flows: Wyoming Wildlife, v. 42, no. 11, p. $6-9,25$.

Wiley, Robert, 1977, Western Wyoming water development: Wyoming Wildlife, v. 41, no. 11 , p. 28-30.

Williams, G. P., 1978, Bank-full discharge of rivers: Water Resources Research, v. 14, no. 6, p. 1141-1154.

Wolman, M. G., 1955, The natural channel of Brandywine Creek, Pennsylvania: U.S. Geological Survey Professional Paper 271, 56 p.

Wolman, M. G., and Leopold, L. B., 1957, River flood plains; some observations on their formation: U.S. Geological Survey Professional Paper 282-C, p. 87-109.

Wolman, M. G., and Miller, J. P., 1960, Magnitude and frequency of forces in geomorphic processes: Journal of Geology, v. 68 , no. 1 , p. 54-74. 